\title{
NUTRIENT REMOVAL USING MICROALGAE IN WASTEWATER-FED HIGH RATE PONDS
}

\author{
A Thesis \\ presented to \\ the Faculty of California Polytechnic State University, \\ San Luis Obispo
}

\author{
In Partial Fulfillment \\ of the Requirements for the Degree \\ Master of Science in Civil and Environmental Engineering
}

by

Matthew Neal Rodrigues

June 2013 
(C) 2013

Matthew Neal Rodrigues

ALL RIGHTS RESERVED

Page ii 
COMMITTEE MEMBERSHIP

TITLE:

NUTRIENT REMOVAL USING MICROALGAE IN WASTEWATER-FED HIGH RATE PONDS

AUTHOR:

DATE SUBMITTED:

COMMITTEE CHAIR:

COMMITTEE MEMBER:

COMMITTEE MEMBER
Matthew Neal Rodrigues

June 2013
Dr. Tryg Lundquist, Associate Professor, Civil \&

Environmental Engineering

Dr. Yarrow Nelson, Professor, Civil \& Environmental

Engineering

Dr. Chris Kitts, Professor, Biological Sciences 


\section{ABSTRACT \\ NUTRIENT REMOVAL USING MICROALGAE IN \\ WASTEWATER-FED HIGH RATE PONDS}

Matthew Neal Rodrigues

This thesis discusses the mechanisms associated with the removal of organic matter, nitrogen and phosphorus in wastewater-fed high rate algae ponds (HRAP) designed to operate as triplicates. Research was conducted at the San Luis Obispo Water Reclamation Facility (SLOWRF) as a pilot-scale study of nine 30-square meter ponds one foot in depth. During period of study, triplicates were operated at hydraulic retention times (HRT) of 4, 3 or 2-days. Main objectives for the study were to determine minimum HRTs required to achieve secondary and tertiary treatment. Experimental conditions such as $\mathrm{CO}_{2}$ supplementation, nighttime aeration and operation of ponds in series were employed to evaluate optimal conditions for efficient nutrient removal. Ponds were continuously fed primary effluent with the following water quality characteristics: 5-day total biochemical oxygen demand $\left(\mathrm{TBOD}_{5}\right)$ of $124 \mathrm{mg} / \mathrm{L}, 5$-day soluble carbonaceous biochemical oxygen demand of $67 \mathrm{mg} / \mathrm{L}\left(\mathrm{scBOD}_{5}\right)$, total suspended solids (TSS) of $66 \mathrm{mg} / \mathrm{L}$, volatile suspended solids (VSS) of $65 \mathrm{mg} / \mathrm{L}$, total ammonia nitrogen (TAN) of $34 \mathrm{mg} / \mathrm{L}-\mathrm{N}$, oxidized nitrogen of $1.1 \mathrm{mg} / \mathrm{L}-\mathrm{N}$, total Kjeldahl nitrogen $(\mathrm{TKN})$ of $42 \mathrm{mg} / \mathrm{L}-\mathrm{N}$ and dissolved reactive phosphorus (DRP) of 3.3mg/L-P. Nutrient removal efficiencies were compared between summer months (April - October) and winter months (November - February). Average pond temperatures during summer and winter were 
$20.4{ }^{\circ} \mathrm{C}$ and $14.9^{\circ} \mathrm{C}$, respectively. Average TAN removal efficiencies of 2-day HRT ponds ranged from $62 \%$ in winter to $78 \%$ in summer. Operation of ponds at an increased 3-day HRTs resulted in corresponding seasonal increases of TAN removal by $14 \%$ and 12\%. In 4-day HRT ponds operating in series after a 3-day HRT set, TAN removal efficiency was $98 \%$ in winter and $99 \%$ in summer. Aeration increased nitrification and nitrate concentrations in 2-day HRT ponds to10mg/L-N $\pm 4.4 \mathrm{mg} / \mathrm{L}-\mathrm{N}$. DRP concentrations and BOD removal efficiencies within replicate ponds were similar throughout seasonality. DRP was $1.2 \mathrm{mg} / \mathrm{L}-\mathrm{P} \pm 0.66 \mathrm{mg} / \mathrm{L}-\mathrm{P}$ at a 4-day HRT operating in series, $2.2 \mathrm{mg} / \mathrm{L}-\mathrm{P} \pm 0.57 \mathrm{mg} / \mathrm{L}-\mathrm{P}$ at a 3 -day HRT and $2.6 \mathrm{mg} / \mathrm{L}-\mathrm{P} \pm 0.58 \mathrm{mg} / \mathrm{L}-\mathrm{P}$ at a 2 -day HRT. Aeration had no measureable effect on BOD removal. BOD removal efficiency was $97 \%$ at a 4-day HRT in series with a 3-day HRT and 95\% at 3-day and 2-day HRTs.

Keywords: high rate algae pond, nitrification, denitrification, volatilization, microalgae, hydraulic retention time, secondary treatment, tertiary treatment 


\section{ACKNOWLEDGMENTS}

I would like to express my gratitude to those who supported me during my research.

To my family: For your support through my educational career, limitless encouragement and ever-present interest in my endeavors as an engineer and as an individual.

To my thesis committee: It was humbling to have such dedicated, intelligent advisers to look up to. I am privileged to have had each of you involved throughout my research.

To my fellow graduate students: Your company, positivity and inspiration were greatly appreciated. I would like to especially thank Michael Chang and Max Wallack for their tireless contributions and assistance throughout my research.

To ENVE 400 students: Without your commitment to this project, our research would have not been possible. I am forever thankful for your time and hard work.

To Ian Woertz: For motivating and encouraging me to take on the demanding leadership position of our research program. As a pioneer for Cal Poly's algae technology research, you paved the way for my involvement in this rewarding experience.

To Dr. Tryg Lundquist: I was fortunate to have a mentor who was so passionate about his profession and relentlessly devoted to the pursuit of beneficial research.

To Elliott Ripley: Your commitment to teamwork accelerated the progression of this project and your work ethic provided a positive and effective environment for our research. This began as a pursuit for an accelerated degree, but resulted in a lifelong friendship and excessive stints of laughter en route to the finish line.

To the San Luis Obispo Water Reclamation Facility: Thank you for offering us the property, supplies and motivation to not only complete our studies, but to help us excel within the scope of our work.

This project was supported with joint-funding by the California Energy Commission, C3RP, US Office of Naval Research, MicroBio Engineering Inc. and the US Department of Energy. 


\section{Table of Contents}

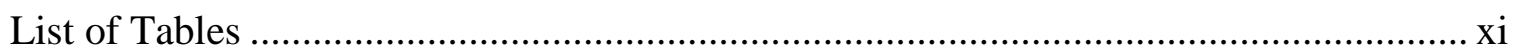

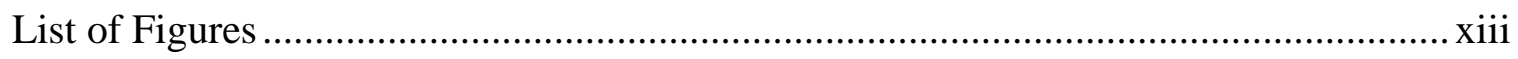

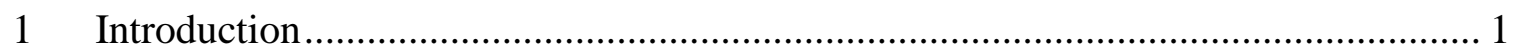

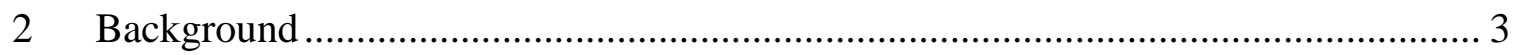

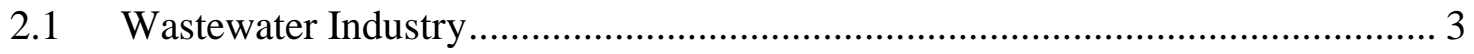

2.2 Wastewater Treatment using Microalgae......................................................... 4

2.2.1 $\quad \mathrm{CO}_{2}$ Addition to Wastewater-fed High Rate Algae Ponds .................... 8

2.3 Nutrient Removal in HRAP Wastewater Treatment ........................................ 8

2.3.1 Mechanisms of Nitrogen Removal ................................................. 8

2.3.2 Mechanisms of Phosphorus Removal.................................................. 13

2.3.3 Mechanisms of BOD Removal..................................................... 15

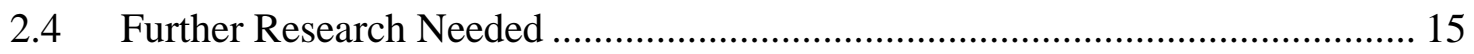

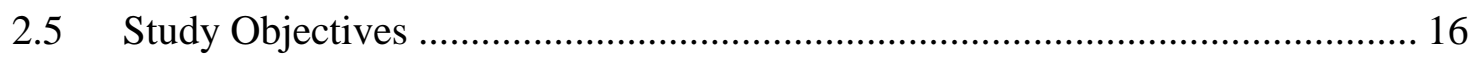

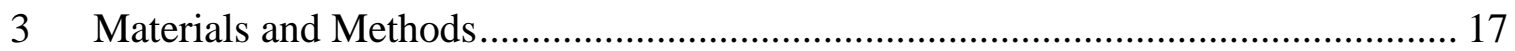

3.1 Pilot Plant Layout ............................................................................... 19

3.2 Pilot Plant Operation and Maintenance ............................................................ 20

3.2.1 Pilot Plant Startup ....................................................................... 20

3.2.2 Monitoring and Maintenance........................................................... 20

3.2.3 Operational Variables ..................................................................... 22 
3.2.4 Water Fowl Control 23

Experimental Procedures........................................................................... 25

3.3.1 Experiment I: Varying HRT .................................................... 25

Experiment II: Ponds in Series .................................................. 26

3.3.3 Experiment III: Aeration of 2-day HRT Ponds .............................. 29

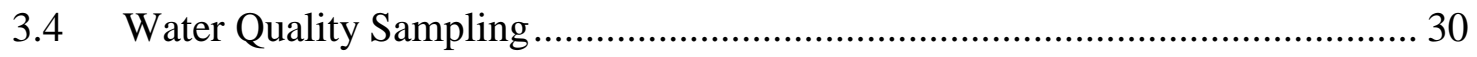

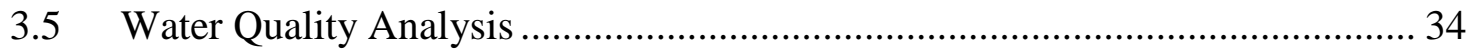

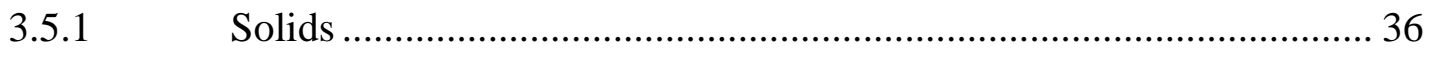

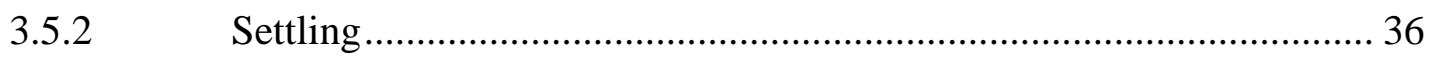

3.5.3 Biochemical Oxygen Demand.................................................... 37

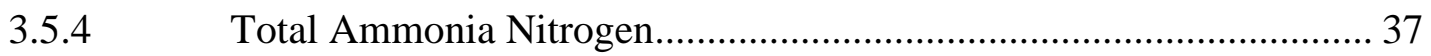

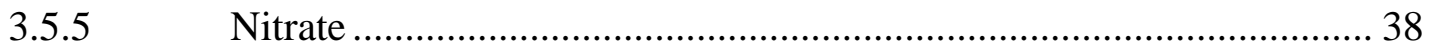

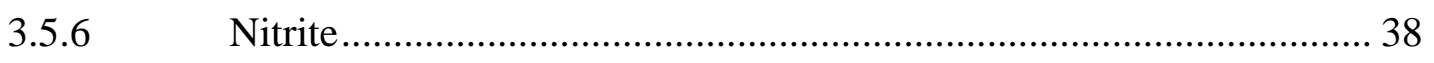

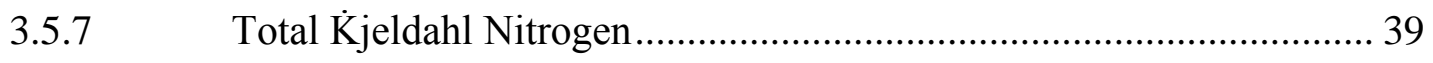

3.5.8 Dissolved Reactive Phosphorus................................................... 39

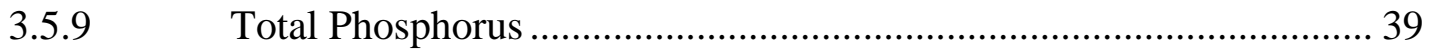

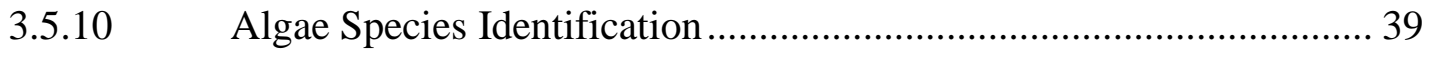

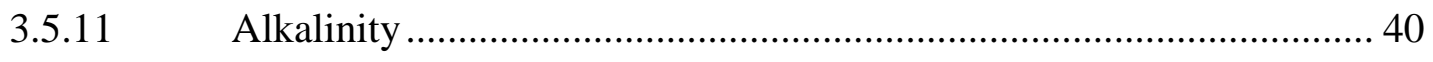

3.5.12 Quality Assurance and Quality Control......................................... 40

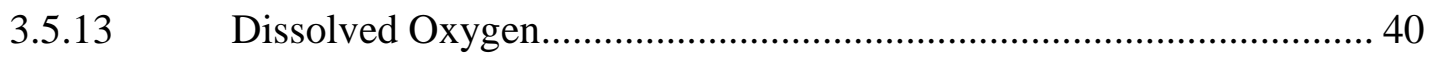


3.5.14 Temperature and $\mathrm{pH}$.

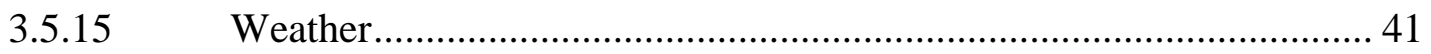

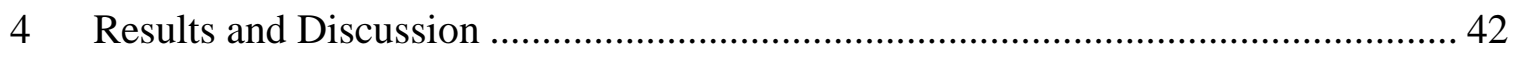

4.1 Pond Influent Water Characteristics ........................................................ 42

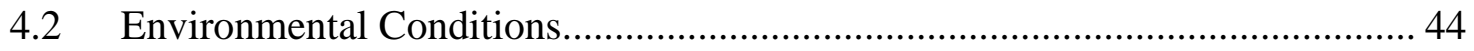

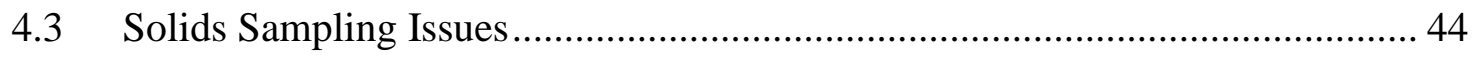

4.3.1 Assumptions for Data Analysis .................................................. 46

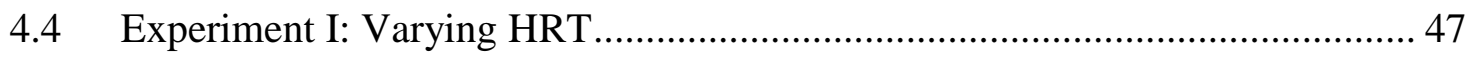

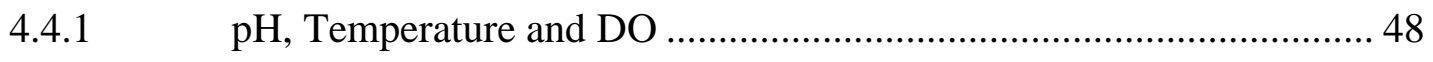

Nitrogen Removal................................................................. 51

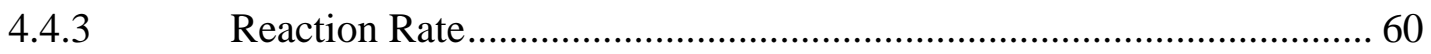

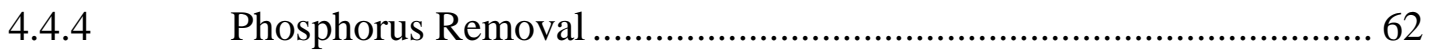

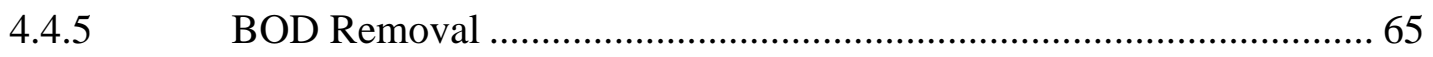

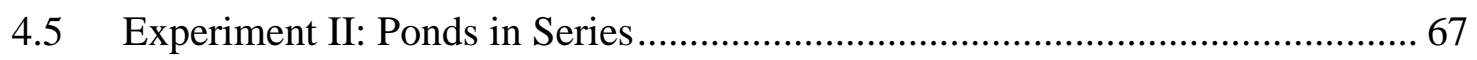

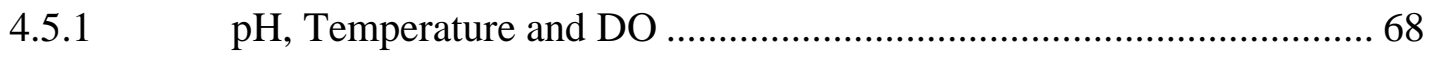

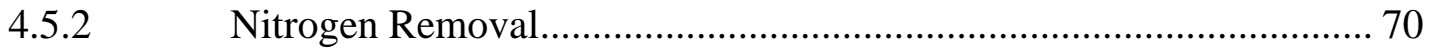

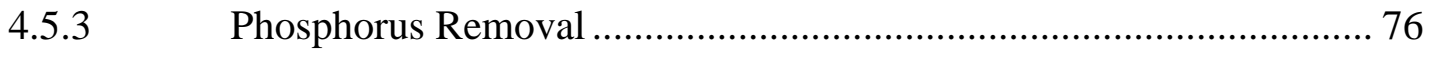

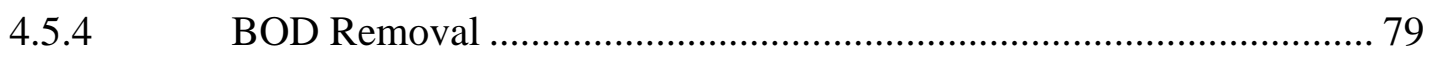

4.6 Experiment III: Aeration of 2-day HRT Ponds .......................................... 82

4.6.1 DO Variation Throughout Pond …............................................. 82 
4.6.2 $\mathrm{pH}$, Temperature and DO . 83

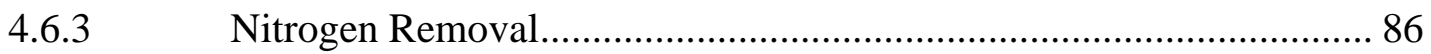

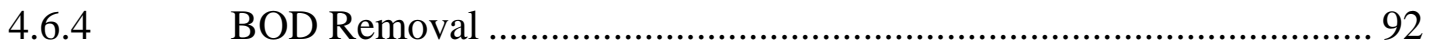

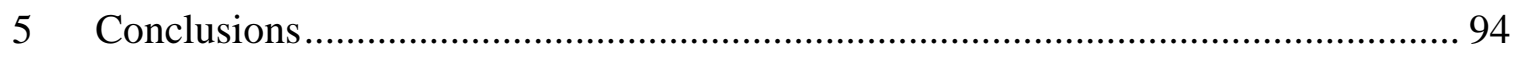

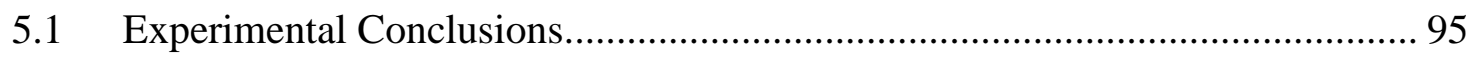

5.1.1 Experiment I: Varying HRT …............................................... 95

5.1.2 Experiment II: Ponds in Series …........................................... 96

5.1.3 Experiment III: Aeration of 2-day HRT Ponds ............................... 97

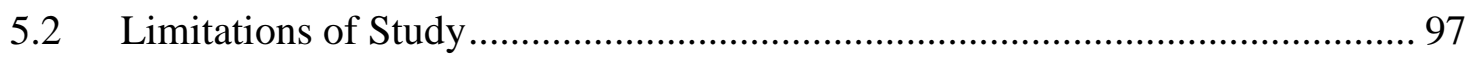

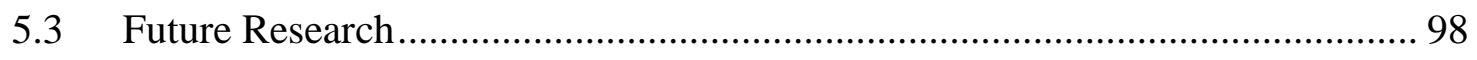

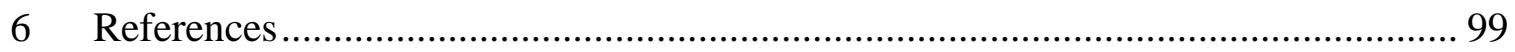

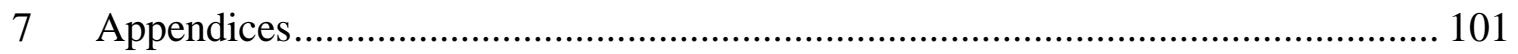

Appendix A Sample Schedule................................................................... 102

Appendix B $\quad$ Experimental and Operational Events ........................................ 104

Appendix C Start-Up TAN Concentration in Alpha Ponds ................................ 106

Appendix D Morning and Evening TAN Concentrations.................................. 107

Appendix E $\quad$ San Luis Obispo Weather .......................................................... 108 


\section{List of Tables}

Table 3.1. Analytical methods chosen for measurements of organics, nutrients

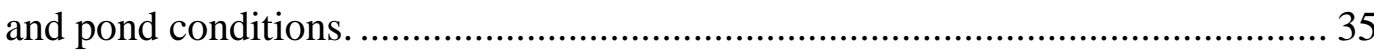

Table 4.1. Assumptions considered during analysis and discussion of results............... 47

Table 4.2. TAN removal in Beta ponds during Experiment I......................................... 53

Table 4.3. TAN removal in Gamma ponds during Experiment I................................... 54

Table 4.4. Comparison of average TAN removal efficiencies and extreme

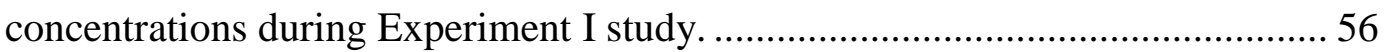

Table 4.5. Comparison phosphorus removal between ponds operating at different

HRTs

Table 4.6. BOD removal between Beta and Gamma sets operating at different

HRTs.

Table 4.7. TAN removal and pond effluent concentrations of ponds in series compared to Influent TAN characteristics 71

Table 4.8. Phosphorus removal comparison of ponds in series.

Table 4.9. BOD removal efficiencies and concentrations of ponds operating in series.

Table 4.10. Aeration effects on TAN removal efficiency and concentrations between experimental and control ponds.

Table 4.11. Secondary treatment results of aeration experiment. 92

Table A.1. Sampling schedule for listed constituents during operation of pilot plant 103 
Table B.1. Weekly schedule of grab samples and notable operational changes in ponds, such as, $\mathrm{CO}_{2}$ addition to Alpha ponds, aeration to Gamma Ponds and inoculation experiments in Beta ponds. .............................................. 105 


\section{List of Figures}

Figure 2.1. Cyclical symbiotic relationship between bacteria and microalgae in a

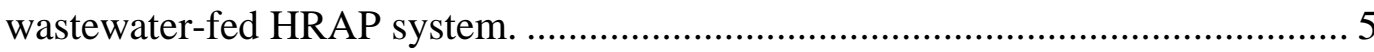

Figure 2.2. Cross section schematic of high rate pond design with typical design dimensions

Figure 2.3. Layout and cross section schematic of an Advanced Pond System. 7

Figure 3.1. Aerial view of Algae Field Station layout at the SLOWRF. 18

Figure 3.2. Process flow diagram for pilot plant operation. 19

Figure 3.3. Weekly procedure for cleaning tube settlers. 22

Figure 3.4. Water-fowl in and around Beta and Gamma ponds. 24

Figure 3.5. Netting used to prevent water fowl from entering pond. 24

Figure 3.6. Experiment I process flow diagram................................................... 26

Figure 3.7. Experiment II process flow diagram. .................................................. 27

Figure 3.8. Diagram of Alpha ponds during operation of ponds in series..................... 28

Figure 3.9. Layout of aeration plans for Gamma ponds during Experiment III. ............. 30

Figure 3.10. Photo of composite sampling points located at probe stands................... 31

Figure 3.11.Influent composite sampling point in Gamma headtank.......................... 32

Figure 3.12. Composite sampling point for tube settler effluent. ................................ 32

Figure 3.13. Photo of Masterflex ${ }^{\circledR}$ Digi-Staltic ${ }^{\circledR}$ pump drive used to collect

composite samples.

Figure 4.1. Time series of Influent alkalinity concentration during experimentation. 43

Figure 4.2. Photo of mixed grab samples from Pond 8 45 
Figure 4.3. Photo of mixed composite samples from Pond 8.

Figure 4.4. $\mathrm{pH}$ and DO time series of Beta and Gamma sets from May 2012 to

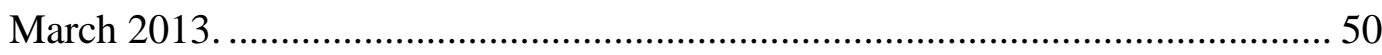

Figure 4.5. Daily average $\mathrm{pH}$ time series for Beta and Gamma Sets........................... 50

Figure 4.6. Daily minimum and maximum percent saturation in Beta and Gamma

Sets. 51

Figure 4.7. TAN time series of Beta ponds from April 25, 2013 to April 26, 2013....... 52

Figure 4.8. Time series TAN concentrations in Gamma pond effluent during Experiment I 55

Figure 4.9. Time series of soluble nitrogen species concentrations in 3-day HRT ponds. 57

Figure 4.10. Time series of soluble nitrogen species concentrations in 2-day HRT

ponds. 58

Figure 4.11. First-order reaction rate coefficient of a 2-day HRT ponds. 61

Figure 4.12. Influent and 2-day pond effluent TAN concentrations throughout entire experimentation period. 62

Figure 4.13. Phosphorus removal in Beta and Gamma sets operating at different

HRTs. 64

Figure 4.14. Beta set $\mathrm{scBOD}_{5}$ concentrations over time compared to Influent

BOD time series. 66

Figure 4.15. Gamma set $\mathrm{scBOD}_{5}$ concentration over time compared to Influent

BOD time series. 66

Figure 4.16. Average temperature and DO (\% saturation) of ponds in series. 69 
Figure 4.17. Average $\mathrm{pH}$ of Round 1 and Round $2 \mathrm{pH}$ during operation of ponds in series.

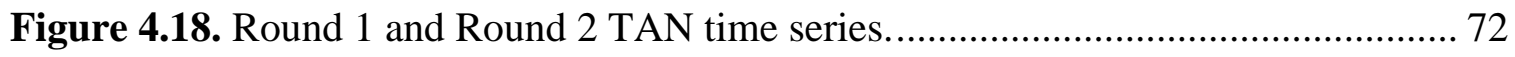

Figure 4.19. Total nitrogen balance between Influent, Round 1 effluent and

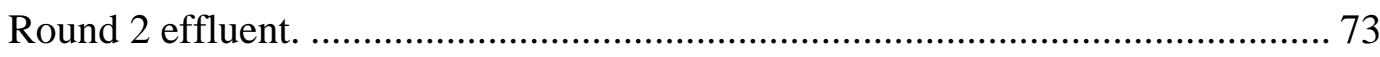

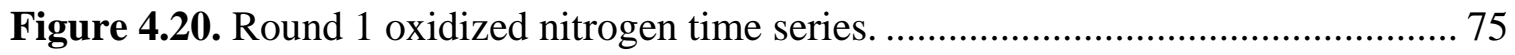

Figure 4.21. Round 2 oxidized nitrogen time series. ........................................... 75

Figure 4.22. Phosphorus concentration time series between influent and ponds in series.

Figure 4.23. Mid-winter total phosphorus balance of tube settler effluent from ponds operating in series. 78

Figure 4.24. Late winter total phosphorus balance of ponds operating in series. 79

Figure 4.25. Experiment II BOD time series comparing Influent BOD characteristics to pond effluent scBOD. 81

Figure 4.26. Time series comparison of $\mathrm{scBOD}_{5}$ concentrations between Round 1 and Round 2. 81

Figure 4.27. Diagram of DO concentration variance throughout Pond 1. 83

Figure 4.28. Minimum DO (\% saturation) in Gamma ponds during aeration experiment. 84

Figure 4.29. Maximum DO (\% saturation) in Gamma ponds during aeration experiment. 84

Figure 4.30. Temperature in Gamma ponds during Experiment III. 85 
Figure 4.31. TAN concentrations in the Influent and Gamma ponds presented as time series. 88

Figure 4.32. Graphical representation of TAN removal efficiencies during

Experiment III. 88

Figure 4.33. Pond 7 soluble nitrogen concentrations during Experiment III................. 90

Figure 4.34. Control pond soluble nitrogen concentrations during Experiment III........ 90

Figure 4.35. Pond 9 soluble nitrogen concentrations during Experiment III.................. 91

Figure 4.36. Gamma scBOD 5 time series during aeration experiment....................... 93

Figure C.1. Time series representation of TAN concentrations in 4-day HRT ponds at startup. 106

Figure D.1. Morning and evening TAN concentrations for Ponds 4 and 7, in comparison to composite samples.

Figure E.1. Daily average air temperature and precipitation in San Luis Obispo, California. 108

Figure E.2. Time series of daily solar radiation HRAPs were exposed to in San Luis Obispo, California. 109 


\section{Introduction}

In the United States, 410 billion gallons of water is withdrawn from water supplies daily. Of this total, $12 \%$ or roughly 48 billion gallons, is collected for domestic and public water supply (Kenny, 2009). In 2001, California's water-related energy use accounted for $19 \%$ of the state's total energy use (CEC, 2005), providing a substantial motive for California's SWRCB commitment to a Recycled Water Policy in early 2009. Approximately $8-10 \%$ of municipal wastewater is utilized for planned reuse projects, but projections suggest an additional 490 billion gallons per day (bgd) of water may be available for reuse by the year 2030 (SWRCB, 2010). Increasing demand for water resulting from an expanding population, combined with expected rise in funding toward water reuse potential (SWRCB, 2010), produces an opportunity for significant advancements in water treatment technology.

Recent establishment of stringent nutrient removal regulations, coupled with the high cost of conventional biological treatment, has created a greater demand for consideration of more energy efficient wastewater systems such as HRAPs (Craggs et al, 2012). HRAPs were first investigated by Oswald and colleagues in the 1950s as an alternative to facultative ponds. Observations in that time had suggested greater removal of organic compounds and nutrients in HRAPs compared to facultative ponds (Craggs et al, 2012).

Utilization of microalgae cultures during biological treatment not only alleviates energy demand but also provides opportunity to effectively recover nutrients (Benemann, 2003). Wastewater treatment using microalgae may lessen the need for commercial fertilizers due to the fact that algae grows exceptionally well in nutrient rich wastes (Oswald, 1995). 
From a cost perspective, HRAP operation and maintenance expenses are minimal compared to AS systems and nutrient removal efficiencies are enhanced from $\mathrm{CO}_{2}$ addition to ponds. In comparison to energy intensive conventional treatment systems, HRAPs with $\mathrm{CO}_{2}$ supplementation abate GHG emissions by $100-400 \mathrm{~kg}$ of $\mathrm{CO}_{2} / \mathrm{ML}$ treated (Craggs et al, 2012).

A downside to HRAP wastewater treatment is the requirement for a large land area due to the shallow depth characteristic of high rate pond design (Park et al, 2010). Required land area may be lessened in the case that HRAPs attain sufficient treatment performance at low-HRTs. Modeling of nutrient removal mechanisms of mixed microalgae cultures would further accelerate the practicality of commercial-scale HRAPs. Optimization of environmental and operational parameters in large-scale systems would be required to prove the feasibility of HRAPs as secondary and tertiary treatment systems for domestic wastewater.

The studies presented within this thesis were conducted to determine secondary and tertiary treatment capability of wastewater-fed HRAPs operating at low HRTs, ranging from 2-4 days. $\mathrm{CO}_{2}$ was added to ponds operating in series to assist in achieving a target total nitrogen concentration of $10 \mathrm{mg} / \mathrm{L}-\mathrm{N}$. During periods of low TAN removal in winter, 2-day HRT ponds were aerated to promote nitrification. Results were expected to contribute to the lack of treatment performance analysis of pilot-scale HRAP systems fed with domestic wastewater. 


\section{Background}

This section provides an overview of wastewater treatment in relation to its industrial importance and energy recovery potential. Further discussion entails a summary of HRAP design and purpose, nutrient removal mechanisms in suspended growth processes, treatment capabilities of HRAPs and limitations of the technology.

\subsection{Wastewater Industry}

After implementation of the Clean Water Act (CWA) in 1972 during a technologyforcing period, wastewater treatment systems were installed around the United States to satisfy water quality objectives (Metcalf \& Eddy, 2003). Since regulatory standards were created in the 1970s, centralized activated sludge (AS) plants have been the primary choice for nutrient removal technologies of municipal wastewaters (Oswald, 2003). As these systems currently reach their functional lifetimes, wastewater treatment plants are experiencing greater treatment demands and stricter enforcement of standards (Metcalf \& Eddy, 2003). AS and biological nutrient removal (BNR) processes have become less favorable due to their high cost resulting from the need to continuously aerate the aerobic organisms that treat the wastewater. If we rely on energy intensive $20^{\text {th }}$ century technologies to treat our wastewaters, treatment expenses will become unaffordable for many communities (Oswald, 2003).

In 2008, the USEPA's Clean Watersheds Needs Survey determined \$298.1 billion is necessary for a 20-year capital needs plan to improve wastewater systems and water

collection. Aside from the needs for pipe repair, management programs and sewer corrections, $\$ 105.3$ billion was apportioned to enhancement of secondary and advanced wastewater treatment in order to comply with regulations set forth in the CWA (USEPA, 
2012b). Given that urban, agricultural or industrial wastewaters may contain nitrogen and phosphorus concentrations up to three orders of magnitude higher than surface waters, there is a need for treatment of inorganic constituents using an innovative, costeffective nutrient removal technology (Noüe et al, 1992) to satisfy objectives of the USEPA and SWRCB.

\subsection{Wastewater Treatment using Microalgae}

Well-designed pond systems cultivate anaerobic bacteria, aerobic bacteria and microalgae to synthesize protein and energy rich algal biomass from the products of biological decomposition of organic matter (Oswald, 1995). When microalgae are combined with wastewater rich in nutrients and organic matter, the resulting symbiotic relationship with bacteria creates an energy efficient and low input technology (Figure 2.1). One unit dry weight of algae produces one and a half units of dissolved oxygen for the aerobic biomass community using solar radiation, an abundant and renewable energy source (Oswald, 2003). Microalgae cells, in addition to providing oxygen for bacteria, are capable of nutrient removal, heavy metal adsorption and disinfection (Oswald, 2003). Brackish, fresh, sea water or diluted waste waters are all sufficient sources for microalgae growth, capable of average annual productivities up to $15 \mathrm{~g}$ dry weight $/ \mathrm{m}^{2} /$ day in areas where solar energy is plentiful (Oswald, 1995). 


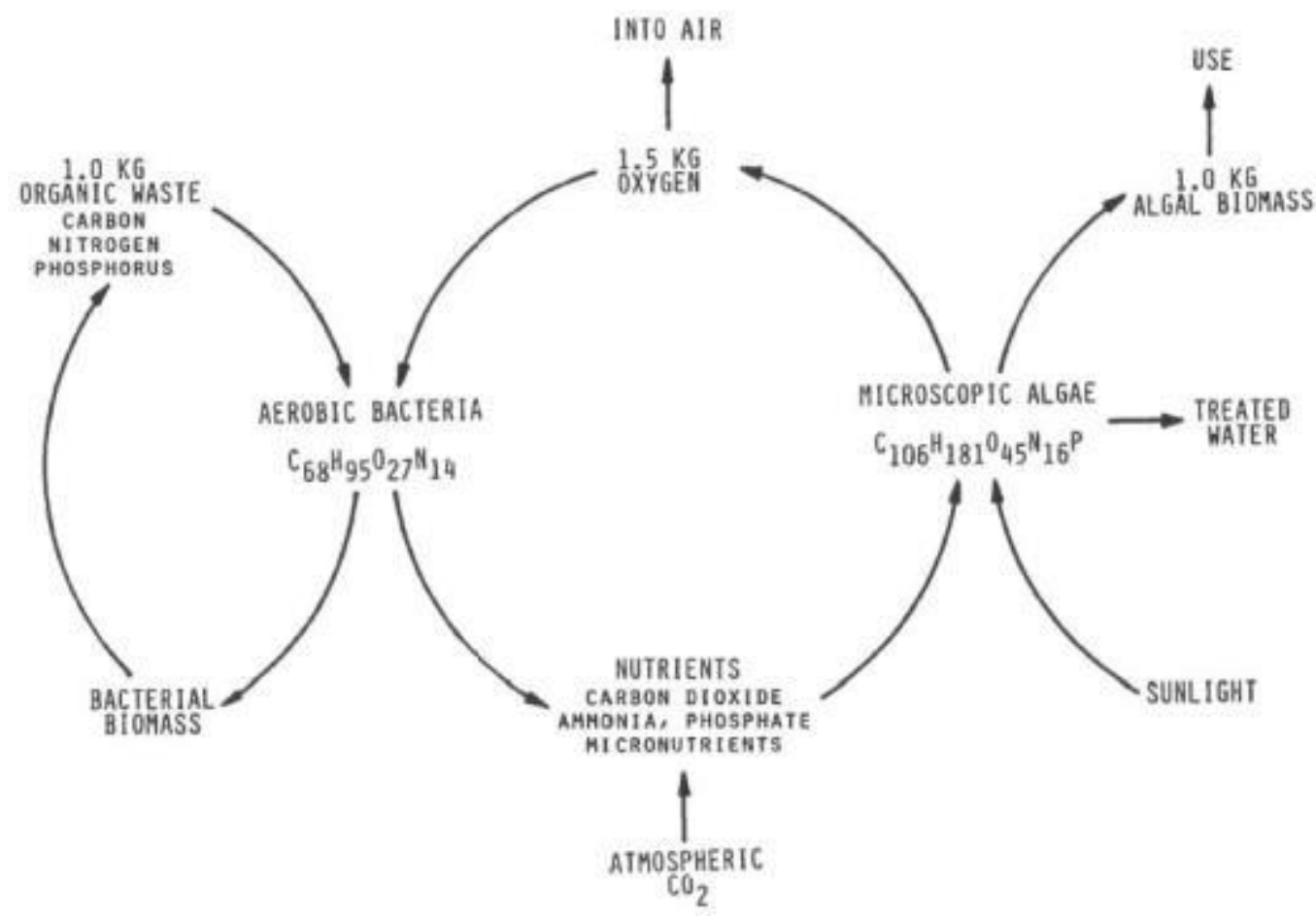

Figure 2.1. Cyclical symbiotic relationship between bacteria and microalgae in a wastewater-fed HRAP system. (Nurdogan, 1980)

HRAPs are channelized in a raceway pattern with low-energy mixing by paddle wheels (mixing velocity $<0.3 \mathrm{~m} / \mathrm{s}$ ) and a shallow depth (Figure 2.2). The design mimics a wellmixed stream flow within the pond channels, resulting in a biological system capable of treating primary effluent wastewater (Craggs et al, 2012). Variables affecting high rate pond performance include detention time, pond depth, sewage strength, light intensity, and temperature (Oswald, 1957). Control of wastewater pond operation and treatment performance is limited by natural variables such as microalgal species growth (Oswald, 2003) and reduced biomass yields from grazing by herbivorous organisms (Park et al, 2010).

Although recent research has aimed to assess feasibility of HRAPs for alternative secondary and tertiary biological treatment systems, their performance has also been evaluated within advanced pond system (APS). APS technology consists of four ponds 
in series to efficiently treat wastewater while recovering resources (Figure 2.3):

advanced facultative ponds, HRAPs, sedimentation ponds and maturation ponds (Craggs et al, 2012). As an approximation, for each $\mathrm{kg}$ of BOD removed from AS processes, 1 $\mathrm{kWhr}$ of electricity for aeration contributes to $1 \mathrm{~kg}$ of $\mathrm{CO}_{2}$ production. In comparison, advanced pond systems convert biomass to methane proportional to $1 \mathrm{kWh}$ electric power with minimal energy inputs (Oswald, 2003).

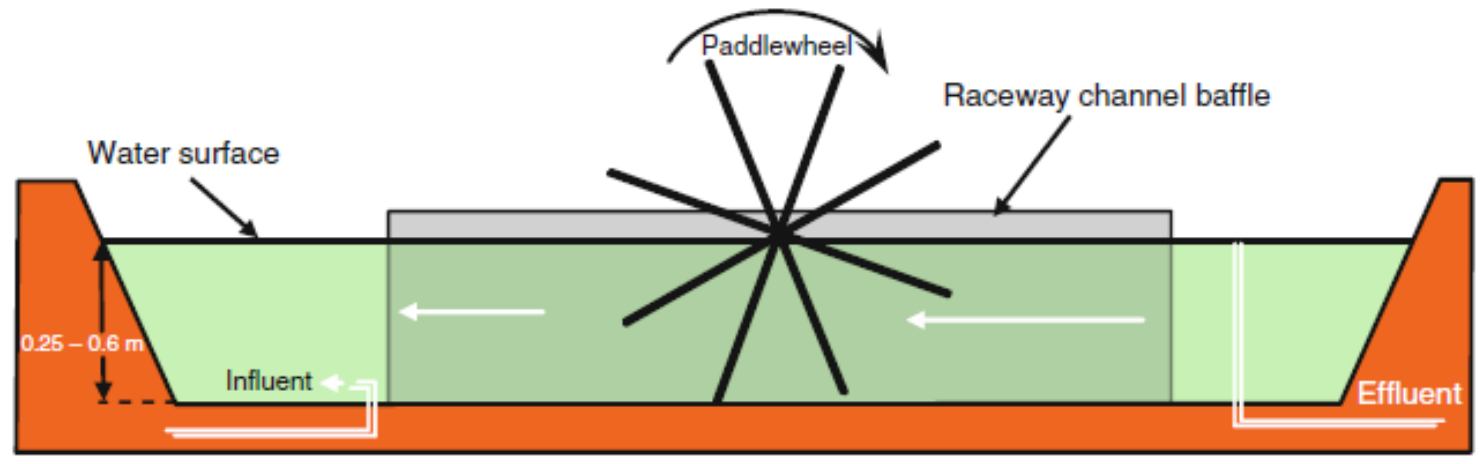

Figure 2.2. Cross section schematic of high rate pond design with typical design dimensions. Raceway channel baffle represents the middle wall of the pond which promotes a raceway flow pattern. (Craggs et al, 2012) 


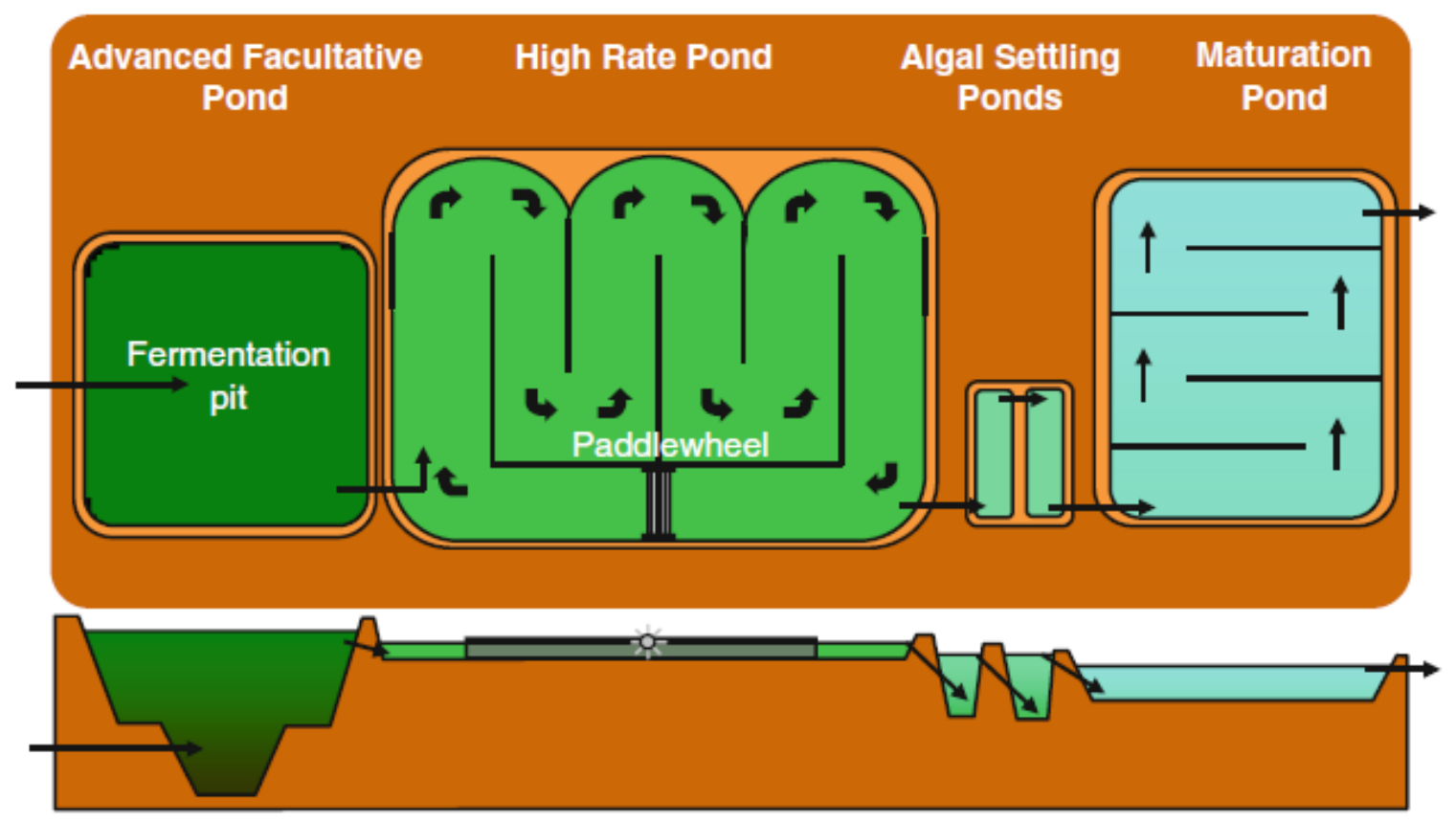

Figure 2.3. Layout and cross section schematic of an Advanced Pond System. Cross section view is provided to illustrate relative depths of ponds. (Craggs et al, 2012) 


\subsection{1 $\mathrm{CO}_{2}$ Addition to Wastewater-fed High Rate Algae Ponds}

Supplementation of $\mathrm{CO}_{2}$ to HRAPs has been a well-known and frequently used technique to improve biomass productivity, nutrient removal and control of algae grazers. Elevated $\mathrm{pH}$ values resulting from consumption of inorganic carbon during algae cell growth may be controlled by $\mathrm{CO}_{2}$ addition to maintain a $\mathrm{pH}$ of 7.5 to 8.5 , an optimal range for algae and bacteria. $\mathrm{CO}_{2}$ addition can also lead to the manipulation of nutrient removal mechanisms by reducing $\mathrm{pH}$, therefore preventing ammonia volatilization or autoflocculation. In comparison to energy intensive conventional treatment systems, HRAPs with $\mathrm{CO}_{2}$ supplementation abate GHG emissions by $100-400 \mathrm{~kg}$ of $\mathrm{CO}_{2} / \mathrm{ML}$ treated (Craggs et al, 2012).

\subsection{Nutrient Removal in HRAP Wastewater Treatment}

The following subsections describe the mechanisms of nitrogen, phosphorus and BOD removal completed by the numerous autotrophic and heterotrophic organisms present in biological treatment systems.

\subsubsection{Mechanisms of Nitrogen Removal}

Discharge of treated wastewater into receiving waters requires low nitrogen concentrations to reduce chances of eutrophication and ensuing oxygen depletion (Mayo \& Mutamba 2004). HRAPs are capable of effective nitrogen removal from wastewater influent if operated at HRTs most suitable to the environmental conditions (Garcia et al, 2000; Mayo \& Mutamba, 2004). Nitrogen removal in suspended growth processes is attained through several mechanisms: nitrification, denitrification, assimilation, volatilization and sedimentation. Typical nitrogen composition of an algal cell is $8 \% \mathrm{~N}$ (Craggs et al, 2012), consequently, indirect nitrogen removal is more prevalent than 
direct nitrogen removal in wastewater-fed HRAPs (Garcia et al, 2000). Indirect nitrogen removal occurs through stripping of $\mathrm{NH}_{4}{ }^{+}-\mathrm{N}$ when $\mathrm{pH}$ levels are raised. Direct nitrogen removal indicates assimilation of nitrogen constituents into algal biomass which would be further removed in separation processes (Garcia et al, 2000). In aquatic environments, higher nitrogen removal results from increased retention times in two ways: (1) increased nitrification and (2) ammonia volatilization at elevated $\mathrm{pH}$ levels (Mayo \& Mutamba, 2004).

The most prevalent nitrogen species in municipal sewage is ammonium nitrogen at levels up to $45 \mathrm{mg} / \mathrm{L}-\mathrm{N}$ assuming a consumptive rate of $120 \mathrm{~L} /$ capita-day. In suspended growth processes, high concentrations of ammonium results in nitrification by autotrophic bacteria. The first oxidation step during nitrification converts ammonium to nitrite, followed by the second step which further oxidizes nitrite to nitrate. Several genera of autotrophic bacteria are capable of nitrification in wastewater treatment. The most common genera responsible for ammonia oxidation (Equation 2-1) to nitrite and the second step of oxidation into nitrate (Equation 2-2) are Nitrosomonas and Nitrobacter, respectively (Metcalf \& Eddy, 2003). Oxidation of ammonia requires approximately $4.57 \mathrm{~g} \mathrm{O}_{2} / \mathrm{g} \mathrm{N}$, represented by stoichiometry in Equation 2-3, to complete the two-step oxidation process for nitrification. In addition, $7.14 \mathrm{~g}$ of alkalinity as $\mathrm{CaCO}_{3} / \mathrm{g}$ ammonia nitrogen converted is required for the total oxidation reaction to be carried out. Nurdogan (1988) observed ammonia removal efficiencies of $85 \%$ in pilot HRAP operating at five day retention times. 
Nitroso-bacteria:

$$
2 \mathrm{NH}_{4}^{+}+3 \mathrm{O}_{2} \rightarrow 2 \mathrm{NO}_{2^{-}}+4 \mathrm{H}^{+}+2 \mathrm{H}_{2} \mathrm{O} \quad \text { Equation 2-1 }
$$

Nitro-bacteria:

$$
2 \mathrm{NO}_{2}^{-}+\mathrm{O}_{2} \rightarrow 2 \mathrm{NO}_{3}^{-}
$$

Total oxidation reaction:

$$
\mathrm{NH}_{4}{ }^{+}+2 \mathrm{O}_{2} \rightarrow \mathrm{NO}_{3}^{-}+2 \mathrm{H}^{+}+\mathrm{H}_{2} \mathrm{O}
$$

Equation 2-3

Volatilization is an indirect mechanism that contributes to ammonia removal. In HRAP wastewater treatment systems, daytime photosynthesis leads to algal biomass readily consuming $\mathrm{CO}_{2}$ and $\mathrm{HCO}_{3}{ }^{-}$, thereby increasing the $\mathrm{pH}$ to 11 or greater (Park et al, 2010). As pH approaches 9.4 at a temperature of $20^{\circ} \mathrm{C}$, concentrations of ammonia gas $\left(\mathrm{NH}_{3}-\mathrm{N}_{\mathrm{g}}\right)$ and ammonium ions $\left(\mathrm{NH}_{4}{ }^{+}-\mathrm{N}\right)$ become equal, while at $\mathrm{pH} 9.4$ or higher, ammonia gas concentration dominates (Mayo \& Mutamba, 2005). Ammonia gas, represented as ammonia-cal-nitrogen $\left(\mathrm{NH}_{3}-\mathrm{N}\right)$, will volatilize from liquid at higher temperatures and elevated pH (Park et al. 2010; Craggs et al, 2012). 90\% of $\mathrm{NH}_{4}{ }^{+}-\mathrm{N}$ is in gas phase during summer conditions of $\mathrm{pH} 10.5$ and $20^{\circ} \mathrm{C}$, while only $20 \%$ is volatile at winter conditions of $\mathrm{pH} 9$ and $10^{\circ} \mathrm{C}$ (Nurdogan, 1988). $\mathrm{CO}_{2}$ supplementation to high-HRT and carbon limited ponds will enhance algal biomass growth and reduce $\mathrm{pH}$ to the optimal level of 8 , thereby creating a more suitable environment for nitrification (Park et al. 2010; Craggs et al, 2012).

When sufficient ammonia is available in liquid phase for conversion into nitrate via nitrification, low dissolved oxygen levels will promote successive reduction of nitrate into nitrogen gas by means of denitrification (Equation 2-4). Conventional wastewater 
treatment systems requiring denitrification often employ the Modified Ludzak-Ettinger (MLE) process to accomplish preanoxic denitrification. Preanoxic denitrification, or dissimilation, occurs when oxygen is substituted for nitrates or nitrites as electron acceptors for the oxidation of inorganic and organic constituents. Postanoxic denitrification occurs after nitrification, whereby BOD is no longer available as an electron donor, resulting in an electron donor source from endogenous decay to complete reduction of nitrate. In AS treatment, completion of simultaneous nitrification and denitrification occurs due to a reduction of DO levels toward the interior of an activatedsludge floc, through which an aerobic environment promotes nitrification and an anoxic environment contributes to denitrification (Metcalf \& Eddy, 2003).

Nitrate reduction steps:

$$
\mathrm{NO}_{3^{-}} \rightarrow \mathrm{NO}_{2^{-}} \rightarrow \mathrm{NO} \rightarrow \mathrm{N}_{2} \mathrm{O} \rightarrow \mathrm{N}_{2}
$$


Direct nitrogen removal includes the assimilation, or uptake, of nitrogen by algal cells and bacteria (Shin \& Polprasert, 1988). Due to the preference for these organisms to use $\mathrm{NH}_{3}-\mathrm{N}$ over $\mathrm{NO}_{3}{ }^{-}$for cell buildup, ammonia removal occurs before nitrates are used for assimilation (Mayo \& Mutamba, 2005). This favorability to use $\mathrm{NH}_{3}-\mathrm{N}$ before $\mathrm{NO}_{3}{ }^{-}$ results because utilization of $\mathrm{NO}_{3}{ }^{-}$requires more energy and availability of nitrate reductase (Nurdogan, 1988). Removal of organic nitrogen as a result of uptake is completed through sedimentation (Shin \& Polprasert, 1988), a low energy nutrient recovery mechanism optimized by high settling efficiencies and proper harvester design. Instead of wasting fixed nitrogen in a mechanized denitrification process, algal ponds can recycle 1 to $2 \mathrm{~g}$ dry weight of protein nitrogen per $\mathrm{m}^{2} / \mathrm{d}$ (Oswald, 1995). Resource recovery resulting from subsequent biomass harvesting is proportional to algal productivity and settleability.

A dependable HRAP wastewater treatment system requires production of well treated water for reuse, reliable low-cost biomass harvesting techniques (Craggs et al, 2012) and minimal operational costs. In consideration of these requirements, significant interest pertaining to high algal productivity within a nitrogen limited pond has been addressed in HRAP literature. Lipid contents of nitrogen limited algal cells may double from $20 \%$ to $40 \%$, while also contributing to improved aggregation of biomass. In contrast, low levels of algal growth are commonly observed in ponds with low nitrogen (Park et al, 2010). Controlled demonstration of adequate nutrient removal within a high productivity pond requires more pilot scale research of wastewater-fed HRAPs and variables affecting lipid content of algal cells. 


\subsubsection{Mechanisms of Phosphorus Removal}

Akin to nitrogen species, presence of orthophosphates is essential for growth of algae and therefore must be removed in the wastewater treatment process to avoid eutrophication in receiving waters (Powell et al, 2009). Phosphorus content in algal cells typically falls within the range of $0.35 \%-1 \%$ (Craggs et al, 2012), but may reach $3.16 \%$ when luxury uptake occurs (Powell et al 2008). Low phosphorus content is observed when assimilation is negatively affected from seasonal variation in algal productivity during winter months or when phosphorus is a limiting nutrient (Craggs et al, 2012).

Phosphorus removal in algal wastewater systems requires further investigation due to the limitation of phosphorus uptake by algal biomass at a rate of $1 \%$ of dry weight (Nurdogan, 1988). Improved phosphorus recovery from biomass in full-scale HRAPs would alleviate the negative environmental impacts of GHG emissions from rock mining (Craggs et al, 2012), which is currently accelerating the depletion of readily available phosphorus.

Phosphorus may be removed from wastewater by precipitation resulting from chemical addition or elevated $\mathrm{pH}$ levels (Powell et al, 2008). Chemical precipitation inflates HRAP operation costs and limits recovery of phosphorus due to production of chemical sludge requiring disposal, thus, said mechanism is an unfavorable removal technique (Powell et al, 2009). Natural means of precipitation occurs during the growth phase of microalgal species as consumption of $\mathrm{CO}_{2}$ and alkalinity typically leads to elevated $\mathrm{pH}$ levels, thereby promoting a process known as autoflocculation (Nurdogan, 1988). Autoflocculation results from formation of phosphate complexes with calcium, magnesium or iron (Powell et al, 2008). Removal of phosphorus by means of 
autoflocculation is limited by the availability of divalent cations in wastewater, but may be improved through the addition of lime to algae ponds (Nurdogan, 1988). Nurdogan (1988) measured orthophosphate removal up to $99 \%$ in $1000-m^{2}$ HRAP operating at 5day HRT by adding $60 \mathrm{mg} / \mathrm{L} \mathrm{CaO}$. Sedimentation of algal biomass would be the successive step in completing phosphorus recovery by means of autoflocculation.

An advantage of biological phosphorus removal as opposed to chemical precipitation is the ability to harvest energy-rich biomass after phosphorus uptake and subsequent sedimentation of microalgae (Powell et al, 2009). Assimilation of phosphorus by algal cells is necessary for development of cellular constituents such as phospholipids, nucleotides and nucleic acids (Powell et al, 2008). In wastewater treatment systems, phosphorus is available in the form of orthophosphates (Metcalf \& Eddy, 2003). Other forms of phosphorus present in sewage include organic phosphorus compounds and polyphosphates, both available for hydrolysis into orthophosphate (Nurdogan, 1988).

When phosphate is introduced into a phosphorus deficient environment (P limiting at 0.2 $\mathrm{mg} / \mathrm{L}-\mathrm{P}$ ), algal cells store the phosphorus in the form of polyphosphates through a process referred to as "luxury uptake" (Nurdogan, 1988; Powell et al, 2008). Polyphosphates are present in two forms: (1) Acid-soluble polyphosphates (ASP) which are actively involved in microalgal metabolism and (2) Acid-insoluble polyphosphates (AISP) a form stored by biomass when phosphate concentrations are limiting. AISP was initially suspected as the primary form of phosphorus storage in algal cells, but ASP has been determined to be used as short term storage when wastewater phosphate concentration is high. Accumulation and consumption of both forms of polyphosphates is proportional to an increase in temperature. Luxury uptake is further accelerated by the introduction of 
wastewater containing phosphorus concentrations of 15-30 mg/L-P. Initially exposing microalgae to high temperature wastewater containing high concentrations of phosphate proves to be the most important design consideration for increasing luxury uptake by microalgae cells (Powell et al, 2009).

\subsubsection{Mechanisms of BOD Removal}

In addition to nitrogen, phosphorus and trace micronutrients, influent wastewaters contain organic content consisting of proteins, carbohydrates, oils and fats. These organic constituents are decomposed by aerobic bacteria until dissolved oxygen is depleted or the organic waste is consumed. Initially, oxidation of organic content provides energy for cell synthesis and maintenance. If the organic waste is consumed completely, cells begin to use their tissue for maintenance in a process known as endogenous respiration (Metcalf \& Eddy, 2003). Additionally, assimilation of organic carbon by heterotrophic microalgae species is possible in low HRT ponds with sufficient glucose, glycerol and acetate present in the wastewater (Perez-Garcia, 2011).

\subsection{Further Research Needed}

Despite its many advantages, HRAP technology requires further attention when addressing winter time treatment, specifically nitrate and dissolved phosphorus removal. Although phosphates are not associated with significant health effects, low phosphorus content characteristic of algae cells limits the amount of phosphorus removal if luxury uptake does not occur. Optimization of phosphorus loading and maximization of biomass growth are two key factors in the improvement of phosphorus removal in

HRAPs. Wastewater plants subject to drinking water treatment quality face a maximum contaminant limit (MCL) discharge standard of 10mg/L-N for nitrates (USEPA, 2012a). 
In winter time months, loss of ammonia by volatilization is reduced while nitrification of ammonia to nitrate increases (Nurdogan, 1988). Nitrate reduction during biological treatment requires low oxygen levels (Metcalf \& Eddy, 2003), making denitrification in an oxygen rich pond full of active autotrophs difficult to achieve. Algae technology research lacks significant nitrogen removal analysis for ponds operating under various conditions at the same location and would further benefit from increased experimentation of operational variables. Once performance limitations due to seasonality are overcome, HRAPs will become an attractive alternative to treat wastewater and produce significant energy recovery outputs.

\subsection{Study Objectives}

Given the aforementioned limitations and issues pertaining to algae wastewater systems, I studied the seasonal differences of treatment performance resulting from: (1) varied HRTs, (2) operating ponds in series with $\mathrm{CO}_{2}$ supplementation and (3) nighttime aeration of ponds with low HRTs. Hypothesis formulated for the respective experimental conditions listed are as follows: (1) HRAPs operating at 3-day and 2-day HRTs are capable of secondary level treatment during summer and winter months, (2) ponds operating in series, totaling a 7-d HRT, will attain tertiary treatment levels of $10 \mathrm{mg} / \mathrm{L}-\mathrm{N}$ for total soluble nitrogen, and (3) aeration will improve TAN removal efficiency by nitrification in 2-day HRT ponds and ponds will maintain $\mathrm{scBOD}_{5}$ concentrations of less than $40 \mathrm{mg} / \mathrm{L}$ throughout winter. 


\section{Materials and Methods}

Throughout this chapter, pilot plant construction, operation and maintenance, sampling methods, experimental procedures and water quality analyses methods will be described. Experiments were completed in nine 30-square meter high rate ponds (HRP) which were operated as three sets of triplicates. These ponds were located at the City of San Luis Obispo Water Reclamation Facility (SLOWRF). Appendix A serves as a summary of scheduled water quality analysis performed during operation.

The HRPs were monitored for wastewater treatment performance, settling efficiency and biomass harvesting capabilities. Since startup in late January 2012, the ponds were operated continuously. The nine ponds (Figure 3.1) were labeled, south to north, with the first triplicate (Pond 1-3) named as "Alpha," the second triplicate (Ponds 4-6) as "Beta," and the last triplicate (Ponds 7-9) as "Gamma." A process flow diagram for the pilot plant can be seen below in Figure 3.2. 


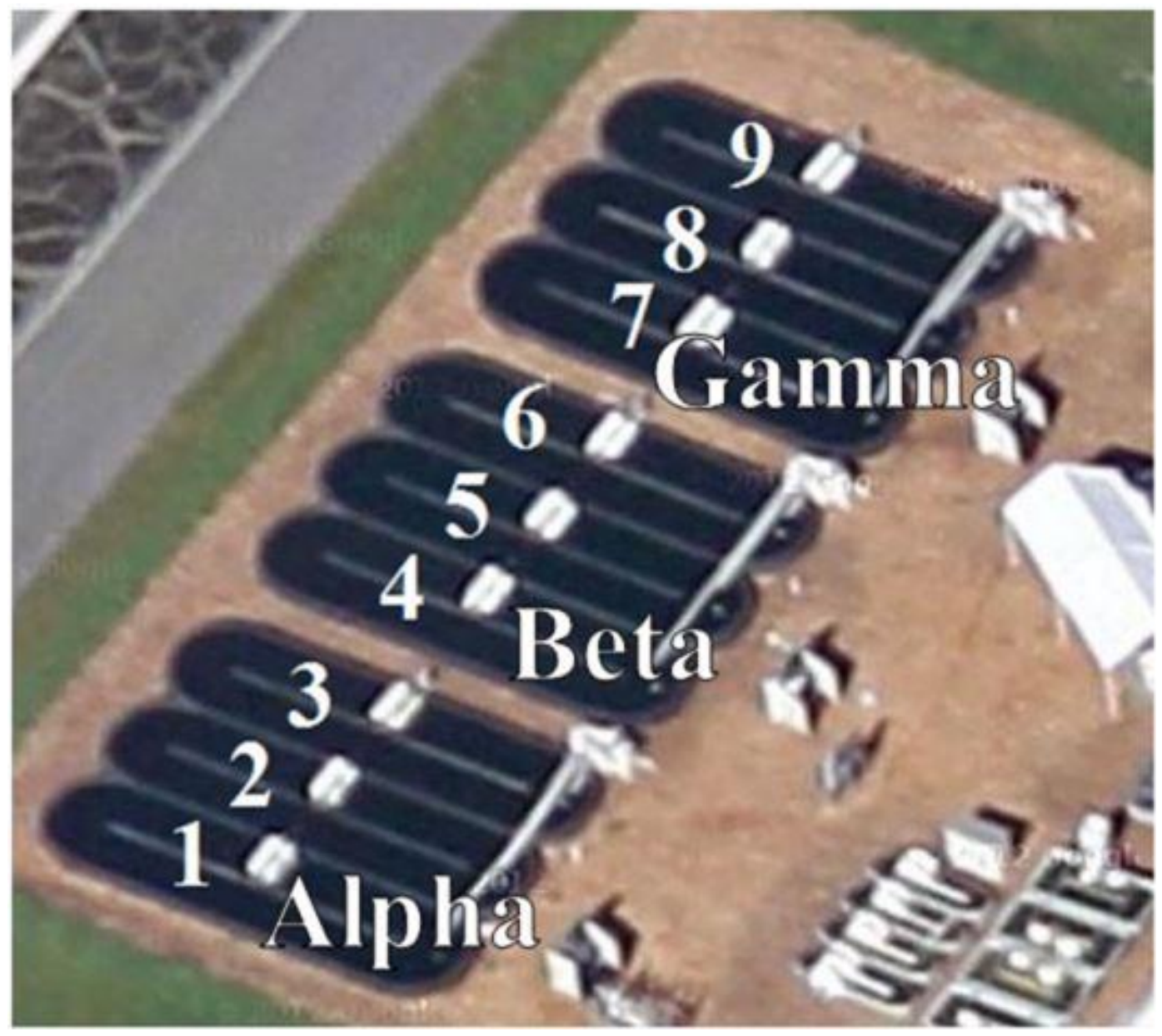

Figure 3.1. Aerial view of Algae Field Station layout at the SLOWRF. Ponds are located between the second primary clarifier and the activated sludge basin. Tube settler units are not shown in photograph. Influent distribution system is located at NE corner of each triplicate. 


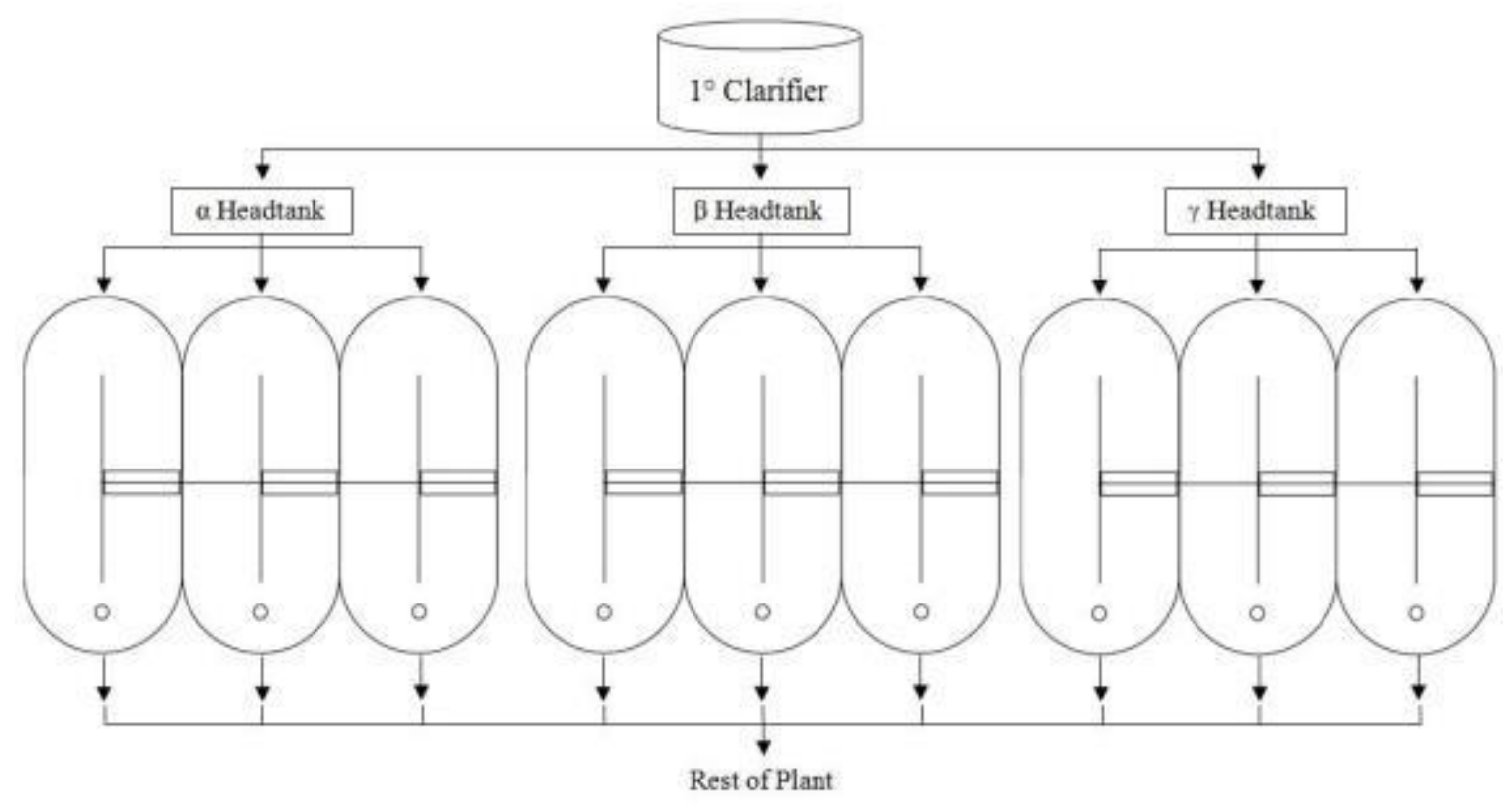

Figure 3.2. Process flow diagram for pilot plant operation. Ponds are numbered 1-9 from left to right. "Rest of Plant" indicates effluent was pumped from collection sump back to the primary clarifier launder. Figure represents operation without tube settler harvesting or operation of ponds in series.

\subsection{Pilot Plant Layout}

Construction of the Algae Field Station (AFS) Pilot Plant began in June 2011 and was completed in January 2012. All nine ponds are identical in dimension and material composition. Primary effluent from the second primary clarifier was pumped into three constant headtanks located at the northeast end of each triplicate. Through a series of three distribution boxes, influent was fed into each pond at the turnaround directly downstream of the paddle wheels. Standpipes of 4" diameter were used to collect pond effluent and control pond depth (Figure 3.1). Further details pertaining to AFS construction and layout are as described in (Ripley, 2013) 


\subsection{Pilot Plant Operation and Maintenance}

Beginning at startup, routine maintenance for the AFS was established to ensure pilot plant was operating as expected and any system interruptions or issues were documented. Refer to Appendix B for notable changes in experimental and operational conditions as well as notation of grab samples. Pilot plant startup, routine maintenance and operational variables are outlined in this section.

\subsubsection{Pilot Plant Startup}

Operation began on January 25, 2012 all nine ponds were fed reclaimed wastewater during the week prior to startup. No algal inoculum was used during operation of ponds. Once algal growth was observed in ponds, primary effluent was fed to ponds to begin the experimentation period. Hydraulic retention time (HRT) was set to 4 days for all ponds.

\subsubsection{Monitoring and Maintenance}

Daily maintenance of the AFS was required to assure proper function of system and accurate readings from probes used for determining operational parameters. Field

operators were on a weekly schedule for completion of all necessary maintenance. Tasks included flow calibration, $\mathrm{DO}$ and $\mathrm{pH}$ probe calibration, tube settler cleaning, filamentous algal control and pump maintenance.

Daily operations were aimed to check for any impedance on proper operation of HRPs as well as monitoring of field conditions and pond performance. Daily checks included visual observation of pond water level, potential leaks, sump pump performance, $\mathrm{CO}_{2}$ tank levels and removal of filamentous algae. Probe arms located near the effluent standpipes frequently collected filamentous algae in ponds with a lower HRT. Three to 
four times a week, $150 \mathrm{~mL}$ beakers were used for grab sample observations of pond effluent. Operators recorded floc characteristics, water clarity and zooplankton presence. Water wheels, paddle wheels and influent distribution boxes were sprayed down to remove organic buildup which would otherwise restrict appropriate inflow through water wheel distribution pipes. Influent flow calibration was completed by measuring flow into each pond a minimum of three times over the course of a minute using a $2000 \mathrm{~mL}$ graduated cylinder. If flows were consistently low or high for a triplicate, the water wheel VFD motor was adjusted accordingly. When algal grazers were present, material used in such pond was isolated to prevent transportation of grazers into a different pond. Calibration of $\mathrm{DO}$ and $\mathrm{pH}$ probes was performed weekly. $\mathrm{pH}$ probe calibration was completed using a high calibration point with $\mathrm{pH} 10$ buffer solution and a low calibration point with $\mathrm{pH} 7$ buffer solution. DO probes were calibrated during sundown hours and in dry conditions to ensure membranes were not exposed to light or moisture during calibration.

Tube settler cleaning was setup on a weekly schedule to take place at least 48 hours before composite sampling began. Harvesters were emptied and sprayed down to remove biomass growth on inside walls and settling tubes (Figure 3.3). Also, algae sludge was removed from tube settlers daily to reduce accumulation and maintain efficient solids removal. Punctuality of scheduled maintenance tasks for tube settlers was emphasized to avoid solids carryover into Alpha ponds during Experiment II. 


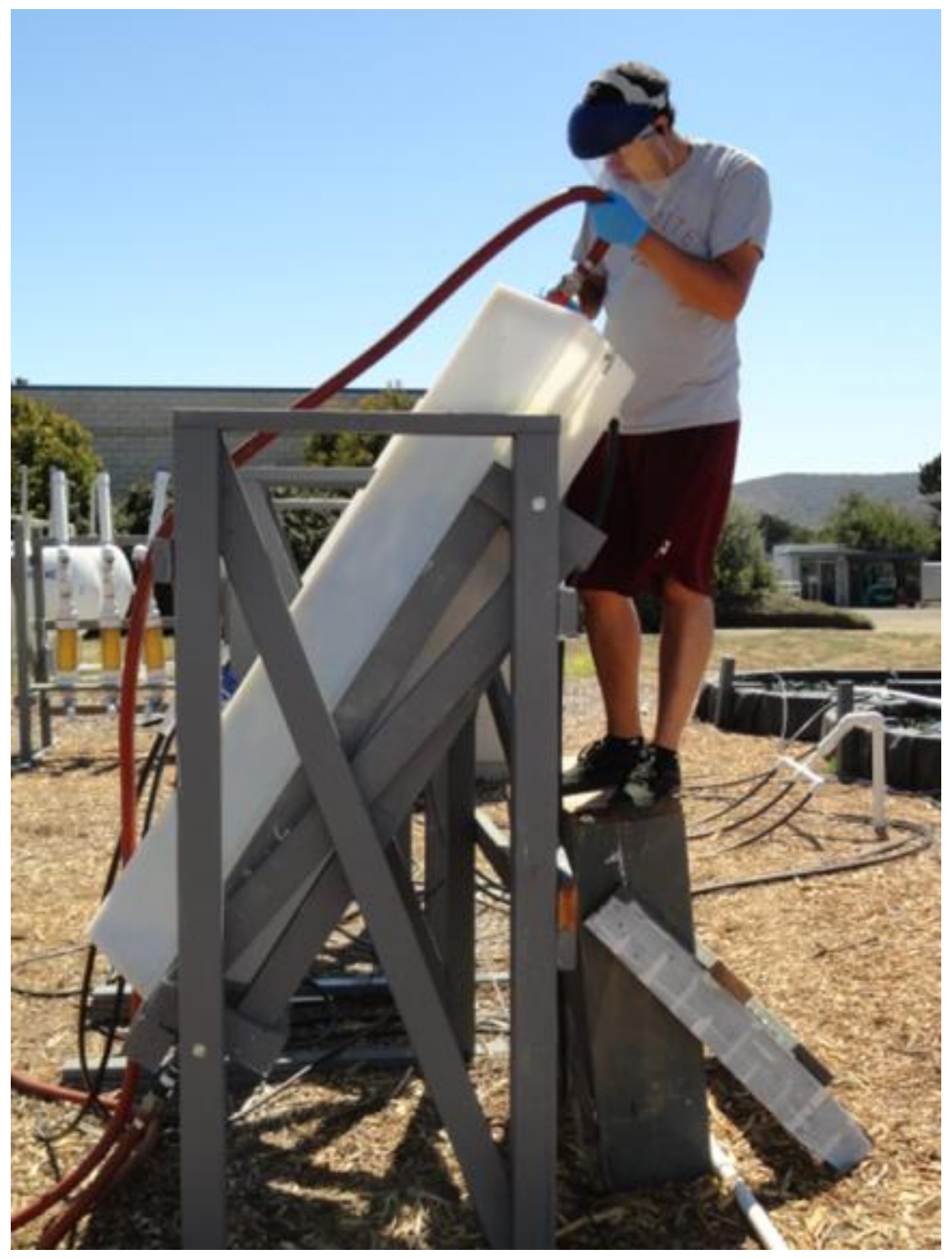

Figure 3.3. Weekly procedure for cleaning tube settlers. Tube settler operation was paused for 23 hours each week to remove all water and biomass.

\subsubsection{Operational Variables}

During experimentation that required addition of carbon, $\mathrm{CO}_{2}$ diffusers were placed in ponds downstream of paddle wheels. Addition of $\mathrm{CO}_{2}$ was controlled by a range of $\mathrm{pH}$ in which solenoids were turned on once $\mathrm{pH}$ reached 8.6 and turned off at $\mathrm{pH}$ 8.5. Diffusers were inspected daily for obstruction to diffuser tube and brushed down if cleaning was necessary. Paddle wheel speed was set to $45 \mathrm{~Hz}$ on the VFD, corresponding 
to $9.1 \mathrm{rpm}$ and remained at that setting throughout entire operation. The pond paddlewheel speed in each triplicate produced a channel velocity of approximately $0.25 \mathrm{~m} / \mathrm{s}, 0.28 \mathrm{~m} / \mathrm{s}$ and $0.27 \mathrm{~m} / \mathrm{s}$ for Alpha, Beta and Gamma, respectively. Tube settler harvesters were integrated into the process flow for all ponds by June 30, 2012. Cole Parmer peristaltic pumps were used to withdraw $0.8 \mathrm{~L} / \mathrm{min}, 1.6 \mathrm{~L} / \mathrm{min}$ and $0.8 \mathrm{~L} / \mathrm{min}$ from Alpha, Beta and Gamma ponds, respectively. Alpha and Gamma tube settlers operated at efficient solids removal overflow rates while Beta was subject to a higher pumping rate to meet an influent flow into Alpha ponds corresponding to the desired 4-day HRT.

\subsubsection{Water Fowl Control}

During water quality analysis of Total Kjeldahl Nitrogen on pond effluent and influent samples in early July, data observation revealed a total nitrogen imbalance between influent and low-HRT ponds. During the warm months of summer, water fowl, commonly ducks and cowbirds, would become accustomed to swimming and feeding in the pilot plant HRAPs (Figure 3.4). Upon consideration of many possible causes, it was agreed that the cause of nutrient imbalance was from the introduction of excess organic nutrients by the excrement of water fowl. To abate the suspected cause, netting was placed four inches over roughly $70 \%$ of the pond surface, the open areas at sampling and influent points as well as paddle wheel operational areas (Figure 3.5). Netting coverage was identical for all ponds material was thin enough that resulting shadow effects were deemed negligible. Further observation of nutrient imbalances led to insight of composite sampling and standpipe issues, as discussed in Section 4-3 


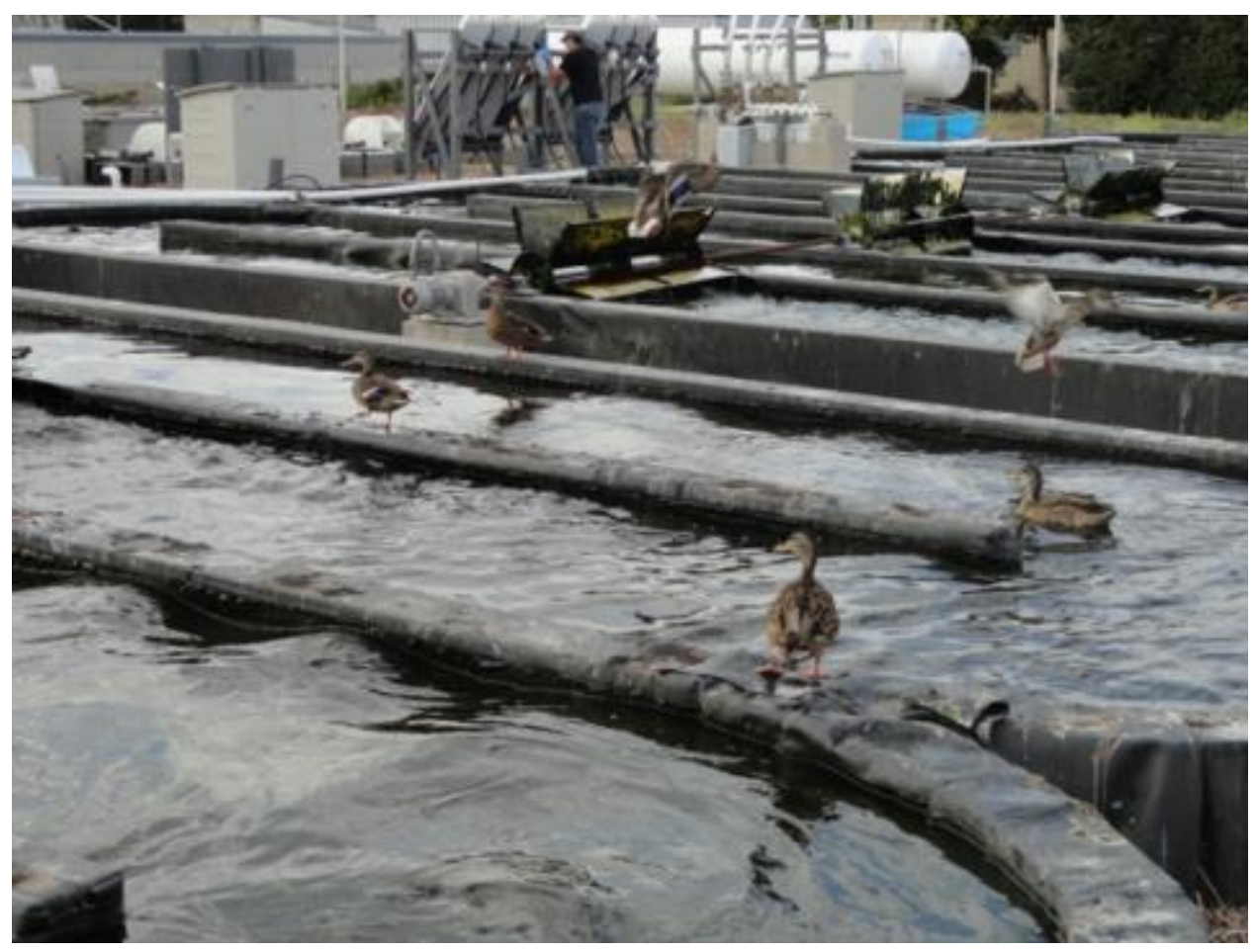

Figure 3.4. Water-fowl in and around Beta and Gamma ponds.

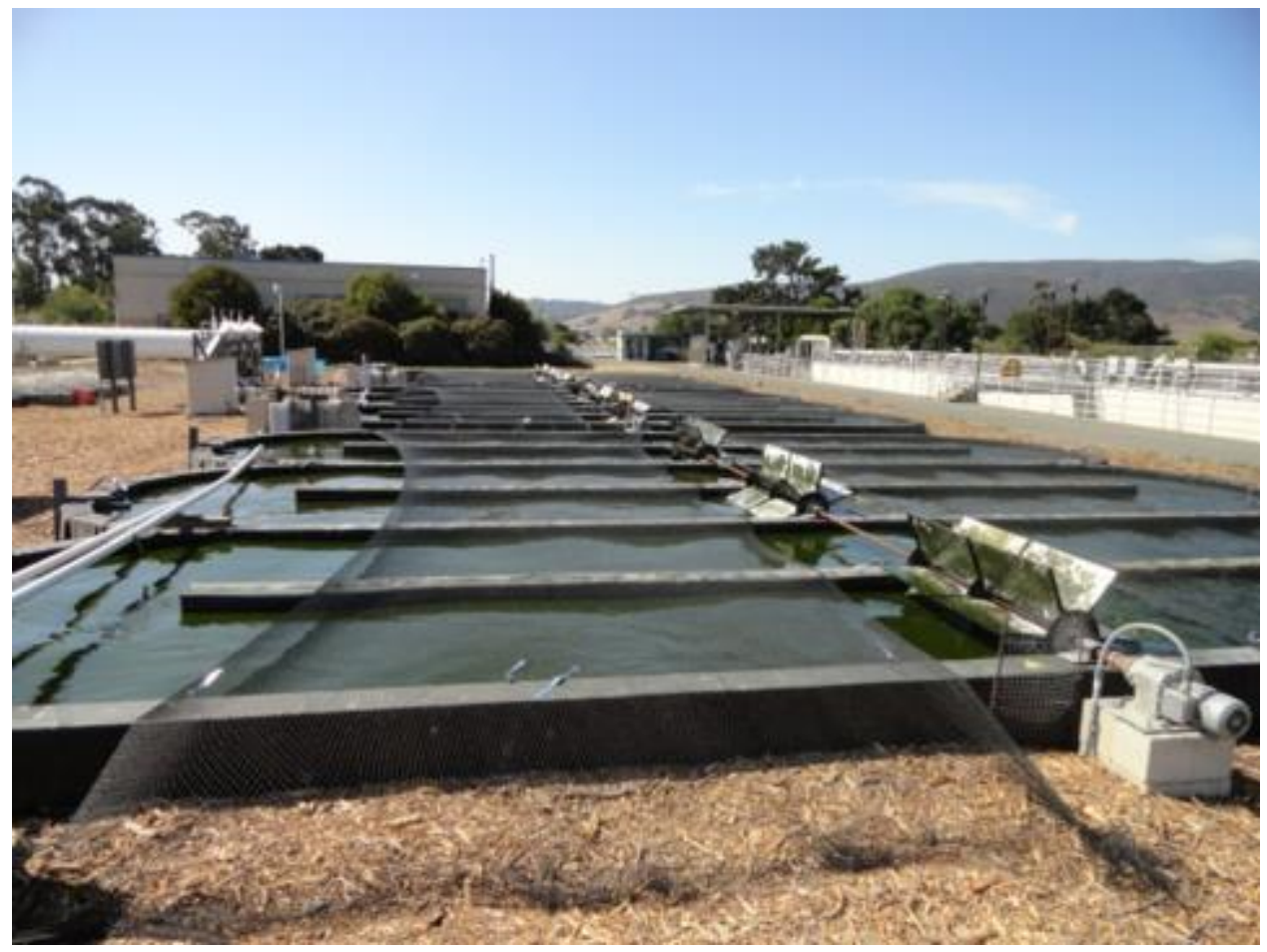

Figure 3.5. Netting used to prevent water fowl from entering pond. The pond turnarounds located at the right hand side of the picture were completely covered with netting. After installation, any presence of water fowl was near the distribution pipes on the left hand side of the photo. 


\subsection{Experimental Procedures}

The following section provides details on the procedures, timelines and important notes of each experiment. From the time of startup until March 31, 2013, the AFS HRPs were subject to three different process flows. At startup, all ponds were set to a 4-day HRT until the beginning of Experiment I to determine a baseline treatment performance. Experiment I entailed setting Alpha, Beta and Gamma to different HRTs. Following Experiment I, Beta ponds and Alpha ponds were set in series, maintaining their respective inflow rates. In the final experiment, two experimental ponds in the 2-day HRT set were aerated at night.

\subsubsection{Experiment I: Varying HRT}

On April 23, 2012, an HRT experiment began to determine treatment performance variation between a controlled set at a 4-day (Alpha) HRT and two experimental sets set at a 3-day (Beta) and 2-day (Gamma) HRT (Figure 3.6). Pond HRTs were lowered due to an increase in temperature and solar radiation during spring months. Pond influent rate was monitored multiple times per week and adjusted to reflect chosen HRT parameters. Experiment I was concluded upon the start of Experiment II on June 1, 2012. 


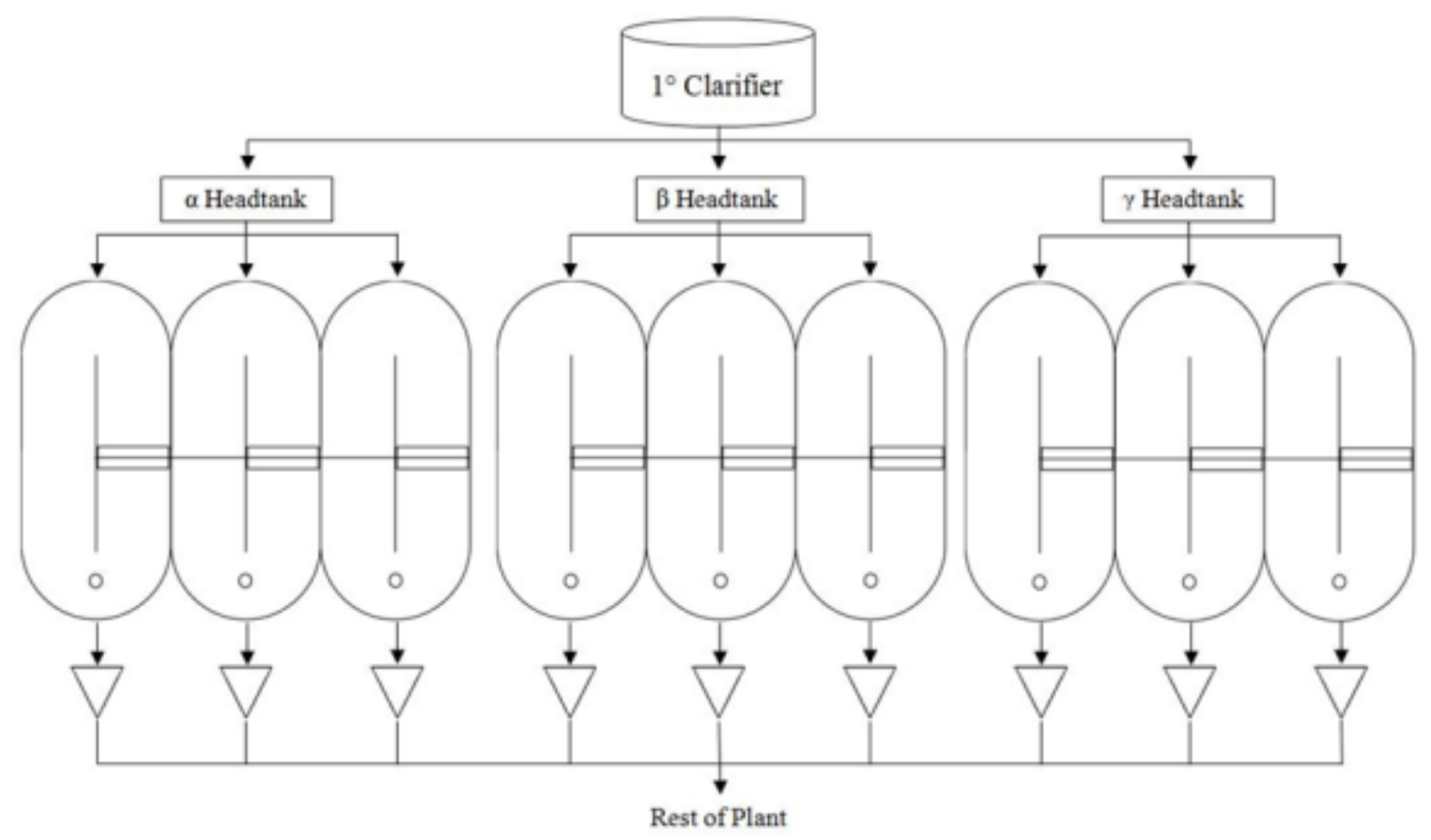

Figure 3.6. Experiment I process flow diagram. Pond numbering is 1-9 from left to right. Triangular shapes represent tube settler harvesting before effluent was discharged back to the primary clarifier launder.

\subsubsection{Experiment II: Ponds in Series}

The second experiment began on June 1,2012 and aimed to attain low nutrient concentrations in the second set of ponds in series. Beta ponds continued to operate at a 3-day HRT, but $1.65 \mathrm{~L} / \mathrm{min}$ of the total $2.2 \mathrm{~L} / \mathrm{min}$ pond effluent flow was directed from the standpipe into tube settlers for each pond (Figure 3.7). Effluent water from the Beta ponds, separated from the biomass of the ponds in respective tube settler s, was directed to Alpha ponds at the 4-day influent rate. It is noted that some biomass was present at the top of the tube settlers when they were not cleaned on schedule, therefore resulting in a carryover of some solids from a Beta pond into and Alpha pond.

Due to the low carbon load into Alpha ponds, supplemental $\mathrm{CO}_{2}$ was added to each pond through diffuser tubes placed immediately downstream of paddle wheels (Figure 3.8). 
$\mathrm{CO}_{2}$ addition was initiated at $\mathrm{pH} 8.6$ and shut off at $\mathrm{pH}$ 8.5. Minimal interruption of $\mathrm{CO}_{2}$ supplementation occurred when tanks ran empty or supply lines were fractured.

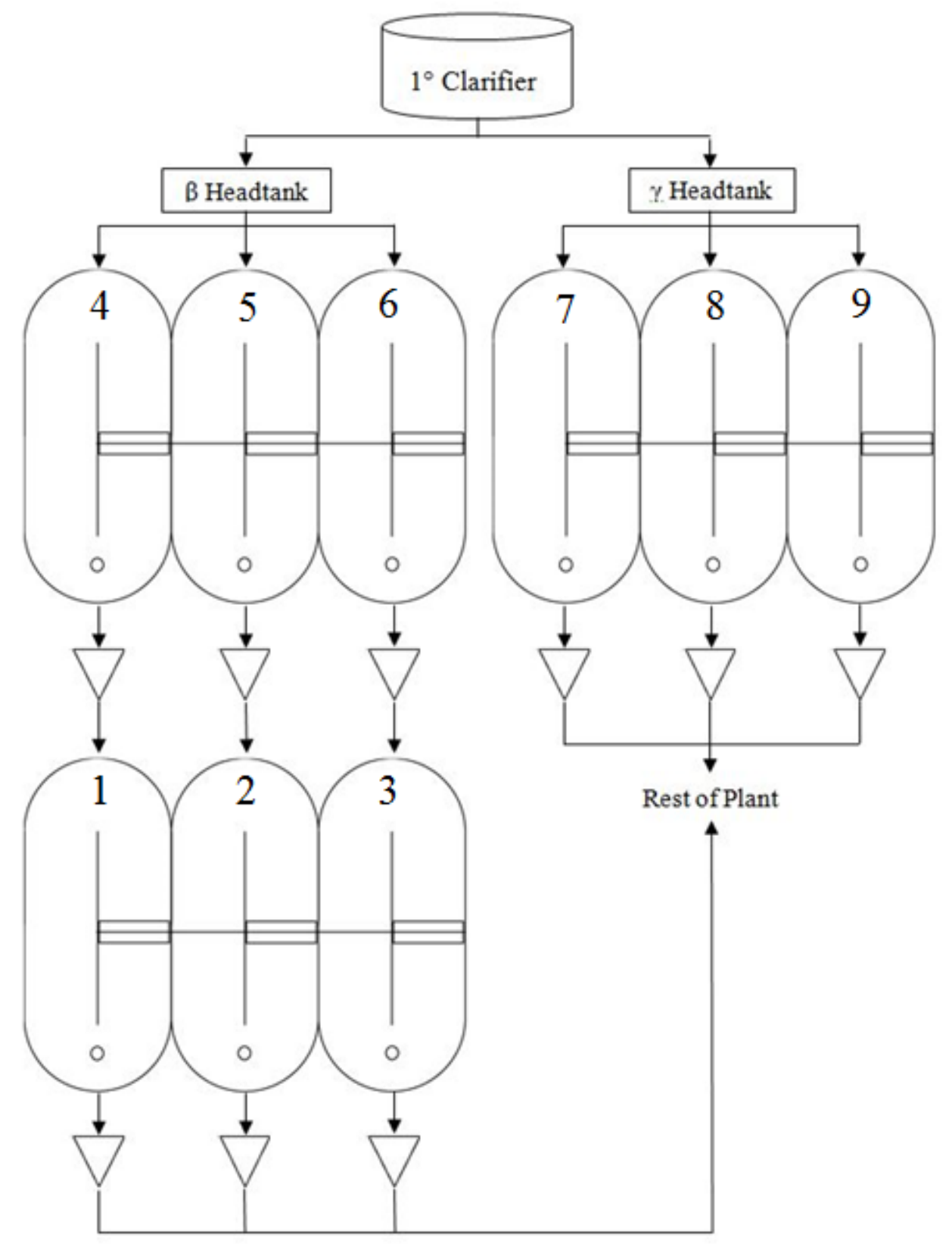

Figure 3.7. Experiment II process flow diagram. Triangular shapes indicate use of tube settlers to separate biomass from pond effluent. Beta pond effluent was pumped at a rate of $1.6 \mathrm{~L} / \mathrm{min}$ through the tube settlers, in order to attain sufficient 4-day HRT flowrate into Alpha ponds. 


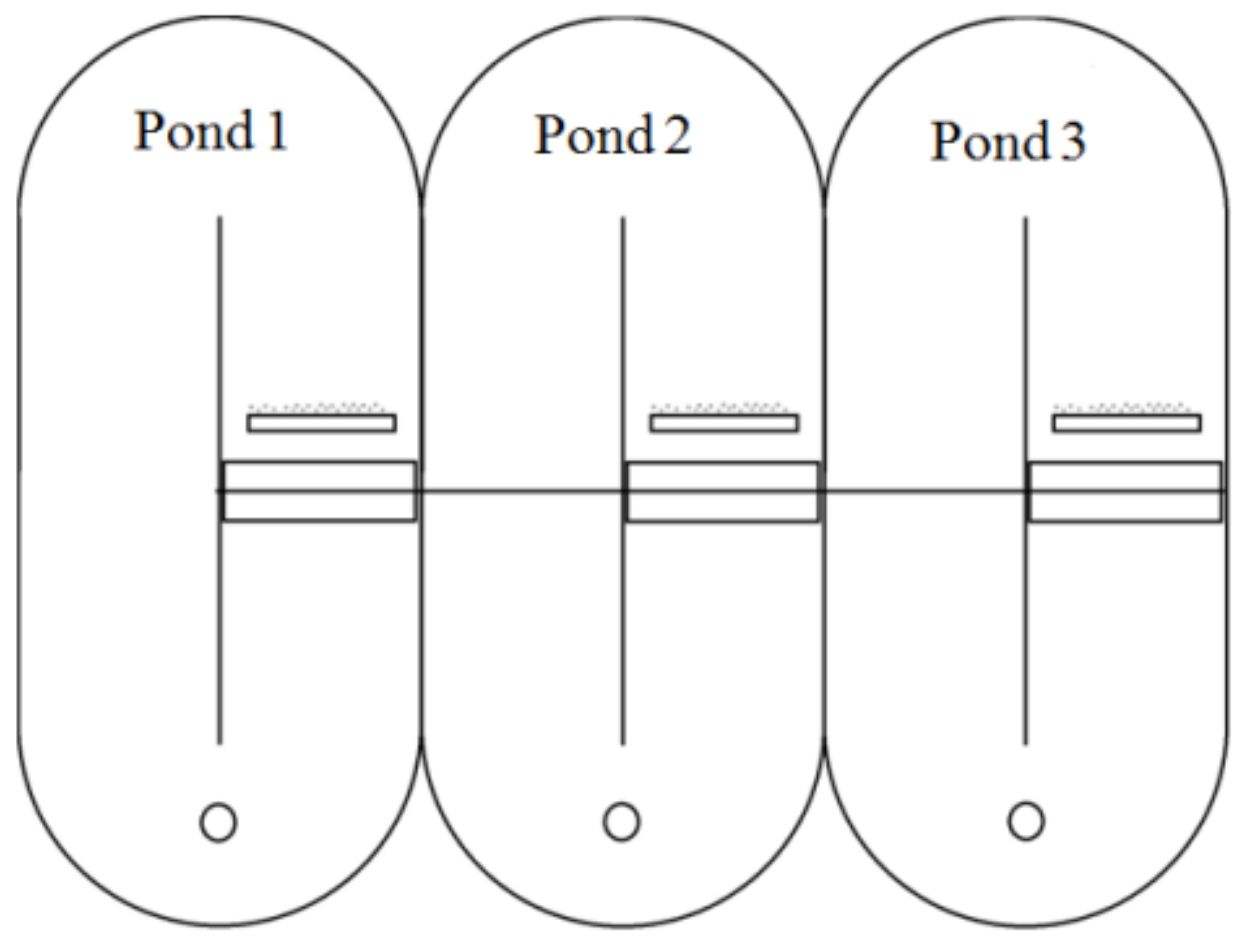

Figure 3.8. Diagram of Alpha ponds during operation of ponds in series. Diffusers, represented by the rectangular bar above the paddle wheels, indicate placement during periods of $\mathrm{CO}_{2}$ supplementation. 


\subsubsection{Experiment III: Aeration of 2-day HRT Ponds}

Experiment III began on November 27, 2012 and continued until February 13, 2013. The purpose of the experiment was to study the effects of nighttime aeration on low HRT ponds which had experienced decreased treatment performance during weeks prior. Ponds 7 and 9, the experimental ponds, were aerated using one blower immediately downstream of the paddle wheel from sundown to sunup. Pond 8 remained unchanged with no aeration as the control pond. On December 10, 2012, a second blower was added to Ponds 7 and 9, on the opposite side of the center wall from the first blower. The final experimental setup is represented in Figure 3.9. It is noted that a new standpipe, designed to abate solids accumulation, was placed in Pond 7 on January 9, 2013. The change in TSS and VSS in Pond 7 over the following weeks did not correlate with expected effects of the standpipe change. 


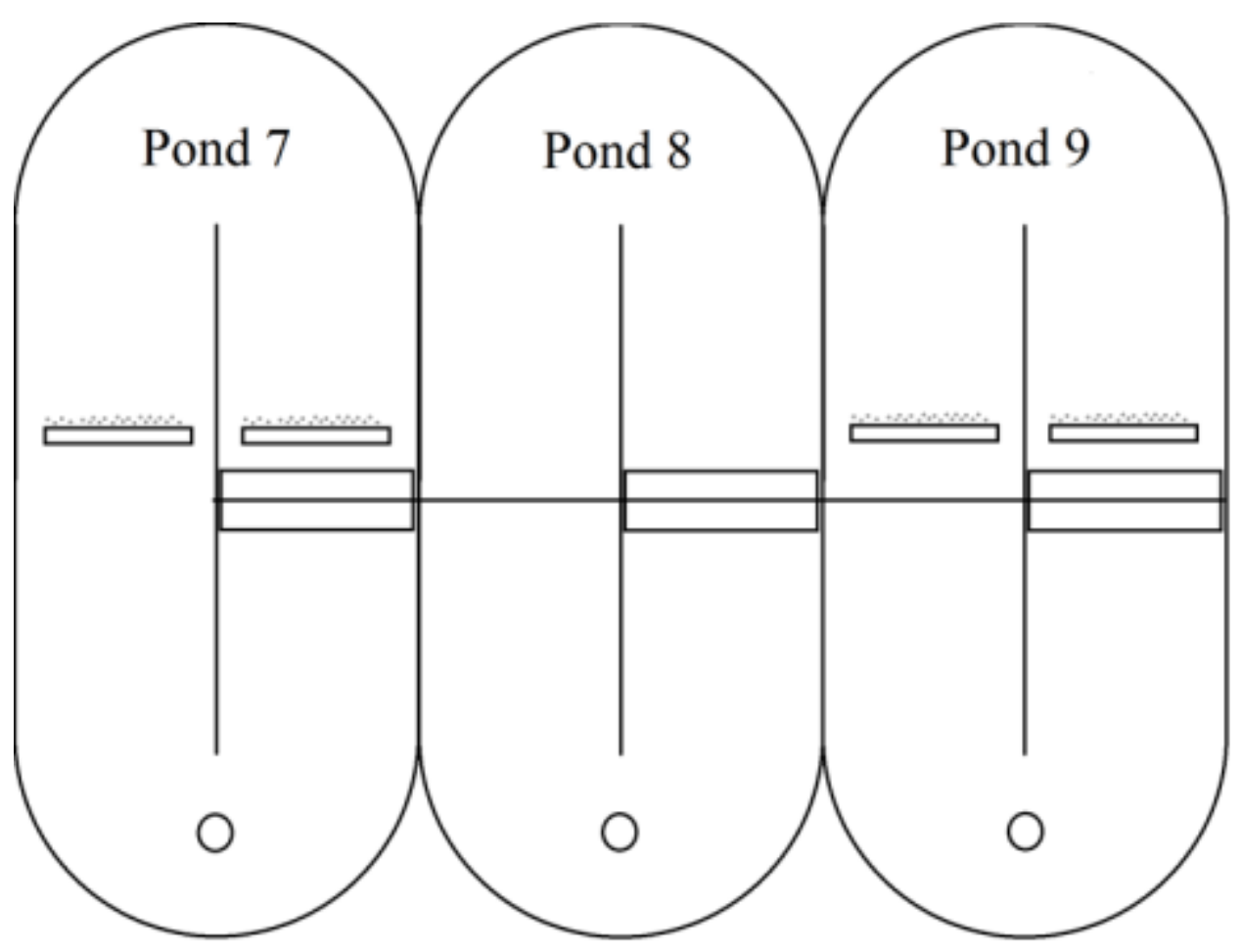

Figure 3.9. Layout of aeration plans for Gamma ponds during Experiment III. Blowers, represented by rectangular bars in Pond 7 and Pond 9 channels, were placed 2" above the channel bed as the indicated positions.

\subsection{Water Quality Sampling}

Water quality sampling and analysis took place weekly, with the first sample date as January 25, 2012. Interruptions in sampling due to power outage, storms or pond maintenance resulted in a 24-hour delay of sampling. Composite samples were collected in 3L LDPE water jugs and transported to laboratory for analysis on the day of collection. Sample jugs were cleaned after each sample date and turned upside down to dry until the following week's sampling date.

A pump house was designated to each triplicate set which contained a fridge for sample preservation and a MasterFlex Digi-Staltic Pump Drive (77310-00) for sample collection. HRP sampling points were located at the end of the probe stand as seen in Figure 3.10 with the sampling tube submerged 2-3 inches below water surface. Influent samples 
were collected as grab samples from startup until June 6, 2012 at the point of inflow into Pond 5. Influent composite sampling was started on June 6, 2012 with sampling point located in Gamma's constant headtank (Figure 3.11). Composite samples referred to as "Pond 2 eff" and "Pond 5 eff" were taken from an overflow weir located behind the respective tube settler (Figure 3.12).

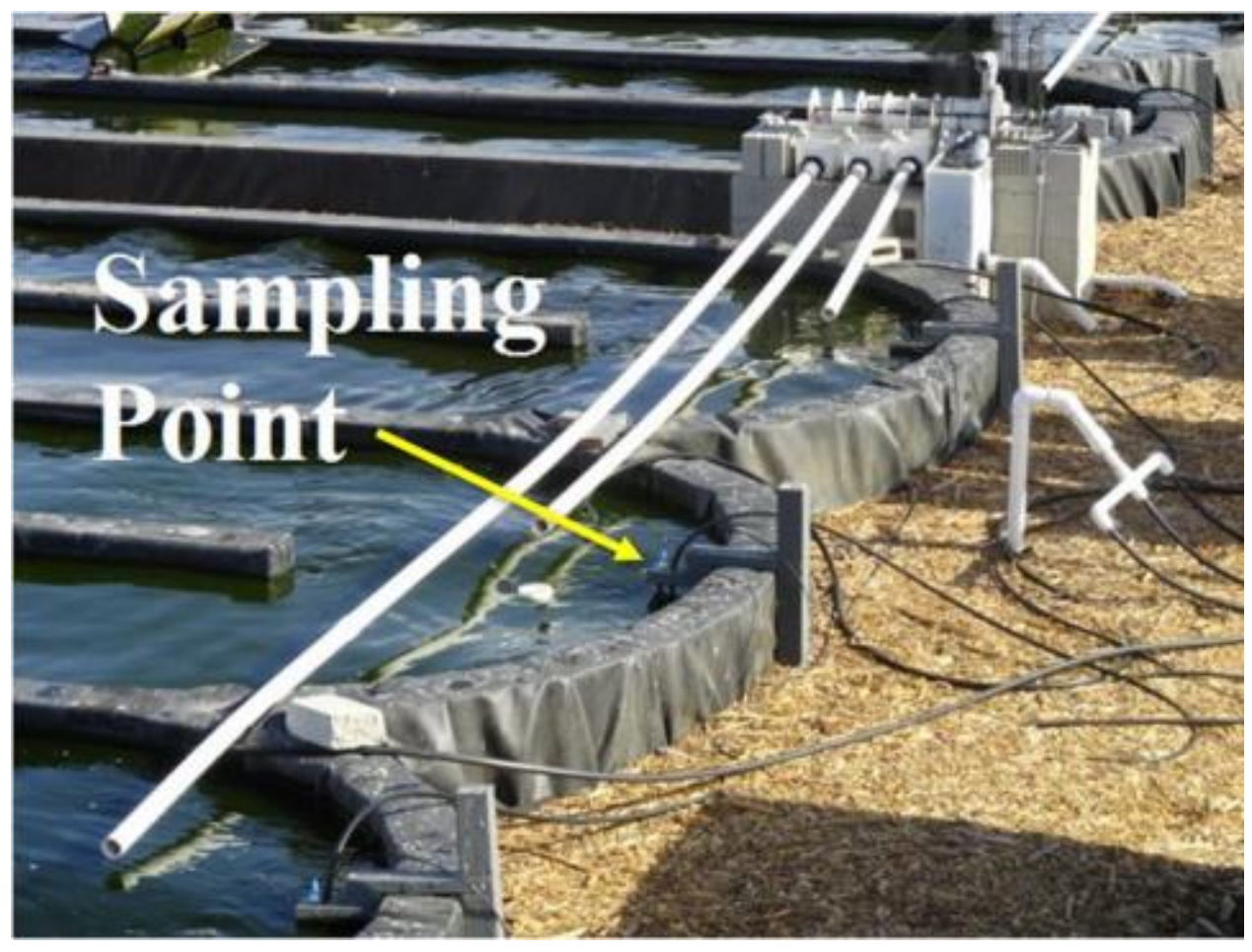

Figure 3.10. Photo of composite sampling points located at probe stands. Larger diameter irrigation tubing is the sample line used for pond effluent transfer to tube settlers. If grab samples were performed, sample was attained by submerging bottle near beginning of turnaround opposite of influent entry into ponds. 


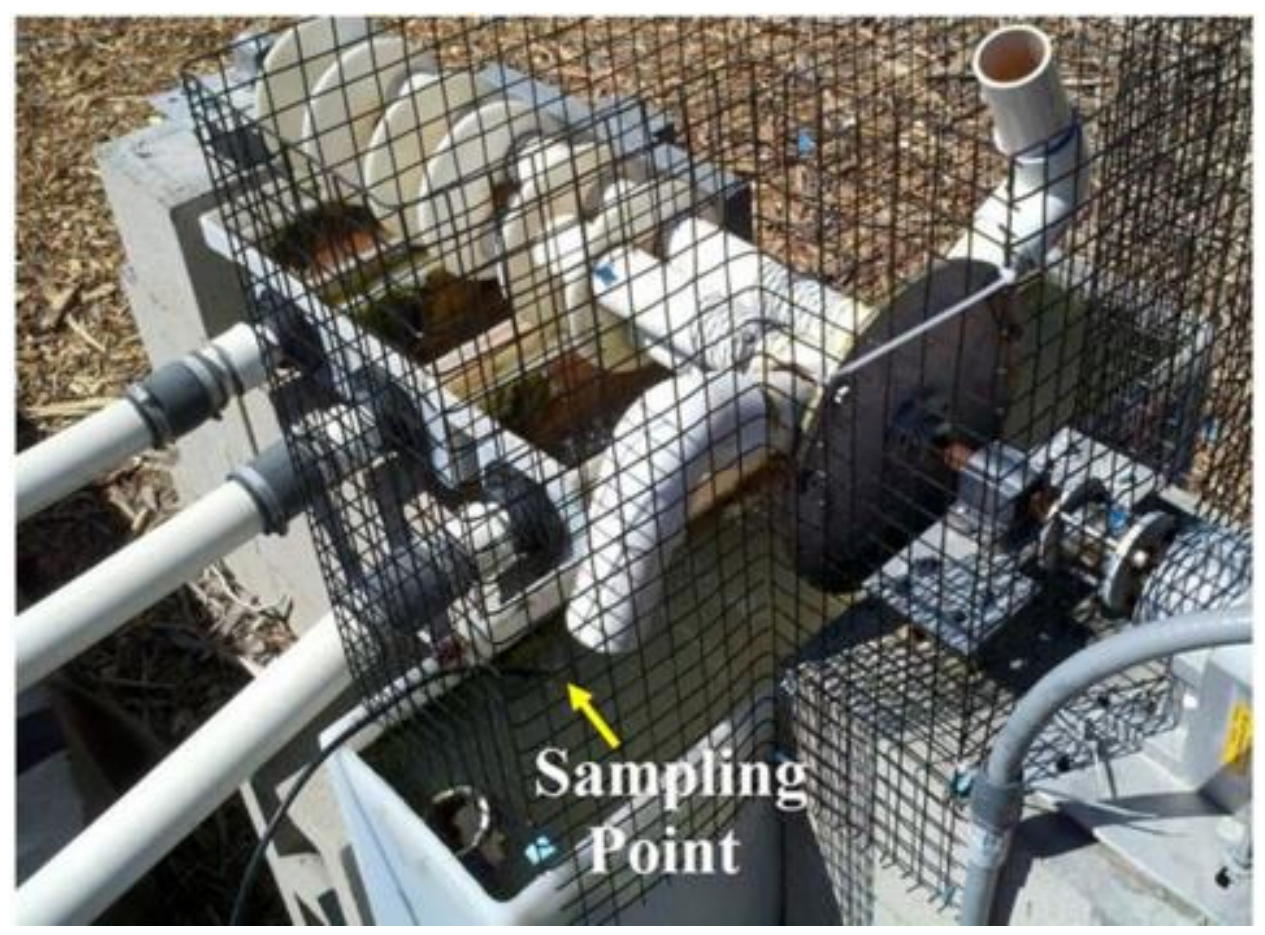

Figure 3.11.Influent composite sampling point in Gamma headtank. Irrigation tubing used for sampling was kept away from scum on the side walls to prevent an unrepresentative sample.

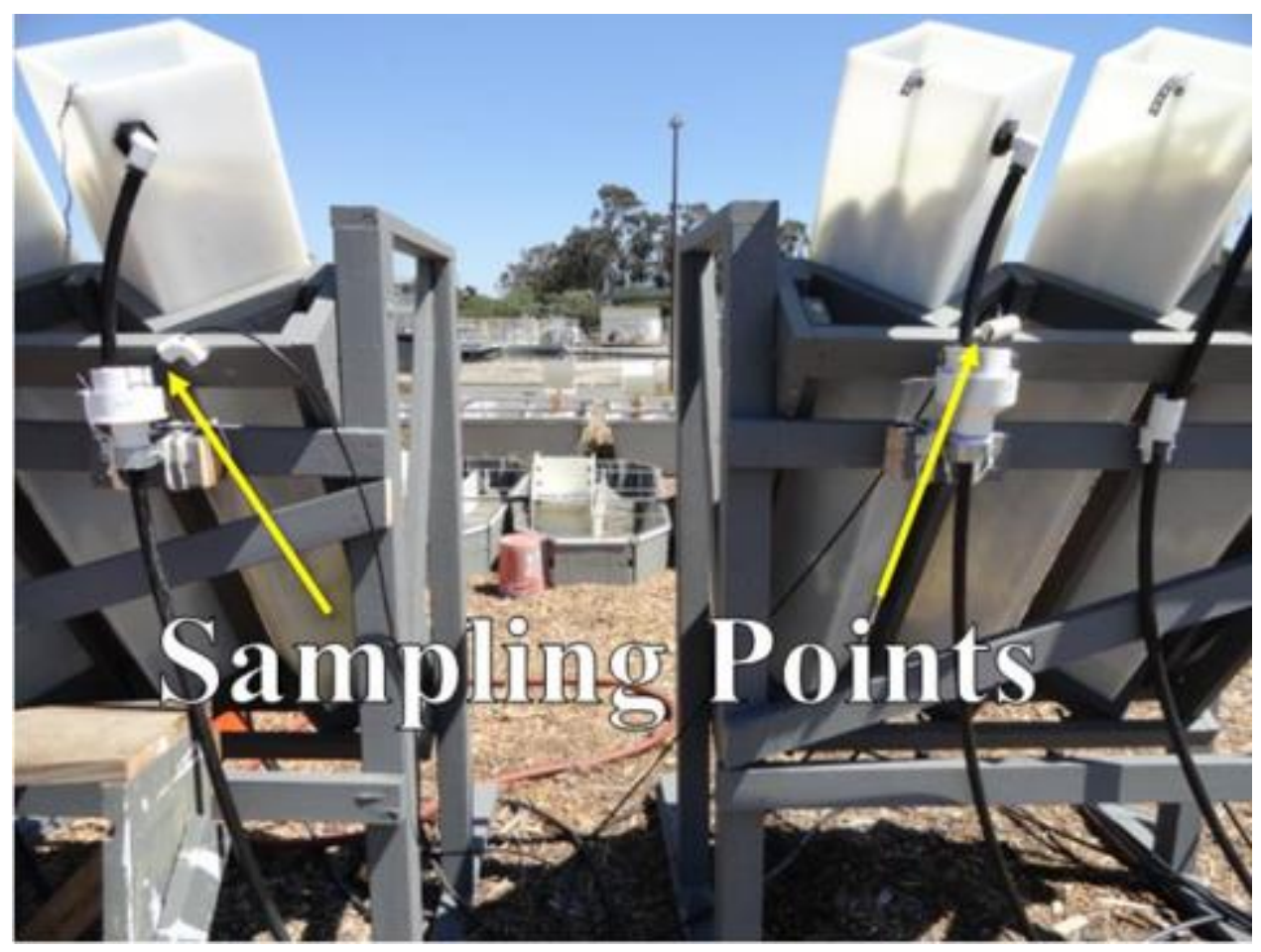

Figure 3.12. Composite sampling point for tube settler effluent. Sample point on left is for "P2 eff," and sample point on the right is for "P5 eff." 
MasterFlex ${ }^{\circledR}$ L/S-25 tubing was used in the peristaltic pump heads to collect composite samples in 30-minute intervals over the course of 24 hours (Figure 3.13). Each sampling sequence would draw roughly $65 \mathrm{~mL}$ from each sample point. Pump drives primed samples for approximately 10 seconds before a sequence of sample line purging. Following each sample day, sample lines were cleaned with $1 \%$ bleach solution by successive purging and priming of each sample tube. Issues pertaining to high solids concentrations attained from composite sampling are later discussed in Section 4-3. The remainder of this section details the parameters monitored throughout the course of operation as well as the APHA Standard Methods used to determine water quality.

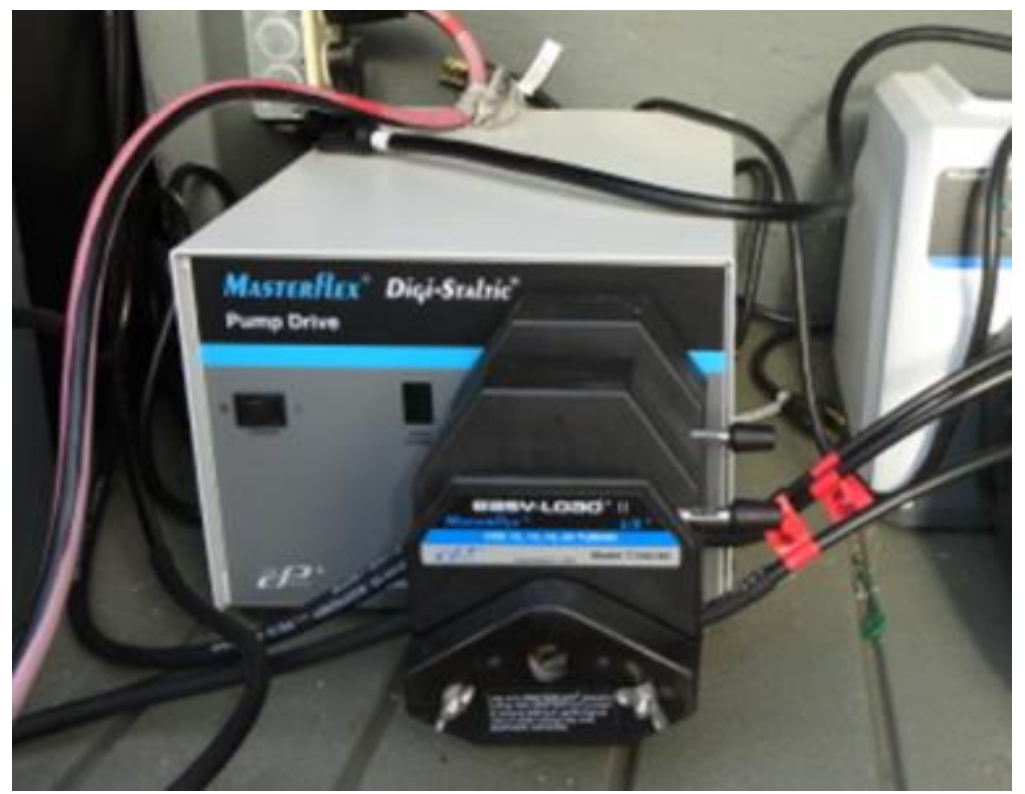

Figure 3.13. Photo of Masterflex ${ }^{\circledR}$ Digi-Staltic ${ }^{\circledR}$ pump drive used to collect composite samples. Irrigation tubing was cleaned with diluted blach water on a weekly basis. L/S-25 tubing was replaced as wear developed over time. 


\subsection{Water Quality Analysis}

This section identifies the analytical methods of all the measured constituents and pond variables. Composite sampling started on Tuesday mornings at $8 \mathrm{am}$ and concluded upon sample collection Wednesday mornings, unless postponed 24 hours for sample issues or holidays. Analysis immediately followed sample collection and all analytical tests were completed within 12 hours, aside from Total Phosphorus (TP) and Total Kjeldahl Nitrogen (TKN), which were acidifed and preserved. A summary of chosen APHA methods corresponding to consituents of interest for water quality analysis is displayed in Table 3.1. 
Table 3.1. Analytical methods chosen for measurements of organics, nutrients and pond conditions.

\section{Constituent}

\section{Organics}

Total and volatile suspended solids and total solids

Total and soluble carbonaceous biochemical oxygen demand

\section{Analytical Method}

Gravimetric with Fisherbrand G4 Glass Fiber filters (Method 2540 D and 2540 E)

5-day, $20^{\circ} \mathrm{C}$, Fisherbrand G4 Glass Fiber filtration (Method $5210 \mathrm{~B}$ )

\section{Nutrients}

Ammonium

Ammonia-Selective Electrode (Method 4500$\left.\mathrm{NH}_{3} \mathrm{D}\right)$

Nitrate

Nitrate Electrode with Nitrate Interference Suppressor Solution (Method 4500- $\mathrm{NO}_{3}{ }^{-} \mathrm{D}$ )

Nitrite Colorimetric, Fisherbrand Multiple Cellulose Ester $0.45 \mu \mathrm{m}$ filtration (Method $4500-\mathrm{NO}_{2}{ }^{-} \mathrm{B}$ )

Total Kjeldahl nitrogen Macro-Kjeldahl (Method 4500- $\mathrm{N}_{\text {org }}$ B) by manual titration

Dissolved reactive phosphorus

Ascorbic Acid, Fisherbrand Multiple Cellulose Ester $0.45 \mu \mathrm{m}$ filtration (Method 4500-P E)

Total phosphorus

Vanadomolybdophosphoric Acid Colorimetric (Method 4500-P C)

\section{Other constituents}
Alkalinity
Sulfuric Acid Titration (Method 2320 B)
Dissolved oxygen
Galvanic Electrode (Method 4500-O G)
$\mathrm{pH}$
Electrometric $\left(4500-\mathrm{H}^{+} \mathrm{B}\right)$
Algae identification
Optical Microscope, Selected Taxonomic References (Method 10900 E. 2.)




\subsubsection{Solids}

Total suspended solids (TSS), volatile suspended solids (VSS) and total solids (TS), were determined per APHA Methods 2540 D and E. Fisher Scientific G4 glass fiber filters with $1.2 \mu \mathrm{m}$ pore size were rinsed with $50 \mathrm{~mL}$ of deionized (DI) water and ashed in a $550^{\circ} \mathrm{C}$ furnace for 15 minutes before being used for solids analysis. An ULTRA Scientific blind solids standard with a TSS range of 70-300 mg/L was used for a quality control check on a weekly basis.

\subsubsection{Settling}

To achieve settling efficiencies and to create observational conclusions on bioflocculation, one liter imhoff cones were filled with pond effluent from all nine ponds each week of sampling. Composite sample bottles were mixed by inverting and shaking before pouring into imhoff cone. After two and twenty-four hours, $150 \mathrm{~mL}$ of supernatant was drawn from each of the nine imhoff cones for TSS analysis. Wide mouth pipettes were used with a sampling point 1 inch below the water surface to avoid sampling floating biomass. Similar to weekly solids analysis, APHA Method 2540 D was also used for determination of two and twenty-four hour TSS.

Observations of bioflocculation, 10-minute settling and supernatant clarity were performed regularly in the field using $150-\mathrm{mL}$ glass beakers. Presence and characterization of grazer species seen in beaker samples were also noted on field data sheets. 


\subsubsection{Biochemical Oxygen Demand}

Total 5-day biochemical oxygen demand $\left(\mathrm{TBOD}_{5}\right)$ and 5-day soluble carbonaceous biochemical oxygen demand $\left(\mathrm{scBOD}_{5}\right)$ was determined using the 5-day BOD test per APHA Method 5210 B. Pond effluent samples were filtered through 1.2- $\mu$ m Fisher Scientific G4 glass fiber filters to attain filtrate for determination of $\mathrm{scBOD}_{5}$ of all samples. Unfiltered primary clarifier effluent was sampled for determining influent $\mathrm{TBOD}_{5}$ and for use as seed for $\mathrm{scBOD}_{5}$ samples. Dilution water was prepared by aerating deionized water for 20 minutes before adding Hach BOD Nutrient Buffer Pillows. Pond and influent scBOD5 samples were prepared with Hach nitrification inhibitor (Formula 2533 ${ }^{\mathrm{TM}}$ ). A glucose-glutamic acid standard and blanks were run with each weekly sample. All BOD determination was completed using Wheaton 60mL BOD bottles with actual sample volume totaling $70 \mathrm{~mL}$ per bottle.

\subsubsection{Total Ammonia Nitrogen}

Weekly total ammonia nitrogen (TAN) concentrations for pond effluent and influent samples were attained using APHA Method $4500-\mathrm{NH}_{3} \mathrm{D}$. An Orion Ammonia Gas Sensing Electrode (Model 95-12) was used with the Corning Model 355 ion analyzer for taking potentiometric measurements on a millivolt scale. Room temperature samples were adjusted to $\mathrm{pH} 11$ or higher using Ricca Chemical Ionic Strength Adjustor (\#412832) before measurement. A calibration curve was prepared with each set of samples with standards of $0.1,1,10$ and $100 \mathrm{mg} / \mathrm{L}-\mathrm{NH}_{3}$ concentrations. The probe was rinsed with deionized water in between samples. Standards were made using a $2500 \mathrm{mg} / \mathrm{L}-\mathrm{NH}_{3}$ stock solution, created with Fisher Scientific ACS Certified ammonium chloride (\#A661-500). Acidified pond effluent and influent samples were stored at $4^{\circ} \mathrm{C}$. 


\subsubsection{Nitrate}

Nitrate analysis of pond effluent and influent samples was completed using APHA Method $4500-\mathrm{NO}_{3}{ }^{-}$D. A Thermo Scientific combination electrode was used to obtain a millivolt reading output from a Corning Model 355 ion analyzer. Buffer solution, made following APHA Method 4500- $\mathrm{NO}_{3}{ }^{-} \mathrm{D}$ 3d., was used to remove interfering ions in room temperature samples before measurement. A low-level concentration technique was used to create the calibration curve each week. Five successive additions of a 100mg/L-N standard were added to a blank sample to produce a five-point curve with concentrations of $0.2,0.6,1.0,2.9$ and $4.7 \mathrm{mg} / \mathrm{L}-\mathrm{N}$. Due to seasonal variations of treatment performance, $5 x-20 x$ dilutions of samples were prepared when undiluted samples were above $1.2 \mathrm{mg} / \mathrm{L}-\mathrm{N}$. Dilutions factors varied while the low-level calibration technique was constant and used every week. Nitrate probe was rinsed in between samples. Detection limit for nitrate analysis using the combination electrode was determined to be $0.1 \mathrm{mg} / \mathrm{L}$ $\mathrm{N}$.

\subsubsection{Nitrite}

Nitrite concentrations were determined using a colorimetric reagent at an absorbance of 543nm, in accordance with APHA Method $4500-\mathrm{NO}_{2}{ }^{-} \mathrm{B}$. Pond effluent and influent samples were filtered through $0.45-\mu \mathrm{m}$ mixed cellulose ester filters before being used for sample preparation. Absorbance of 10x-100x diluted samples were measured at 543nm using a 1-cm path length cuvettes in a SHIMADZU UV-1700 PharmaSpec (S.N. A110244). A calibration curve was made each week using 0, 0.05, 0.10, 0.15 and $0.20 \mathrm{mg} / \mathrm{L}-\mathrm{N}$ standards. 


\subsubsection{Total Kjeldahl Nitrogen}

APHA Method $4500-\mathrm{N}_{\text {org }} \mathrm{B}$ was used to quantify TKN concentrations. Organic nitrogen $(\mathrm{ON})$ and total nitrogen $(\mathrm{TN})$ were determined using TKN values in combination with total ammonia nitrogen, nitrate and nitrite concentrations.

\subsubsection{Dissolved Reactive Phosphorus}

Samples used for measurement of dissolved reactive phosphorus (DRP) were filtered through $0.45 \mu \mathrm{m}$ mixed cellulose ester filters into acid-washed glassware before analysis. The ascorbic acid colorimetric method was used to determine DRP concentrations (APHA Method 4500-P E). A five point calibration curve consisted of standards at 0 , $0.25,0.50,0.75$ and $1.0 \mathrm{mg} / \mathrm{L}-\mathrm{P}$. To ensure accurate measurements, samples were diluted according to the standard concentration range.

\subsubsection{Total Phosphorus}

Acidified, refrigerated samples were prepared for analysis through the Vanadomolybdophosphoric Acid Colorimetric method (APHA Method 4500-P C). Absorbance was measured at 470nm to match expected concentrations of 4-18mg/L-P. The difference between total phosphorus (TP) and DRP values was used to determine particulate phosphorus present in pond effluent samples. Standards ranged from 016mg/L-P during each weeks analysis.

\subsubsection{Algae Species Identification}

Identification of dominant and predominant algal species present in each pond were documented on a weekly basis as described in Ripley, 2013. 


\subsubsection{Alkalinity}

Alkalinity for pond effluent and influent samples were determined by acid titration using $0.02 \mathrm{~N} \mathrm{H}_{2} \mathrm{SO}_{4}$ (APHA Method 2320B).

\subsubsection{Quality Assurance and Quality Control}

Data attained from weekly analysis was used only if established quality assurance and quality control (QA/QC) checks passed. Matrix spikes were performed on analysis pertaining to nutrient concentrations to ensure accurate readings from analytical equipment and as a check for matrix interferences present in samples. A passing value for matrix spike QA/QC was within the range of $85-115 \%$ recovery. In addition, duplicate samples were run during each analytical test to determine if results were reproducible and analytical methods were performed correctly. Acceptable passing ranges for duplicates were within a range of $90-110 \%$ original sample concentration.

\subsubsection{Dissolved Oxygen}

DO measurements began on November 2, 2012 for all nine ponds using Neptune Systems DO probes with a PM3 Module. Probes were placed at the east end of all ponds near the effluent stand pipe. The Apex Neptune System recorded DO values every twenty minutes and logged values for data storage every hour. DO values displayed by system were given in parts per million (ppm), corresponding to an automatic adjustment from pond temperature. DO probes were calibrated once every 1-2 weeks in all ponds. For experimental and operational assurance, a YSI 58 DO meter was used to document any variance between instruments. 


\subsubsection{Temperature and $\mathrm{pH}$}

Temperature and $\mathrm{pH}$ were provided in twenty minute intervals with values available for data extraction at hour intervals. Sensorex combination $\mathrm{pH}$ probes were used to monitor $\mathrm{pH}$ of all nine ponds during entire operational period. From system start up until November 2, 2012, three temperature probes were placed in the middle pond of each set. Temperature values attained from the three probes were assumed to represent temperature of all three ponds in their respective triplicates. Beginning on November 2, 2012, temperature probes were placed in all nine ponds for automatic DO adjustment and temperature output.

\subsubsection{Weather}

Daily weather data was attained from the California Irrigation Management Information System (SIMIS) as described in Ripley, E.B., 2013. 


\section{Results and Discussion}

This chapter presents the results of experiments introduced in Chapter 3 of this thesis. Water characteristics of primary effluent used for influent flow into the HRAPs will be briefly explained, as well as the environmental conditions the ponds operated in. Composite sampling errors, which occurred during periods of experimentation, are also addressed within this chapter. Inoculation experiments, as described in E.B. Ripley, 2013, were performed on May 23, 2012, September 12, 2012 and November 24, 2012 between Ponds 5 and 6 . In cases where data pertaining to nitrogen, phosphorus and csBOD concentrations in Beta ponds appeared affected by inoculations, a vertical line intercepts the $\mathrm{x}$-axis denoting date of inoculation. Mechanical variables such as channel velocity, paddle wheel speed and pond depth remained unchanged throughout all experimental periods.

\subsection{Pond Influent Water Characteristics}

Primary effluent was attained from just inside the weir of the westernmost primary clarifier at the SLOWRF and continuously distributed into each headtank. Wastewater entering the plant consisted of domestic wastewater from potable water consumption, stormwater and drainage runoff from areas north of the wastewater treatment plant. Significant spikes or decreases of a water quality constituents produced in time series graphs were compared to data collected by laboratory analysts at the SLOWRF water quality laboratory to confirm inconsistencies in water quality of influent.

Sufficient alkalinity was present throughout the time of experimentation to supplement nitrification (Figure 4.1). A decrease in alkalinity began on August 15, 2012 after San Luis Obispo switched its drinking water source to Lake Nacimiento, a nearby water body 
with significantly lower (Elliott Ripley, pers coms, 10 May 2013). Primary effluent was used as pond influent due to the optimal level of TBOD as a carbon source to facilitate the bacteria-algae. From April 25, 2012-April 25, 2013, average influent $\mathrm{TBOD}_{5}$ and $\operatorname{csBOD}_{5}$ was measured to be $124 \mathrm{mg} / \mathrm{L}$ and $67 \mathrm{mg} / \mathrm{L}$, respectively. On average, $79 \%$ of the nitrogen present in influent wastewater was total ammonia nitrogen. In the first three months of operation, pond effluent measurements of TAN were limited because of failed QA/QC water quality analysis (Appendix C). Influent TAN measurements on August 8, 2012 confirmed a diurnal pattern characteristic of domestic wastewater in which higher TAN concentrations are present during the morning. See Appendix $\mathbf{D}$ for more information on the diurnal study.

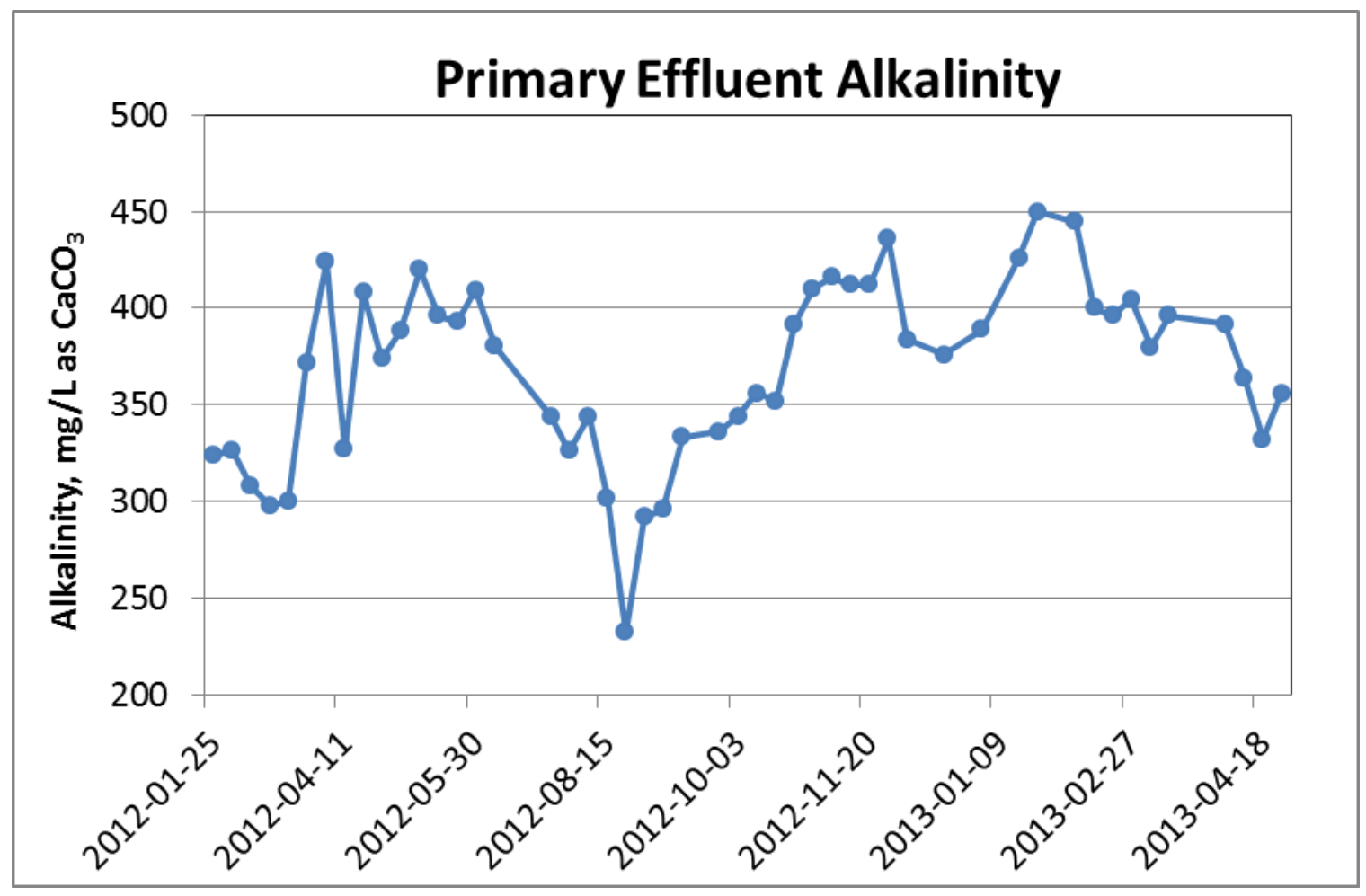

Figure 4.1. Time series of Influent alkalinity concentration during experimentation. Data was recorded from January 23, 2012 to April 25, 2013. Primary effluent was attained from second primary clarifier at the SLOWRF and pumped directly to the three constant headtanks. 


\subsection{Environmental Conditions}

The HRAP pilot plant used for Experiments I, II and III is located in San Luis Obispo, CA, US $(35.28,-120.66)$. San Luis Obispo is located on the central coast of California in a geological region classified as a Mediterranean climate with annual precipitation rates around $15 \%$. For periods of experimentation, monthly average solar radiation peaked at $334 \mathrm{~W} / \mathrm{m}^{2}$ and reached a minimum of $96.9 \mathrm{~W} / \mathrm{m}^{2}$. Monthly average air temperatures ranged from $51-64^{\circ} \mathrm{F}$, reached a maximum monthly average of $79^{\circ} \mathrm{F}$ and a minimum monthly average of $40^{\circ} \mathrm{F}$. Weather statistics were acquired from the Department of Water Resources California Irrigation Management Information System (CIMIS) measured at Station $52(35.31,-120.66)$ on the Cal Poly campus. Appendix E provides time series data of San Luis Obispo's solar radiation, average air temperature and precipitation throughout experimentation period. $\mathrm{pH}, \mathrm{DO}$ and temperature within each set of triplicates were similar and therefore average values of said parameters are commonly used to present differences between triplicates.

\subsection{Solids Sampling Issues}

Nutrient imbalances first witnessed in summer 2012 were temporarily alleviated after installation of netting over pond surfaces to deter water fowl from entering the ponds. Further data acquisition from analytical tests that passed QA/QC revealed solids concentrations highly uncharacteristic of HRAP operation and greater TP and TN in pond effluent than in influent. A solids balance experiment comparing grab samples, composite samples, tube settler feed and standpipe effluent confirmed overestimations of solids in pond effluent (Ripley, 2013). The inflated TSS values were more pronounced in the Gamma set because of its low HRT and high productivity. Sources of error were 
hypothesized to be a result of small diameter tubing used for peristaltic pumps, solids accumulation under probe stands (point of composite sampling) and a weir effect imposed by standpipes which allowed treated water to exit from the system but retained suspended solids. Direct observations of grab samples versus composite samples are represented in Figure 4.2 and Figure 4.3.

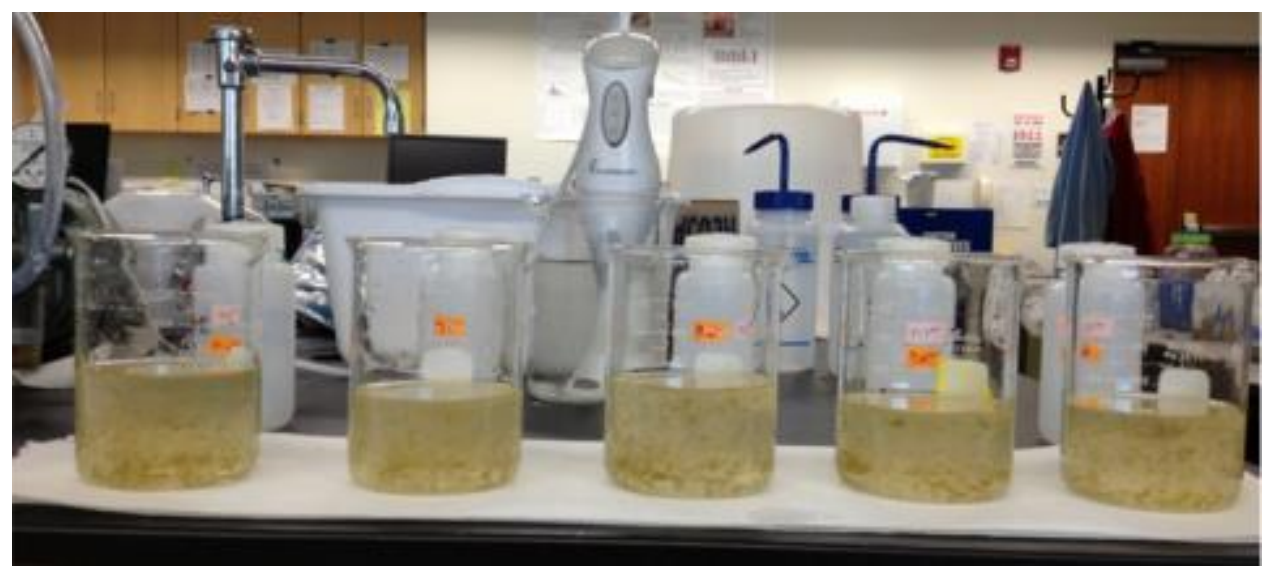

Figure 4.2. Photo of mixed grab samples from Pond 8. Image taken during a February 2013 solids retention experiment. By visual inspection, biomass presence was significantly less in grabs than composites.

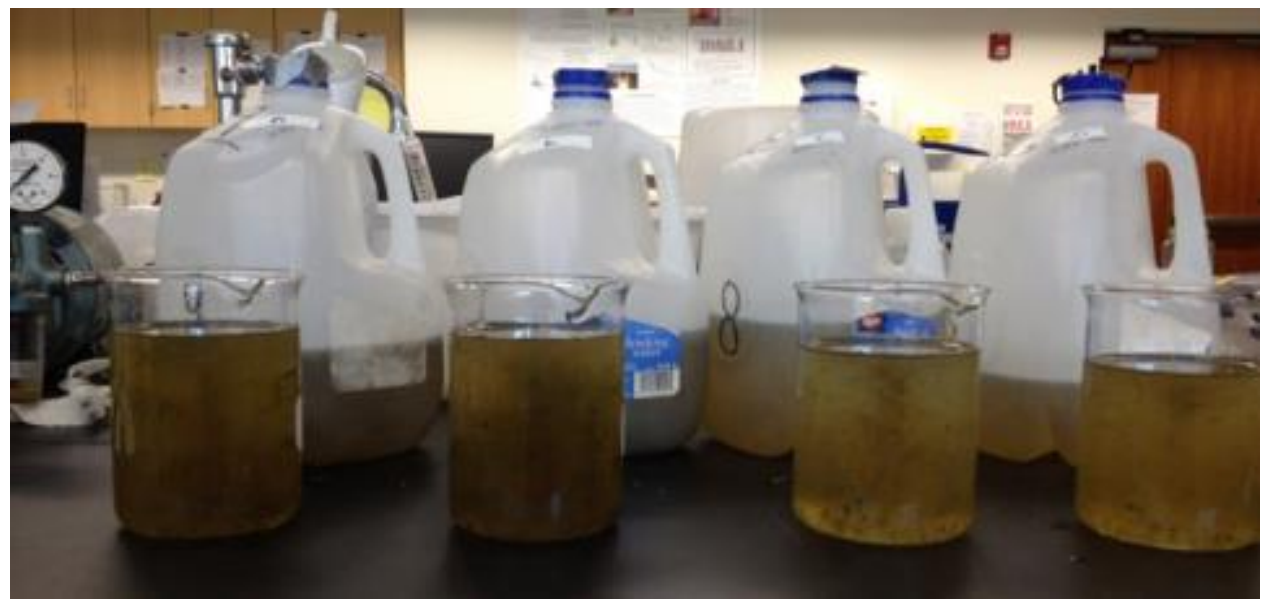

Figure 4.3. Photo of mixed composite samples from Pond 8. Image taken during a solids retention experiment conducted in February 2013.

During the data analysis for a solids balance, several types of standpipes were used to evaluate the most effective way to allow biomass exit through the standpipes. On 
January 10, 2013, standpipes with vertical slots approximately $1 / 4$ " in width were placed in Pond 7 and Pond 8. During continued composite sampling in the two months following installation of slotted standpipes, no significant variation in solids concentration was witnessed. The second set of standpipes (also in Pond 7 and Pond 8) employed to control solids retention contained small diameter holes three inches below the pond surface. Holes were drilled at a diameter large enough to equilibrate ponds in order to maintain pond depth of 12 ”.

\subsubsection{Assumptions for Data Analysis}

Due to occurrence of the aforementioned composite sampling issue, several assumptions were made for data analysis of nitrogen and phosphorus constituents. High solids content within samples were unrepresentative of actual pond characteristics, as supported by studies described in Ripley, 2013. Low solids content of the influent led to the assumption that TP and TKN values of said sample were correct. Pond effluent TP and TKN were determined unusable because TP and TN imbalances were observed when comparing influent to pond effluent, however, Particulate Phosphorus (PP) and ON values were used with composite VSS values to determine phosphorus and nitrogen content of algal biomass. Unrelated to the solids sampling issue, pond effluent csBOD is the measured parameter used to determine BOD removal from influent TBOD entering the ponds. For commercial scale systems, pond effluent would be diverted for biomass separation or filtration before being directed to the next step of the treatment process.

Table 4.1 provides a summary of all assumptions considered during analysis of results. 
Table 4.1. Assumptions considered during analysis and discussion of results. A majority of the assumptions made are in respects to the solids retention issue. Others include selected months for winter and summer seasons, removal efficiency calculations and nutrient content calculations.

\begin{tabular}{|c|c|}
\hline Sample or Value & Assumption \\
\hline BOD Removal & $\begin{array}{l}\text { Pond effluent csBOD representative of BOD } \\
\text { concentration out of HRAP system. }\end{array}$ \\
\hline Influent TP/TKN & $\begin{array}{l}\text { Influent TP and TKN values are valid. Composite } \\
\text { sampling error of overdrawn solids witnessed in } \\
\text { HRAPs did not occur in Gamma headtank, the point } \\
\text { of sampling for system influent. }\end{array}$ \\
\hline Pond Effluent TP/TKN & $\begin{array}{l}\text { Due to overdraw of solids from composite sampling } \\
\text { equipment, TP and TKN values attained for HRAP } \\
\text { effluent samples are deemed invalid. }\end{array}$ \\
\hline $\begin{array}{l}\text { Pond } 2 \text { Eff \& Pond } 5 \text { Eff } \\
\text { TP/TKN }\end{array}$ & $\begin{array}{l}\text { Overflow reservoir used for sampling of tube settler } \\
\text { effluent corresponding to Pond } 2 \text { and Pond } 5 \\
\text { effluent were free of solids buildup, therefore TP } \\
\text { and TKN values are valid for these two samples. }\end{array}$ \\
\hline Soluble Nitrogen Species & $\begin{array}{l}\text { Dissolved nutrients measured in HRAP effluent } \\
\text { samples are assumed to be valid, despite sampling } \\
\text { error. }\end{array}$ \\
\hline $\begin{array}{l}\text { Nitrogen and Phosphorus } \\
\text { Content }\end{array}$ & $\begin{array}{l}\text { Composite PP/Composite VSS }=\% \mathrm{P} \\
\text { Composite ON/Composite VSS }=\% \mathrm{~N}\end{array}$ \\
\hline Seasonality Analysis & $\begin{array}{l}\text { Summer: data pertaining to dates in the months of } \\
\text { April-October } \\
\text { Winter: data pertaining to dates in the month of } \\
\text { November-February }\end{array}$ \\
\hline
\end{tabular}

\subsection{Experiment I: Varying HRT}

Experiment I aimed to attain nutrient removal efficiencies of ponds operating at varied

HRTs. Low HRT ponds were expected to have high biomass productivity with poor nutrient removal, compared to higher HRT ponds which were hypothesized to have 
greater treatment efficiencies coupled with less microalgal growth. From April 25, 2012 to April 25, 2013, Beta and Gamma operated at 3-day and 2-day HRTs, respectively. Alpha operated at a 4-day HRT beginning at startup in January 2012, but was utilized for Experiment II as "Round 2" of the ponds in series operation beginning on June 1, 2012. Henceforth, data series for the triplicates will be referred to as "3-d" for Beta and "2-d" for Gamma.

\subsection{1 pH, Temperature and $\mathrm{DO}$}

Temperatures between 3-day and 2-day pond effluent were similar throughout the course of the experimental period (Figure 4.4). For both sets, summer time average temperatures fell between $15-25^{\circ} \mathrm{C}$ and winter time averages were within the range of $11^{\circ} \mathrm{C}$ and $20^{\circ} \mathrm{C}$. Pond temperatures were greatly influenced by high and low air temperatures because of their shallow depth. Moreover, ponds were greatly influenced by maximum temperatures of $32-45^{\circ} \mathrm{C}$ due to the pond liner being black. Increasing temperatures improve photosynthetic activity, accompanied by an increase in $\mathrm{pH}$ (Figure 4.5), resulting from $\mathrm{CO}_{2}$ consumption. In HRAPs, $\mathrm{CO}_{2}$ is constantly provided by bacteria through oxidation of organic compounds as a carbon source for microalgae to facilitate maintenance and growth. On days with high air temperatures, carbon became limited and $\mathrm{pH}$ levels remained elevated during the high radiation hours. Noticeable depressions and rises in temperature correlated with subsequent increases and decreases in average DO.

Vertical lines with the data plot of Figure represent the dates of the aeration experiment as listed in Chapter 3. DO saturation in the higher HRT set sustained a greater average than the DO saturation in the lower HRT set (Figure 4.6). Low HRT ponds set 
experience lower average DO levels than the high HRT ponds due to higher loading rate of BOD creating more oxygen demand for biochemical processes. Photosynthetic oxygenation during the day allowed for sufficient maximum saturation levels to aid in biological nitrification. The 3 -day set reached levels of saturation as high as $219 \%$ and had maximum levels of saturation over 50\% for the entire period of study. The 2-day set experienced a maximum of $186 \%$ saturation, aside from the $189 \%$ maximum measured during Experiment III. DO in the 2-day ponds maintained 50\% saturation or higher on days of elevated temperature during experimentation. Minimum DO levels in the 3-day set and 2-day set reached 0\% saturation during algal respiration on several days, which suggests opportunity for denitrification to occur at anoxic or anaerobic conditions. Large decreases in maximum or minimum DO between successive data points may be attributed to accumulated biomass on probe membrane, impeding an accurate measurement of the pond's DO level. 


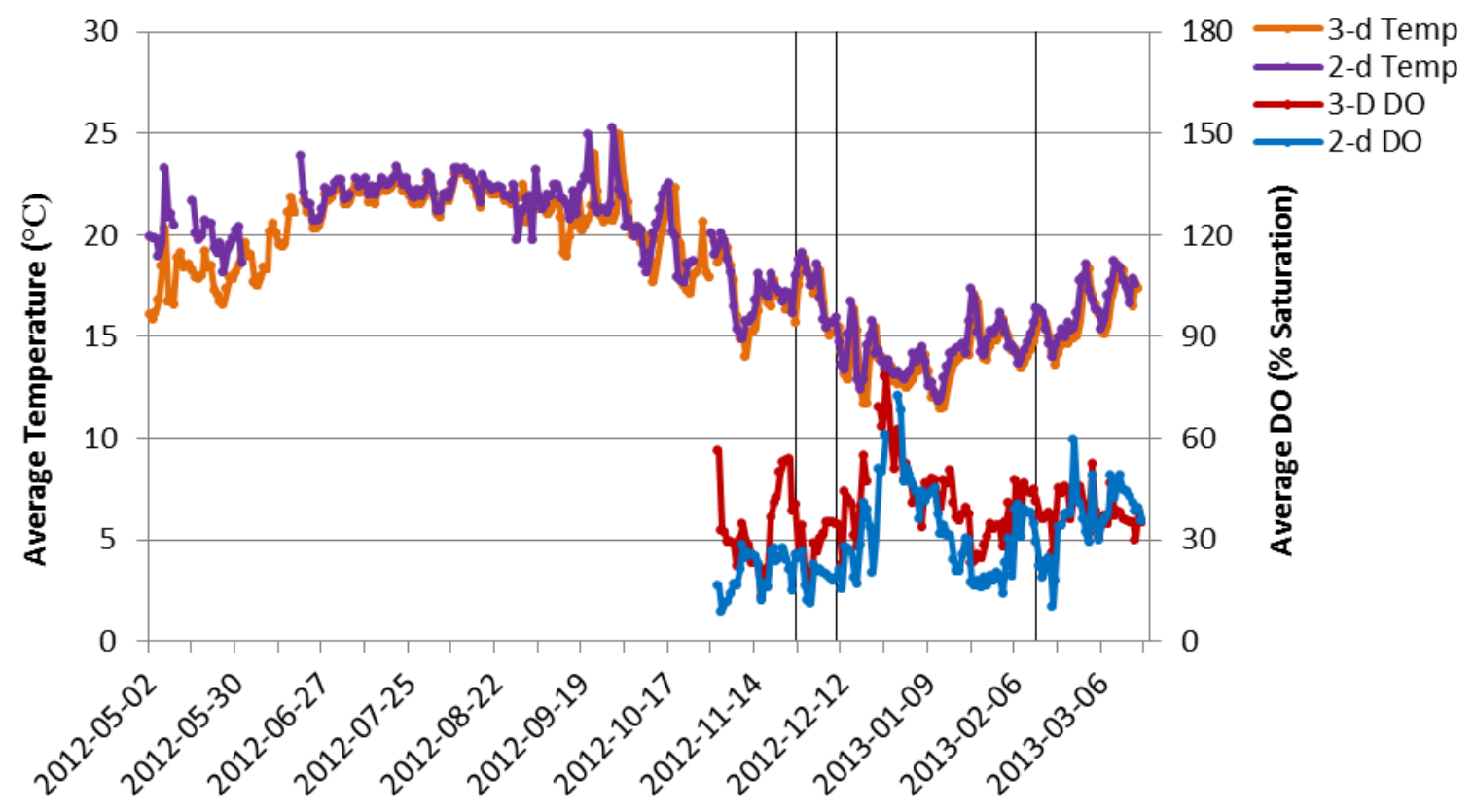

Figure 4.4. $\mathrm{pH}$ and DO time series of Beta and Gamma sets from May 2012 to March 2013. Vertical lines represent the operational changes in Ponds 7 and 9 during Experiment III. Average pond temperatures in summer reached $25^{\circ} \mathrm{C}$ and declined to $11^{\circ} \mathrm{C}$ in winter. DO spikes correspond to cold pond temperature periods as a result of increased gas solubility.

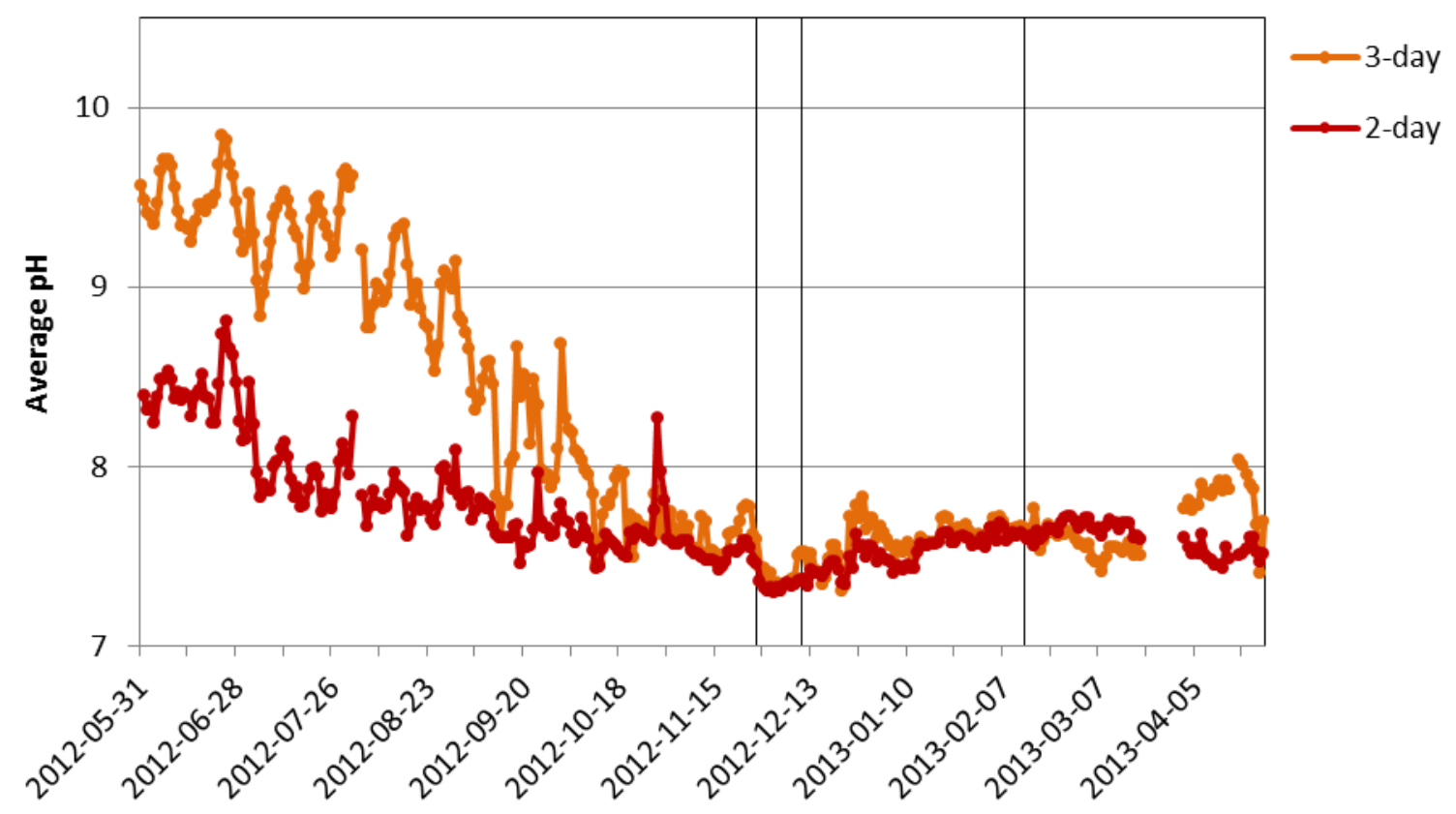

Figure 4.5. Daily average $\mathrm{pH}$ time series for Beta and Gamma Sets.Data collected from May 31, 2012 to April 25, 2013. Vertical lines denote operational changes during Experiment III. 


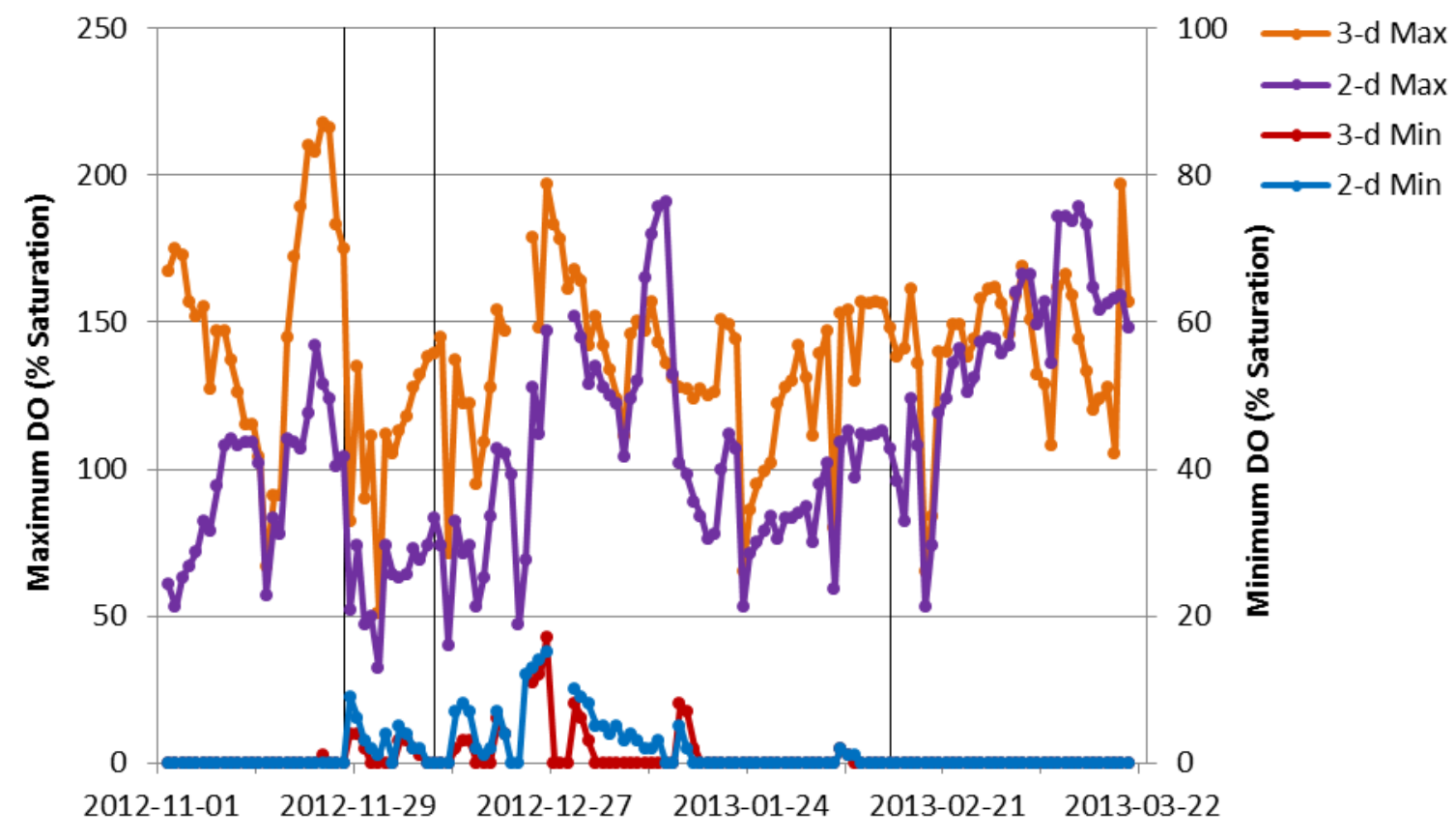

Figure 4.6. Daily minimum and maximum percent saturation in Beta and Gamma Sets. DO measurement began on November 1, 2012 and was monitored until March 21, 2013. Salinity was assumed to have little to no effect on DO concentrations, therefore $10 \%$ saturation $\approx 1 \mathrm{mg} / \mathrm{L}$.

\subsubsection{Nitrogen Removal}

All 3-day ponds attained average ammonia removal efficiencies between $88-91 \%$ for the summer months of April-October. After seasonality took effect on treatment performance, maximum Pond 4 effluent ammonia concentrations reached $27 \mathrm{mg} / \mathrm{L}-\mathrm{N}$ in Pond 4 (Figure 4.7) and a 3-day set average removal of $76 \% \pm 16 \%$ between November 2012 and February 2013 (Table 4.2). An influent ammonia concentration of 18mg/L-N was measured on December 27, 2012, with corresponding minimum winter concentrations of 3-day pond effluent TAN less than 1mg/L-N. Daytime DO concentrations were consistently above $50 \%$ saturation; consequently, nitrification was rarely inhibited by low DO concentration in 3-day ponds.

Winter ammonia removal lessened due to low average monthly solar radiation ranging from $96.9-172 \mathrm{~W} / \mathrm{m}^{2}$, minimum monthly air temperatures as low as $4^{\circ} \mathrm{C}$ and pond 
temperatures below $10^{\circ} \mathrm{C}$ in January 2013. Cold weather reduces the likelihood of elevated $\mathrm{pH}$ levels which promote volatilization of ammonia. Additionally, lower temperatures decrease metabolic activity and substrate utilization rates of bacteria and microalgae, thusly; winter time ammonia removal was poor unless ponds experienced low ammonia loading rates. Using 3-day HRTs in winter resulted in a minimum of $71 \%$ ammonia removal efficiency with a standard deviation of $16 \%$. High standard deviation resulted from winter time ammonia removal fluctuations from 52\% to $98 \%$. Average 3day HRT ammonia removal during summer months was $90 \%$ with a standard deviation of $7 \%$.

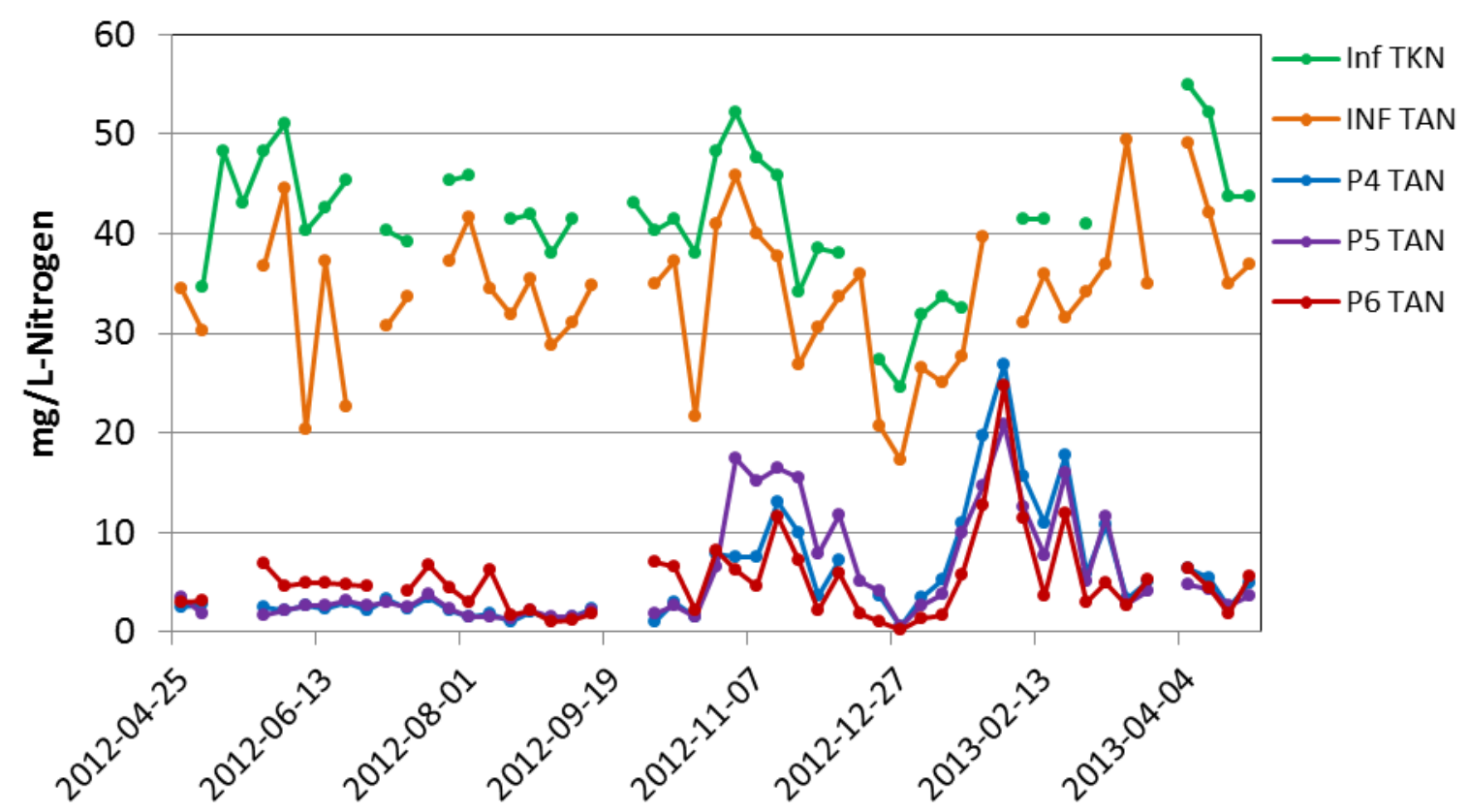

Figure 4.7. TAN time series of Beta ponds from April 25, 2013 to April 26, 2013. Significant reduction in Influent TAN concentrations in November and December 2012 occurred from rainfall dilution of influent wastewaters. Pond effluent spikes in TAN concentrations during February 2013 resulted from decreased air and pond temperatures and subsequent reduced biological activity. 
Table 4.2. TAN removal in Beta ponds during Experiment I.

\begin{tabular}{ccccccc} 
& \multicolumn{2}{c}{ Pond 4 } & \multicolumn{2}{c}{ Pond 5 } & \multicolumn{2}{c}{ Pond 6 } \\
\cline { 2 - 7 } & Summer & Winter & Summer & Winter & Summer & Winter \\
\cline { 2 - 7 } Max TAN (mg/L-N) & 11 & 27 & 18 & 21 & 8 & 25 \\
Min TAN (mg/L-N) & 1.0 & 0.5 & 1.3 & 0.6 & 1.0 & 0.2 \\
Avg \%TAN Removal & $91 \%$ & $72 \%$ & $90 \%$ & $71 \%$ & $88 \%$ & $84 \%$ \\
Standard Deviation & $6 \%$ & $16 \%$ & $8 \%$ & $16 \%$ & $6 \%$ & $13 \%$ \\
\# of samples & 29 & 15 & 29 & 16 & 28 & 16
\end{tabular}

Average summer removal efficiency of $76 \%$ or better was observed in all 2-day ponds (Table 4.3). Increased pond effluent TAN was observed when influent TAN concentrations were greater than 35mg/L-N (Figure 4.8). An influent ammonia concentration of $46 \mathrm{mg} / \mathrm{L}-\mathrm{N}$ in late summer led to a maximum 2-day pond effluent concentration of $28 \mathrm{mg} / \mathrm{L}-\mathrm{N}$ corresponding to $38 \%$ removal efficiency. Pond 7 and 9, aerated during most of the winter period, decreased in ammonia removal efficiency by $13 \%$ from summer to winter to $69 \%$ and $63 \%$, respectively. Pond 8 , which remained without aeration the entire winter period, performed at an average removal efficiency of 54\%. During the cold temperatures throughout winter, Ponds 7, 8 and 9 removed ammonia at 98\%, 95\% and 95\% efficiency, respectively, when influent ammonia was at its minimum. Data corresponding to the lowest 2-day ammonia removal of $26 \%$ was measured the week after aeration was shut off. 
Ammonia concentrations in 2-day pond effluent were greatly influenced by seasonality and influent ammonia concentrations, resulting in significant fluctuations of TAN removal and pond effluent concentrations. Standard deviation for average percent removal of influent TAN is more than $13 \%$ for all ponds during both seasons (Table 4.3). Furthermore, aeration in Pond 7 and 9 contributed to greater standard deviations for 2day average removal efficiencies in winter $( \pm 20 \%)$. Maximum $\mathrm{pH}$ levels remained below 10 in all 2-day ponds from June 2012 to April 2013, thus, volatilization of ammonia was an unlikely mechanism of nitrogen removal at said HRT.

Table 4.3. TAN removal in Gamma ponds during Experiment I.

\begin{tabular}{ccccccc} 
& \multicolumn{2}{c}{ Pond 7 } & \multicolumn{2}{c}{ Pond 8 } & \multicolumn{2}{c}{ Pond 9 } \\
\cline { 2 - 7 } & Summer & Winter & Summer & Winter & Summer & Winter \\
\cline { 2 - 7 } Max TAN (mg/L-N) & 23 & 26 & 28 & 32 & 29 & 25 \\
Min TAN (mg/L-N) & 1.8 & 0.4 & 2.2 & 0.9 & 1.8 & 0.9 \\
Avg \%TAN Removal & $82 \%$ & $69 \%$ & $76 \%$ & $54 \%$ & $76 \%$ & $63 \%$ \\
Standard Deviation & $13 \%$ & $20 \%$ & $19 \%$ & $21 \%$ & $17 \%$ & $16 \%$ \\
\# of samples & 29 & 16 & 29 & 15 & 29 & 16
\end{tabular}




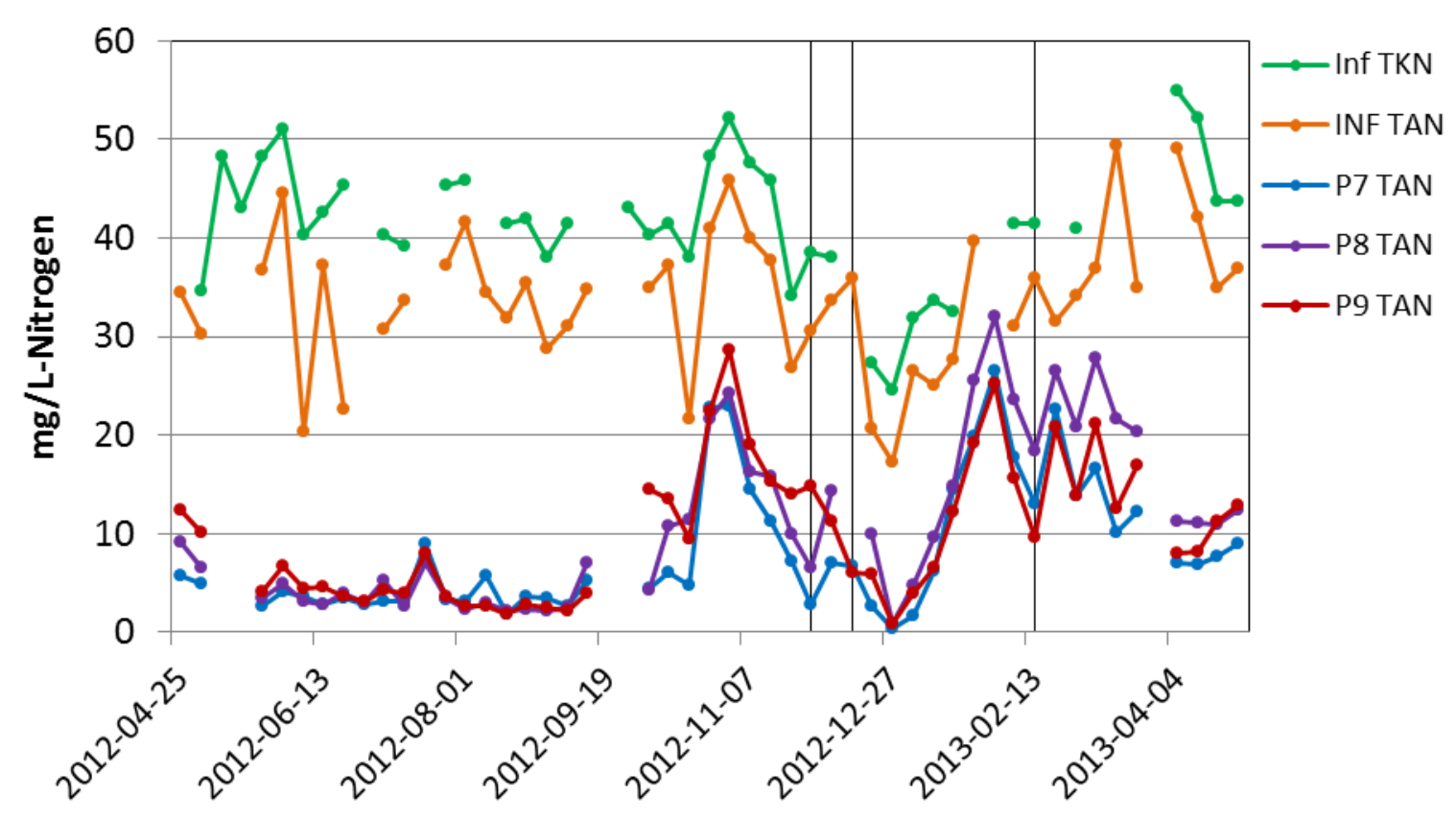

Figure 4.8. Time series TAN concentrations in Gamma pond effluent during Experiment I. Vertical lines in plot area represent implementation of blowers and ending of aeration as described in Experiment III methods.

Ammonia, the primary source of nitrogen for microalgae growing in domestic wastewater, is oxidized and assimilated more effectively when photosynthetic oxidation is increased as a result of high solar radiation and high temperatures. In both sets, ammonia removal efficiency increased during summer months and when influent ammonia loading was low. Analysis of removal during winter months is most appropriately done by comparing the 3-day set to the control pond of the 2-day set (Pond 8). Implementation of blowers in Ponds 7 and 9 resulted in more effective winter time ammonia removal than the control pond without aeration. Variation among the three ponds is further detailed in results pertaining to Experiment III (Section 4.6).

Average summer and winter ammonia removal efficiencies were greater in the 3-day sets by $12 \%$ and $14 \%$, respectively (Table 4.4). The greatest contrast of ammonia removal between sets occurred in winter when Pond 6 (84\%) removed 30\% more ammonia, on 
average, than Pond 8 (54\%). Longer HRT allows more time for biochemical interactions between organisms to further utilize and remove substrate via direct removal mechanisms. Direct removal is predominant since frequent biochemical oxidation of compounds and high influent rates in low-HRT ponds results in higher $\mathrm{CO}_{2}$ levels and decreased $\mathrm{pH}$. Although significant indirect removal is unlikely in both sets, volatilization is more likely to contribute to nitrogen removal at a 3-day HRT during summer when $\mathrm{pH}$ may increase to above 10.5.

Table 4.4. Comparison of average TAN removal efficiencies and extreme concentrations during Experiment I study.

\begin{tabular}{rcccccc}
\cline { 2 - 7 } & \multicolumn{2}{c}{ Influent } & \multicolumn{2}{c}{ 3-day HRT } & \multicolumn{2}{c}{ 2-day HRT } \\
\cline { 2 - 7 } & Summer & Winter & Summer & Winter & Summer & Winter \\
\cline { 2 - 7 } Max TAN (mgL-N) & 49 & 40 & 18 & 27 & 29 & 32 \\
Min TAN (mgL-N) & 20 & 17 & 1.0 & 0.2 & 1.8 & 0.4 \\
Avg TAN (mg/L-N) & 36 & 31 & $90 \%$ & $76 \%$ & $78 \%$ & $62 \%$ \\
/Avg \%Removal & & & & & & \\
Standard Deviation & 7.1 & 6.6 & $7 \%$ & $16 \%$ & $17 \%$ & $20 \%$ \\
\# of samples & 29 & 16 & 86 & 47 & 87 & 47
\end{tabular}

Concentrations of oxidized nitrogen species in 3-d and 2-d sets were above $5 \mathrm{mg} / \mathrm{L}-\mathrm{N}$ for most analysis dates during the experimental period (Figure 4.9 \& Figure 4.10). Nitrite levels reduced to less than $2.5 \mathrm{mg} / \mathrm{L}-\mathrm{N}$ during winter time in the 3 -day set. Nitrite remained low in Pond 8, the non-aerated control pond, throughout winter aside from two spikes at $11 \mathrm{mg} / \mathrm{L}-\mathrm{N}$ and $5.9 \mathrm{mg} / \mathrm{L}-\mathrm{N}$. Both spikes occurred during periods of low 
ammonia removal efficiency. Tertiary treatment was not attained in the 2-day set in respects to a 10mg/L-N total nitrogen limit. Coupled with effective organic nitrogen removal from separation processes, the 3 -d set would have met drinking water total nitrogen discharge limits during periods in late summer of 2012. A more feasible method to achieve total nitrogen limits is operation of ponds in series, as detailed in the next section.

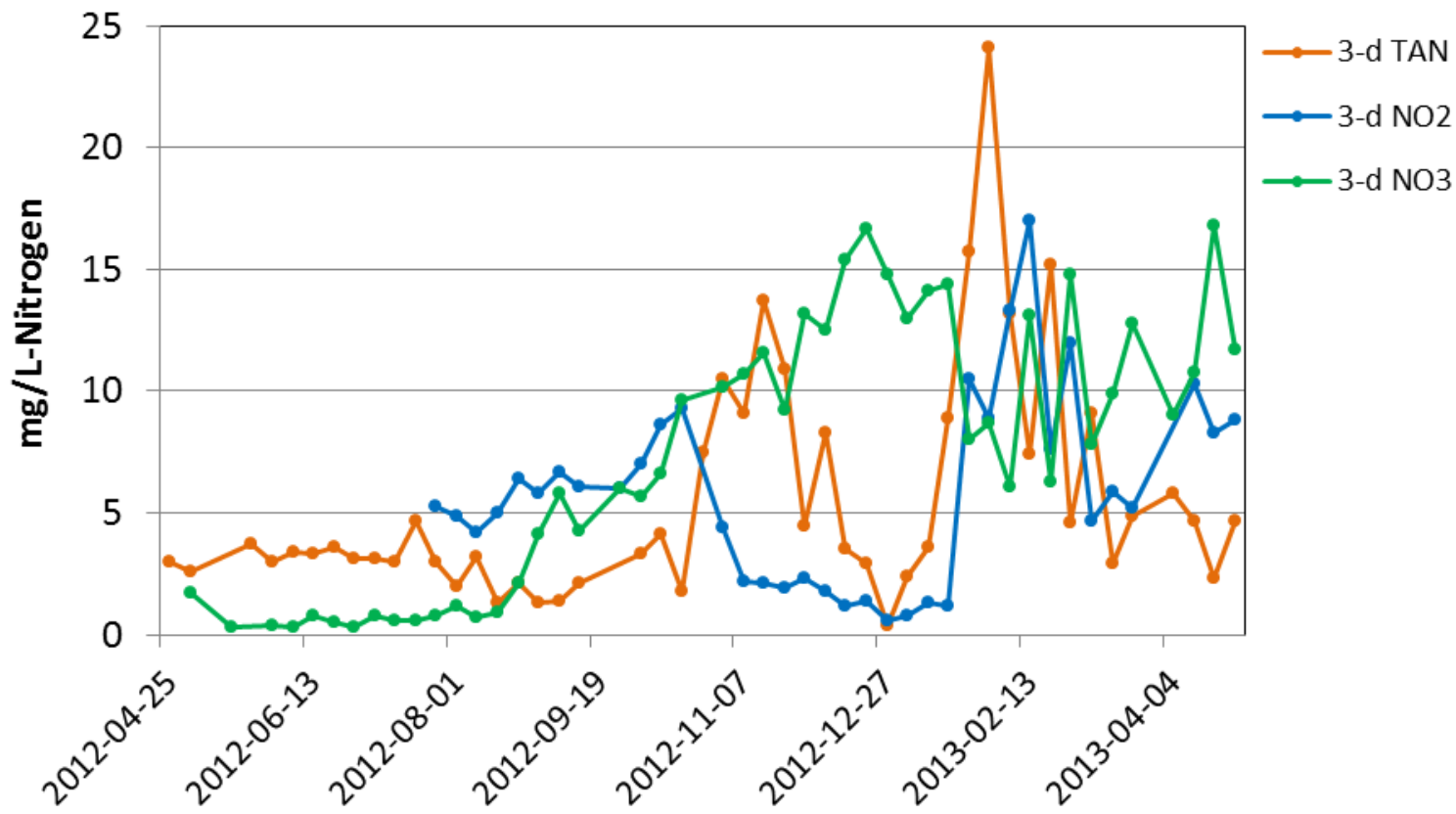

Figure 4.9. Time series of soluble nitrogen species concentrations in 3-day HRT ponds. Dip in "3-d TAN" data series in late December 2012 attributed to decreased ammonia loading and Influent dilution from rainstorm event. Nitrate-N spiked in winter 2012 and summer 2013, corresponding to low pond effluent TAN concentrations. 3-day set oxidized nitrogen concentrations as high as $42 \mathrm{mg} / \mathrm{L}-\mathrm{N}$ were observed during Experiment I. 


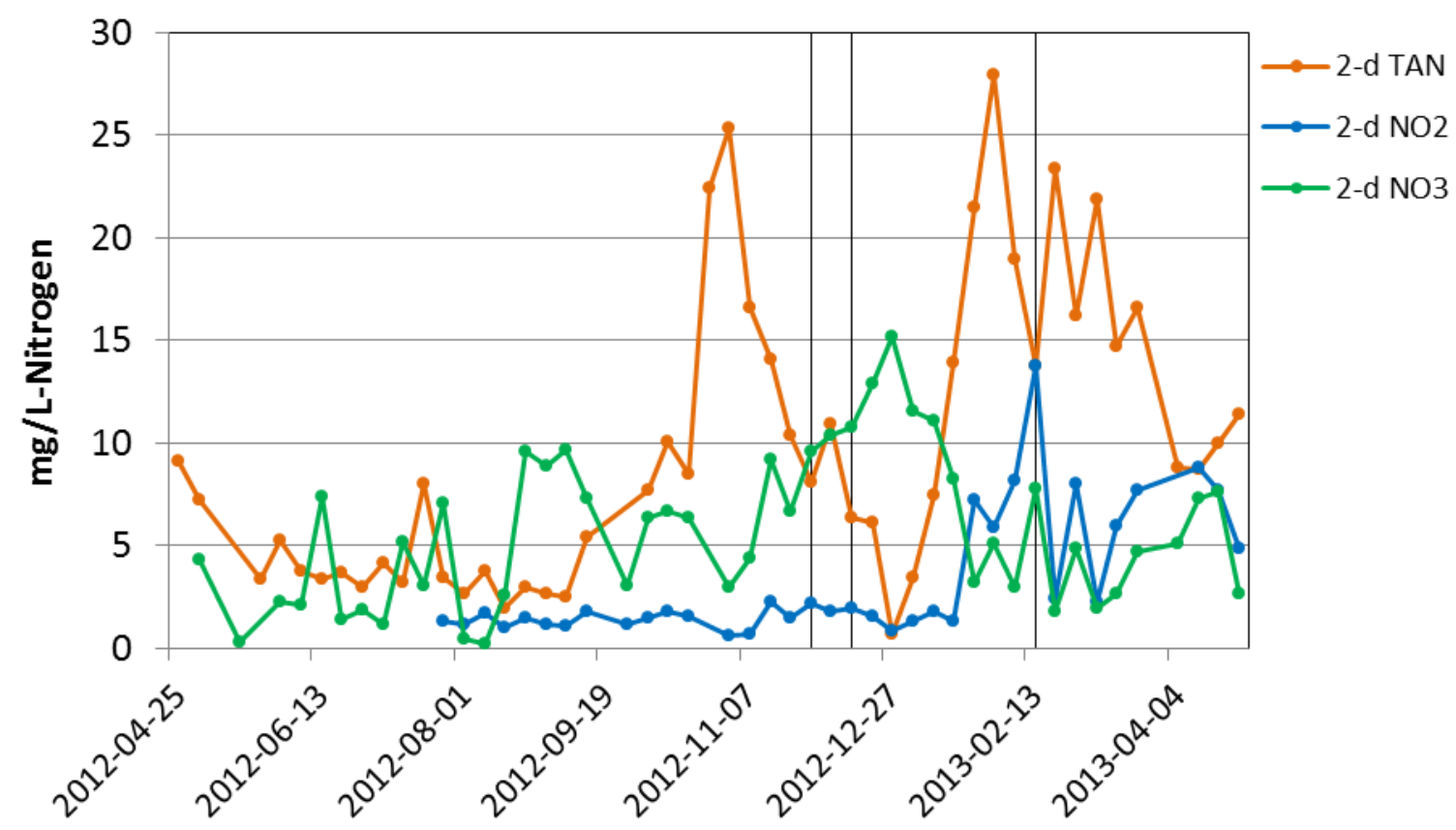

Figure 4.10. Time series of soluble nitrogen species concentrations in 2-day HRT ponds. Vertical lines represent events related to aeration of Ponds 7 and 9 during Experiment III. 2-day TAN concentrations less than $5 \mathrm{mg} / \mathrm{L}-\mathrm{N}$ were observed through most summer months and during the end of the 2012 calendar year. Maximum soluble nitrogen concentration of $39 \mathrm{mg} / \mathrm{L}-\mathrm{N}$ was measured in winter. Influent wastewater was diluted in December due to significant precipitation and reduced ammonia loading.

Quantitative estimations of denitrification and nitrification removal mechanisms are difficult to attain due to random fluctuation between concentrations of oxidized nitrogen species. During composite sampling, it is possible to have impeded photosynthetic activity by drawing samples into a dark environment, free of solar radiation, therefore allowing respiration to begin, and inhibiting oxidation of nitrite. Nitrate spikes result during weeks when low influent ammonia concentrations were measured and during the winter months when $\mathrm{pH}$ and pond temperature remained low. During August and September, 2012, similar ammonia removal in both sets resulted in increased nitrite concentrations in the 3-day compared to increased nitrate levels in the 2-day set. Such relationship would suggest incomplete denitrification, assuming both sets could have achieved $0 \%$ saturation during summer nights and enough carbon was available to 
complete the oxidation-reduction reaction. Without knowledge of predominant species of nitrifying and denitrifying species, conclusions attributing nitrite accumulation to incomplete nitrification or incomplete denitrification are speculative.

Nighttime DO levels reached 0\% saturation in both sets, presenting conditions favorable for denitrification. Furthermore, sufficient BOD was available in influent wastewater to stimulate nitrification and denitrification at selected HRTs. Nitrite peaked in the 3-day and 2-day sets around 23mg/L-N and 17mg/L-N, respectively, on February 13, 2013. Assimilation of ammonia typically declines in winter time, as well as volatilization, therefore more ammonia is available for oxidation to nitrate. Nitrate reached maximum concentrations of $18 \mathrm{mg} / \mathrm{L}-\mathrm{N}$ in both sets during winter months. During several weeks, oxidized nitrogen was predominantly in the form of nitrite in the 3-day set, whereas nitrate was the prevalent oxidized nitrogen species in the 2-d ponds.

It was hypothesized that TAN assimilation would lessen during winter, resulting in higher nitrate concentrations by means of complete nitrification. Excluding winter dates when ammonia concentrations were low in primary effluent, nitrate increased in concentration and ammonia removal was reduced, supporting aforementioned hypothesis. Nitrogen content was determined by relating pond effluent VSS to organic nitrogen concentration for all 3-day and 2-day ponds. Difference in nitrogen content between summer and winter months was negligible, contradictory to the prediction pertaining to assimilation. Nitrogen content of microalgal cells in the 3-day set was $11 \% \pm 2 \%$ and $12 \% \pm 2.6 \%$ in the 2-day set. No correlation between nitrogen content and influent ammonia concentration was made. Further aeration studies, or attainment of pond 
characteristics such as ORP, would be necessary for determining reliability of 3-day and 2-day HRT HRAPs as a tertiary treatment process.

\subsubsection{Reaction Rate}

The 2-day set operated for this experiment had notable variances in ammonia removal efficiency due to seasonality. During Experiment I, pH levels remained below 10.5, therefore making volatilization of ammonia unlikely. Microalgae and bacteria readily assimilate ammonia nitrogen to synthesize cellular constituents. Using first order kinetics for a continuous flow stir-tank reactor, or CSTR, estimations of reaction rate constants were made assuming steady-state conditions in the 2-day set.

Reaction rate constants $(k)$ fell to less than $1 \mathrm{~d}^{-1}$ during colder winter months as temperature and solar radiation decreased, creating a less suitable environment for algae growth (Figure 4.11). The reaction rate constant exceeded $5 \mathrm{~d}^{-1}$ during summer in 2012 and once during December, 2012. August 2012 marked the warmest month in San Luis Obispo for the calendar year with an average maximum daily temperature of $26^{\circ} \mathrm{C}$. Elevated temperatures led to a monthly average ammonia removal efficiency of $92 \%$, with a standard deviation of $3 \%$. Reaction rate is inversely proportional to concentration out of the constituent chosen for determination of reaction kinetics (Equation 4-1), therefore, high ammonia removal efficiencies resulted in periods of elevated reaction rates. On December 27, 2012, influent ammonia dropped to $17 \mathrm{mg} / \mathrm{L}-\mathrm{N}$, ammonia removal efficiency and $k$-value (Figure 4.12). C:N ratio is another variable with possible influence on reaction rates, as inferred from the high $k$-value corresponding to low ammonia loading. 


$$
C_{\text {out }} / C_{\text {in }}=1 /(1+k \cdot \mathrm{HRT})
$$

Equation 4-1

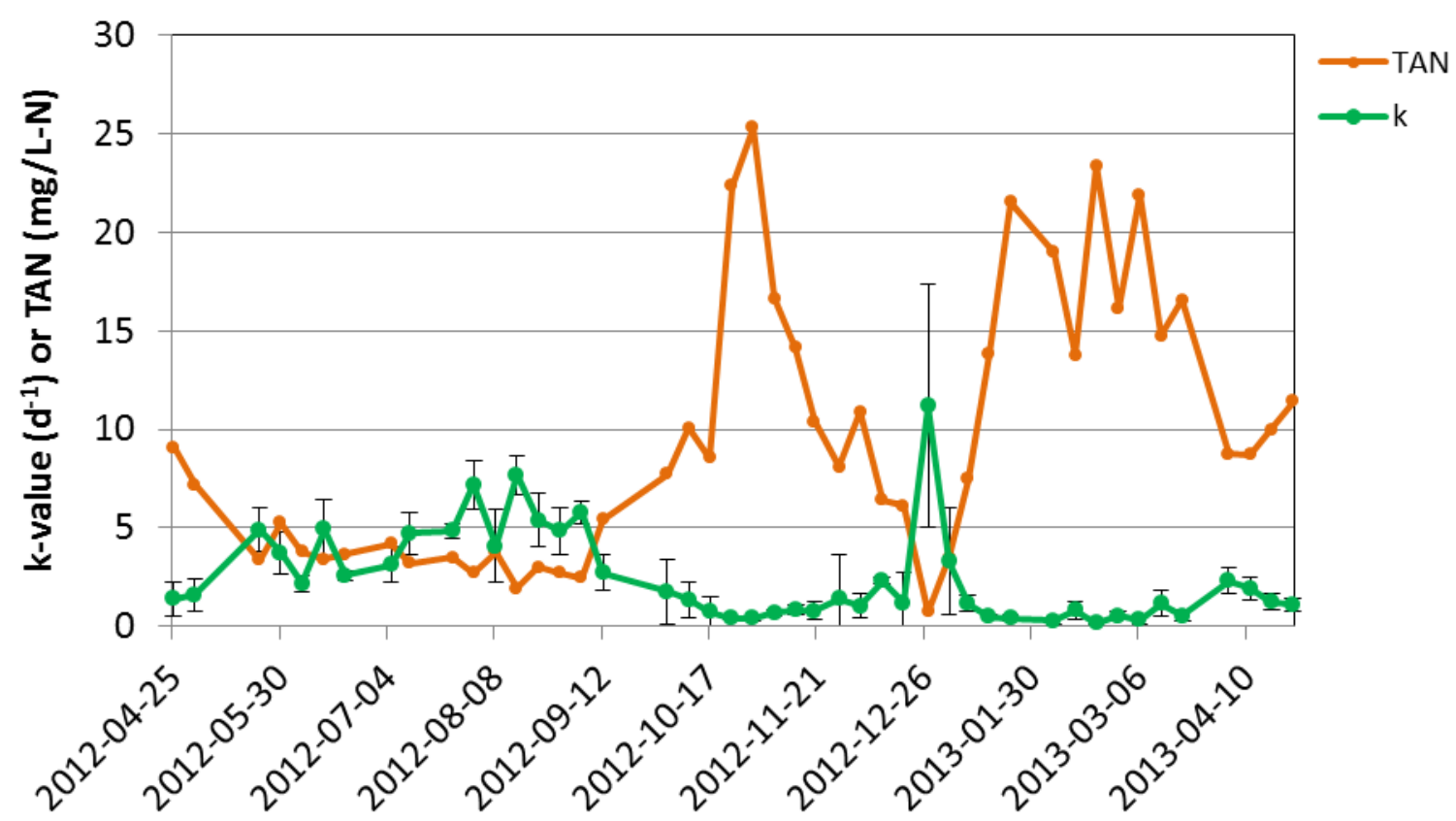

Figure 4.11. First-order reaction rate coefficient of a 2-day HRT ponds. Influent TAN concentration $\left(C_{i n}\right)$ and average 2 -day HRT pond effluent TAN concentrations $\left(C_{\text {out }}\right)$ were used as the two parameters by which $k$ is dependent upon. Spike in late December, coinciding with low pond effluent TAN concentrations and diluted influent wastewater, displays a $k$ value unrepresentative of winter time substrate utilization. 


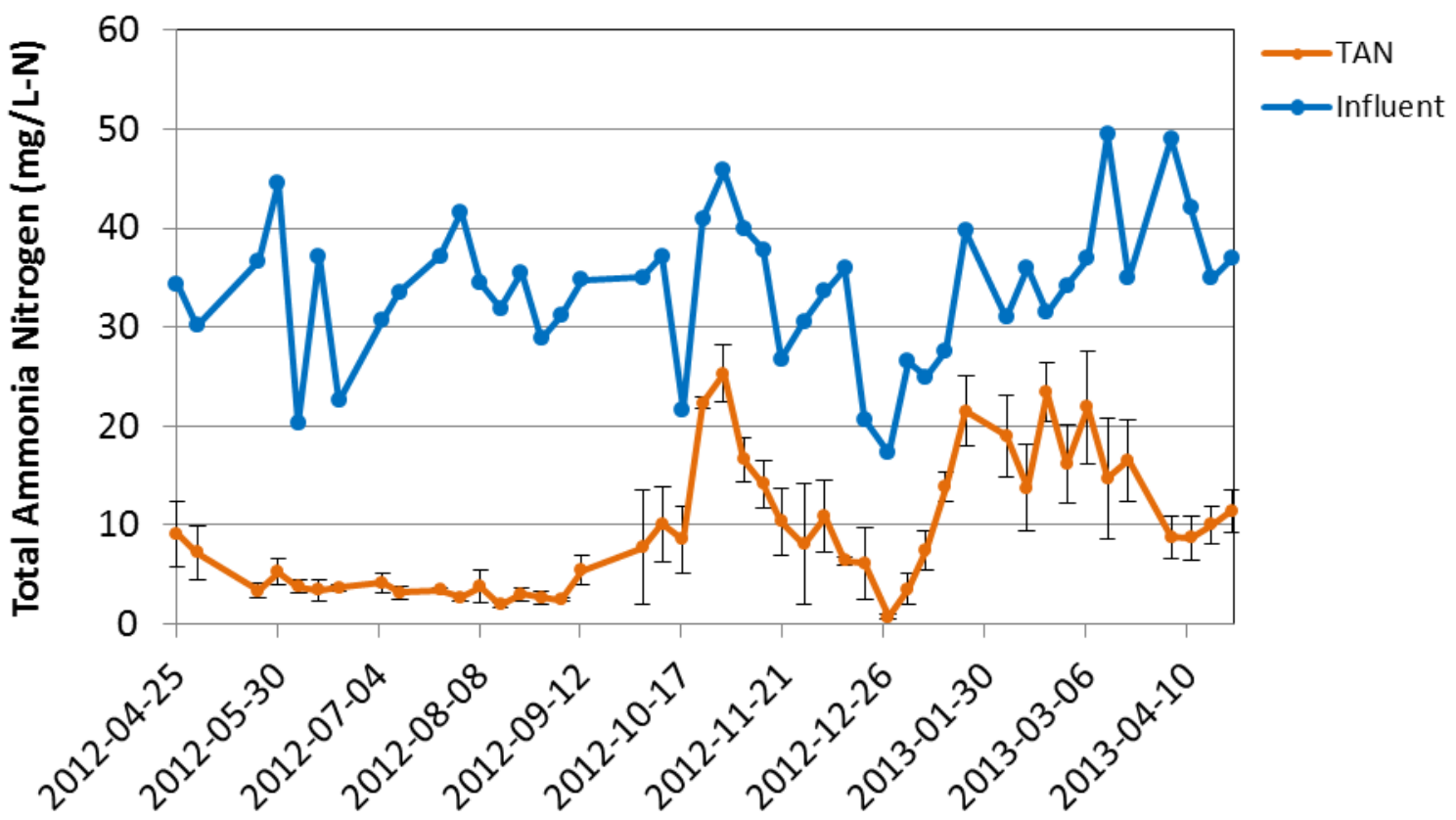

Figure 4.12. Influent and 2-day pond effluent TAN concentrations throughout entire experimentation period. Values in this time series were used to calculate the average $k$ value shown in Figure 4.11.

\subsubsection{Phosphorus Removal}

Minimum DRP concentrations were witnessed during summer months, but minimum average concentrations were lower during winter months. Phosphorus uptake by microalgal cells is proportional to pond temperature (Powell et al, 2009), explaining reduced 3-day pond effluent DRP concentrations as low as $0.64 \mathrm{mg} / \mathrm{L}-\mathrm{P}$ in summer (Table 4.5). Pond effluent concentrations during winter correspond to low Influent DRP concentrations and two low Influent TP data points of 3.9mg/L-P and 5.1mg/L-P (Figure 4.13). $\mathrm{pH}$ measurements in 3-day and 2-day ponds never exceeded 10.5, thus, DRP removal by way of autoflocculation was unlikely. If avoiding addition of lime, as is the case for present pilot study, phosphorus removal equivalent to tertiary treatment levels may not be achieved in HRAPs operating at 3-day and 2-day HRTs. 
Phosphorus content was attained from three data sets of TP analysis on pond effluents matched with analogous composite pond effluent VSS measurements. It is noted the August 8 and 15 sample dates used for phosphorus content estimation may have been affected by introduction of phosphorus by water fowl, as described in Chapter 2. For nine total samples in each set, average phosphorus content and standard deviations were calculated to be $2.7 \%^{ \pm} 1.2 \%$ and $2.3 \%{ }^{ \pm} 0.5 \%$ in 3-day and 2-day sets, respectively. Calculated phosphorus content implies luxury uptake occurred in all six ponds during the period of study. Minimum winter Influent concentrations of DRP may have induced luxury uptake of polyphosphates present in the primary effluent. Primary phosphorus removal was most likely completed through assimilation of orthophosphates by bacterial and algal biomass.

Quantification of phosphorus removal during Experiment I is limited by lack of acquired TP data. Since degradation of particulate phosphorus into DRP occurs during metabolic activity, calculating phosphorus removal efficiencies by comparison of pond effluent to influent DRP concentrations produces misleading results of treatment performance. As with organic nitrogen removal, particulate phosphorus would be removed by separation processes before treated water exits HRAP system, hence, total DRP would represent pond effluent phosphorus concentrations. Low phosphorus content of algal, even under luxury uptake conditions, results in low removal of DRP in wastewater-fed HRAPs. Powell et al (2009) concluded that exposing algae to high temperature wastewater rich in phosphorus would promote luxury uptake. 
Table 4.5. Comparison phosphorus removal between ponds operating at different HRTs.

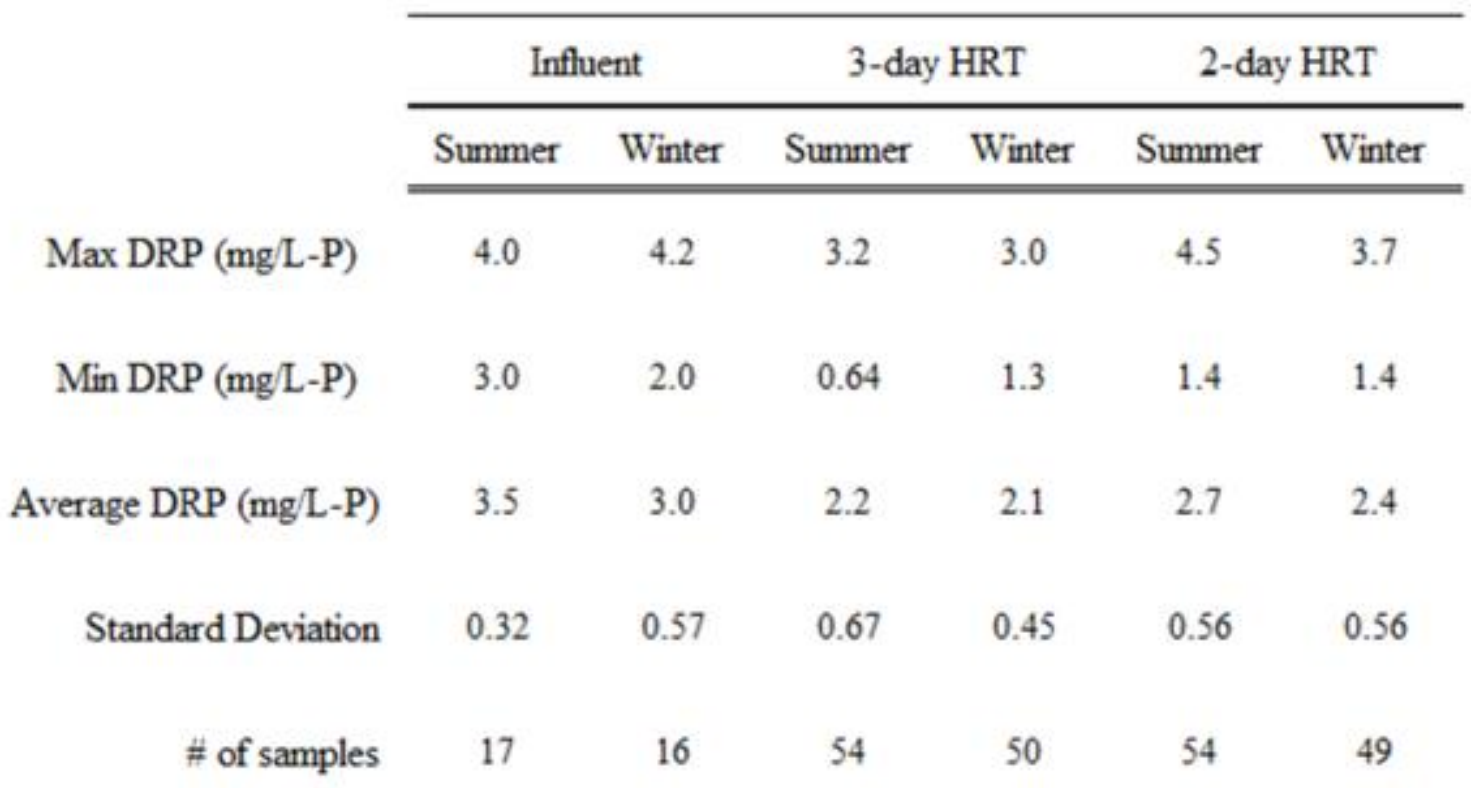

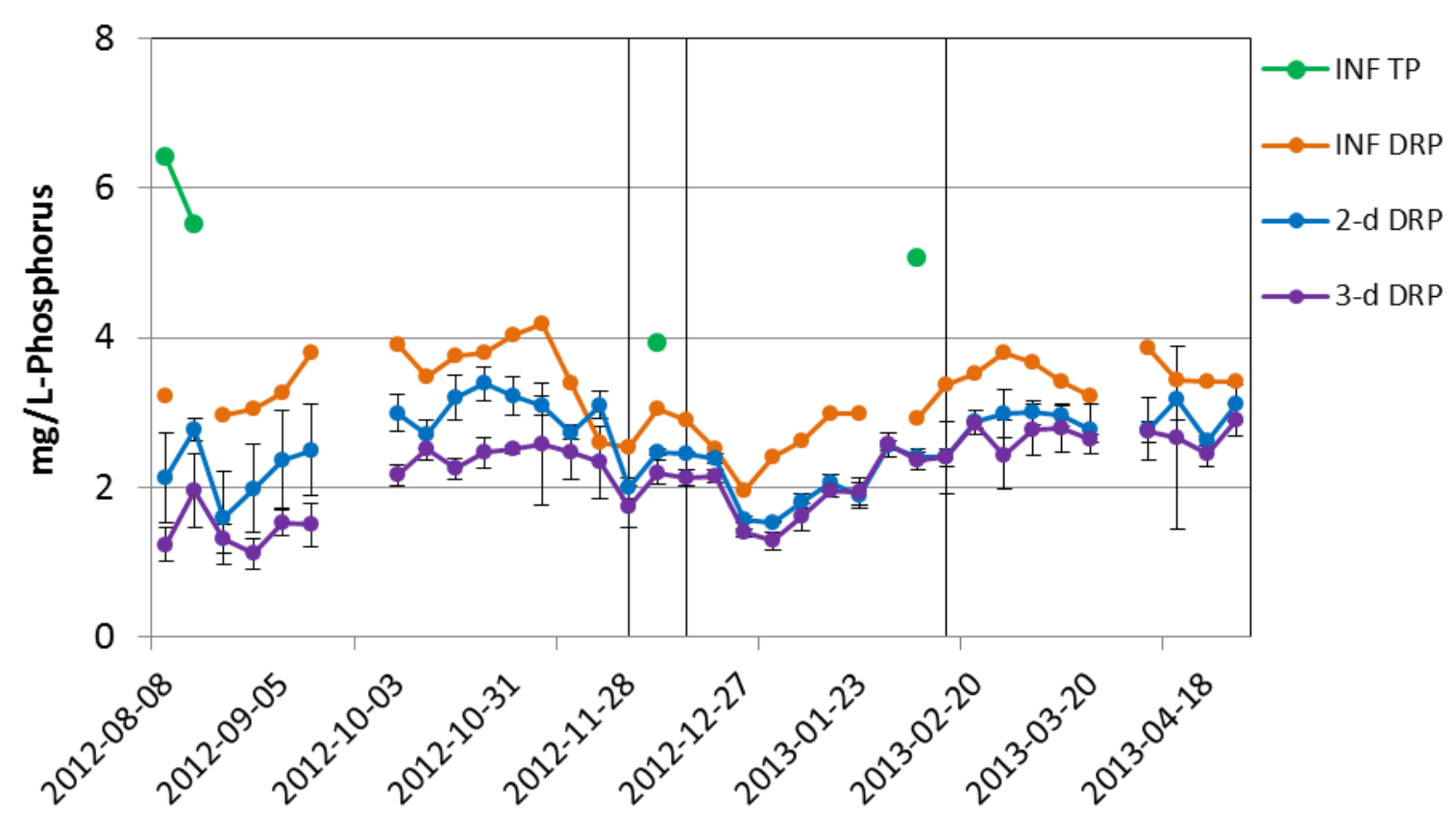

Figure 4.13. Phosphorus removal in Beta and Gamma sets operating at different HRTs. Vertical lines indicate aeration experiment operations in Gamma. Aeration was assumed to have no effect on phosphorus removal, thus, DRP comparison between sets is acceptable within the period of experimental pond aeration. 


\subsubsection{BOD Removal}

Photosynthetic oxygenation effectively contributes to bacteria's metabolic processes and subsequent decomposition of organic and inorganic constituents during their oxidative processes. BOD removal in 3-day and 2-day sets was not affected by seasonality of HRAP systems, in part because substantial oxygen is almost always available as an electron acceptor (Figure 4.14 \& Figure 4.15). Both sets averaged 95\% BOD removal during the year with little variation (Table 4.6). scBOD was consistently measured under $10 \mathrm{mg} / \mathrm{L}$ through average Influent TBOD concentrations of $136 \mathrm{mg} / \mathrm{L}$ in summer months and $103 \mathrm{mg} / \mathrm{L}$ during winter. Achievement of less than $30 \mathrm{mg} / \mathrm{L}$ scBOD in all 3-day and 2-day ponds demonstrates that low-HRT HRAPs are capable of secondary treatment. In future studies, determination of tube settler effluent TBOD (samples P2 eff and P5 eff for present research) would be required to more accurately determine BOD removal efficiencies of HRAP operations which employ tube settlers for sedimentation.

Influent BOD loading rates are related to several nutrient removal pathways and sufficient strength of wastewater BOD is required in biological treatment systems. Additional analysis of total organic carbon (TOC) and chemical oxygen demand (COD) levels would aid in C:N:P estimates to further evaluate Influent BOD effects on mechanisms such as denitrification, which is inhibited by low carbon concentrations. Biological treatment systems with efficient nutrient removal typically implement mechanical operations to manipulate loading rates in attempts to keep biological activity healthy. Biomass recycling effect and diel study of peak BOD concentrations, accompanied with instantaneous nitrogen species measurements would accelerate nutrient removal modeling of HRAP systems. 


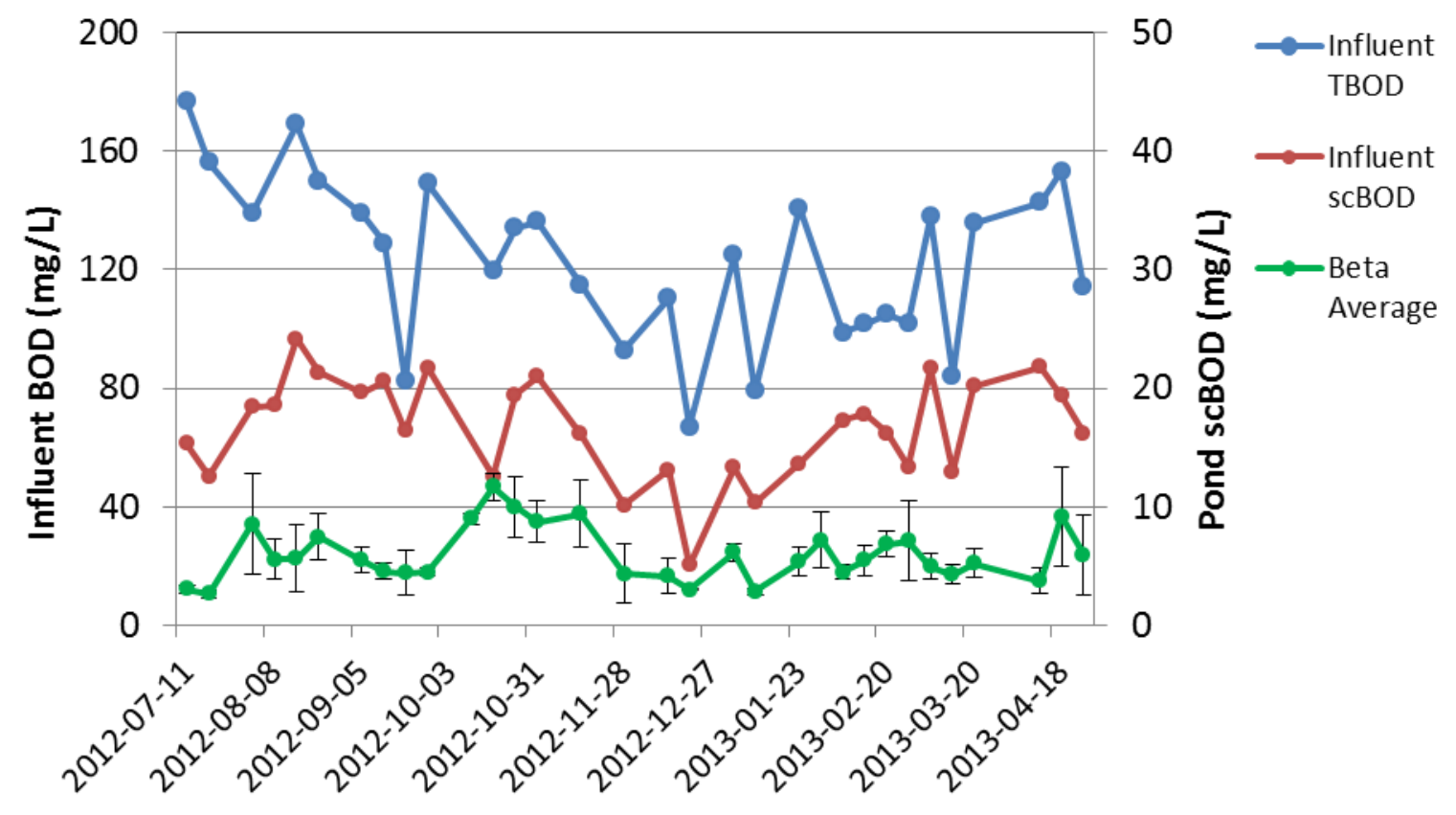

Figure 4.14. Beta set $\mathrm{scBOD}_{5}$ concentrations over time compared to Influent $\mathrm{BOD}$ time series. Influent BOD concentrations are scaled in respects to primary $y$-axis on the left while pond $\mathrm{scBOD}_{5}$ is aligned with secondary y-axis. Interpolation of data was applied to data sets where gaps had existed in the time series.

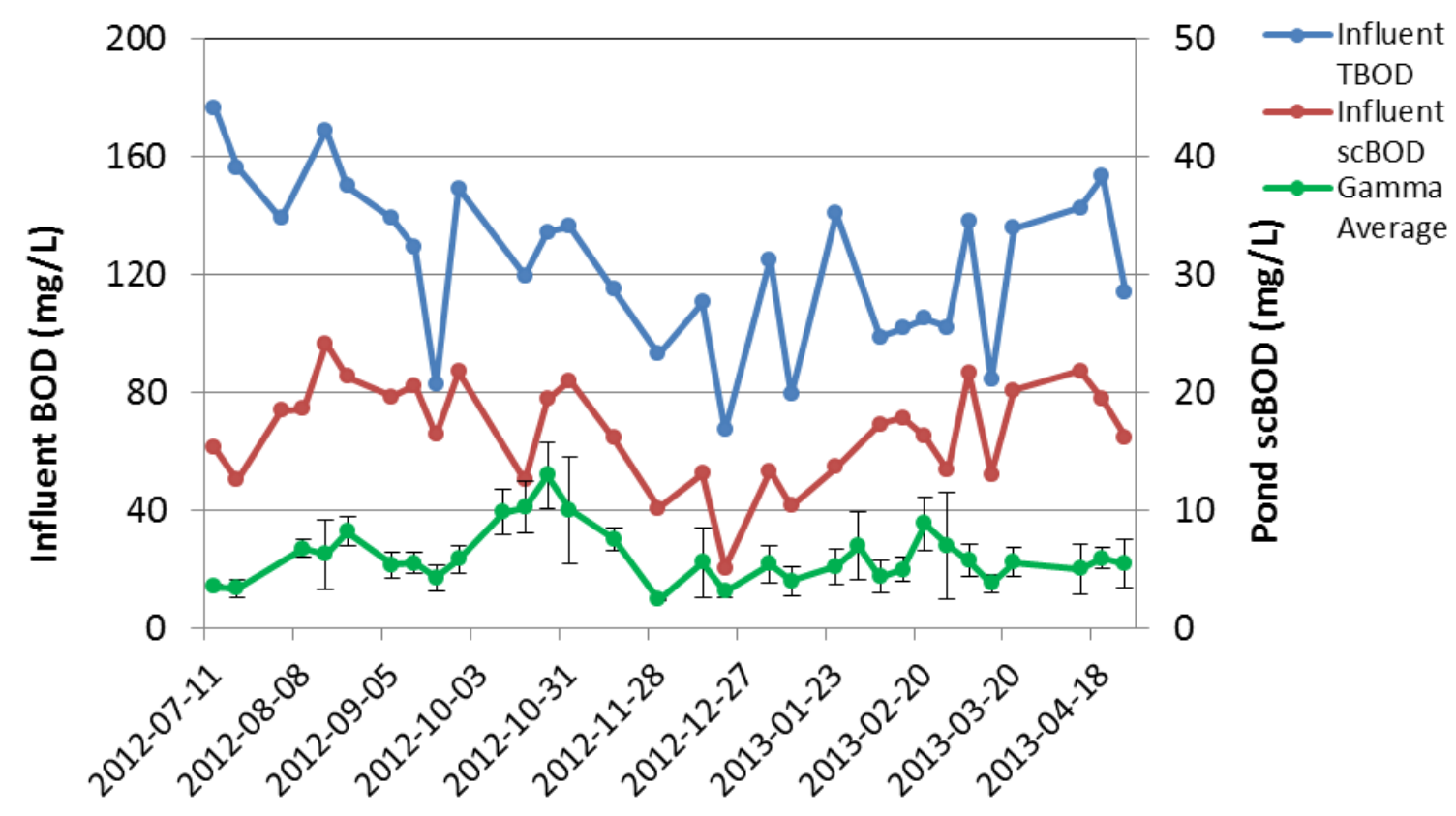

Figure 4.15. Gamma set $\mathrm{scBOD}_{5}$ concentration over time compared to Influent BOD time series. Influent $\mathrm{BOD}$ concentrations are scaled in respects to primary $\mathrm{y}$-axis on the left while pond $\mathrm{scBOD}_{5}$ is aligned with secondary y-axis. Interpolation of data was applied to data sets where gaps had existed in the time series. 
Table 4.6. BOD removal between Beta and Gamma sets operating at different HRTs.

\begin{tabular}{|c|c|c|c|c|c|c|}
\hline & \multirow{2}{*}{\multicolumn{2}{|c|}{ Influent }} & & & & \\
\hline & & & \multicolumn{2}{|c|}{ 3-day HRT } & \multicolumn{2}{|c|}{ 2-day HRT } \\
\hline & Summer & Winter & Summer & Winter & Summer & Winter \\
\hline $\operatorname{Max} \mathrm{TBOD} / \mathrm{scBOD}(\mathrm{mg} / \mathrm{L})$ & 177 & 141 & 13 & 12 & 16 & 12 \\
\hline Min $\mathrm{TBOD} / \mathrm{scBOD}(\mathrm{mg} / \mathrm{L})$ & 82 & 67 & 2.3 & 2.4 & 2.6 & 2.4 \\
\hline $\begin{array}{l}\text { Avg TBOD }(\mathrm{mg} / \mathrm{L}) \\
\text { Avg BOD Removal }\end{array}$ & 136 & 103 & $95 \%$ & $95 \%$ & $95 \%$ & $95 \%$ \\
\hline Standard Deviation & 25 & 20 & $2.3 \%$ & $2.0 \%$ & $2.3 \%$ & $2.2 \%$ \\
\hline$\#$ of samples & 18 & 11 & 41 & 30 & 37 & 32 \\
\hline
\end{tabular}

\subsection{Experiment II: Ponds in Series}

Experiment II was conducted to determine extent of treatment levels possible in the second unit of ponds in series. Objective was to evaluate HRAP capability of attaining total nitrogen levels of 10mg/L-N or less. Separation of biomass from 3-day HRT Beta pond effluent was completed using tube settlers (refer to E.B. Ripley, 2013 for specifications) before treated water was redirected at a 4-day HRT flowrate of $1.6 \mathrm{~L} / \mathrm{min}$ into Ponds 1, 2 and 3. Alpha ponds in series were expected to have higher nutrient removal efficiencies compared to Beta ponds, which were hypothesized to have greater biomass production but less effective treatment performance.

$\mathrm{CO}_{2}$ supplementation began on June 1,2012 , the same day ponds were switched to operate in series, as indicated by vertical lines on time series graphs. $\mathrm{CO}_{2}$ diffusers functioned on independent solenoids, programmed to add $\mathrm{CO}_{2}$ once $\mathrm{pH}$ reached 8.6 and 
turn off when $\mathrm{pH}$ reached 8.5. A grazer control experiment was conducted on Pond 1 from July 17 to August 9, 2012 by supplementing the pond at night with $\mathrm{CO}_{2}$ and allowing natural $\mathrm{pH}$ rise during the day. No significant difference in Pond 1 treatment performance resulted from period of alteration to regular experimental conditions of $\mathrm{pH}$ range.

\subsection{1 pH, Temperature and DO}

Temperatures in Round 1 and Round 2 ponds remained similar through seasonal variation (Figure 4.16). Average temperatures remained above $20^{\circ} \mathrm{C}$ in both sets from June to October and dropped to less than $12^{\circ} \mathrm{C}$ in January. Average DO saturation in Round 2 ponds remained between $100 \%$ and $150 \%$ from November 2012 until conclusion of experiment. Round 1 ponds had higher carbon loading and therefore exhibited average DO saturation less than $50 \%$ during most weeks. Filamentous biomass was not found in Alpha as commonly as it was in Beta and Gamma, as a result, imprecise readings were not caused by obstruction of the probe membrane in Ponds 1, 2 and 3. DO measurement were not taken until November 2, 2013, therefore changes in DO resulting from operating pons in series was not determined. 

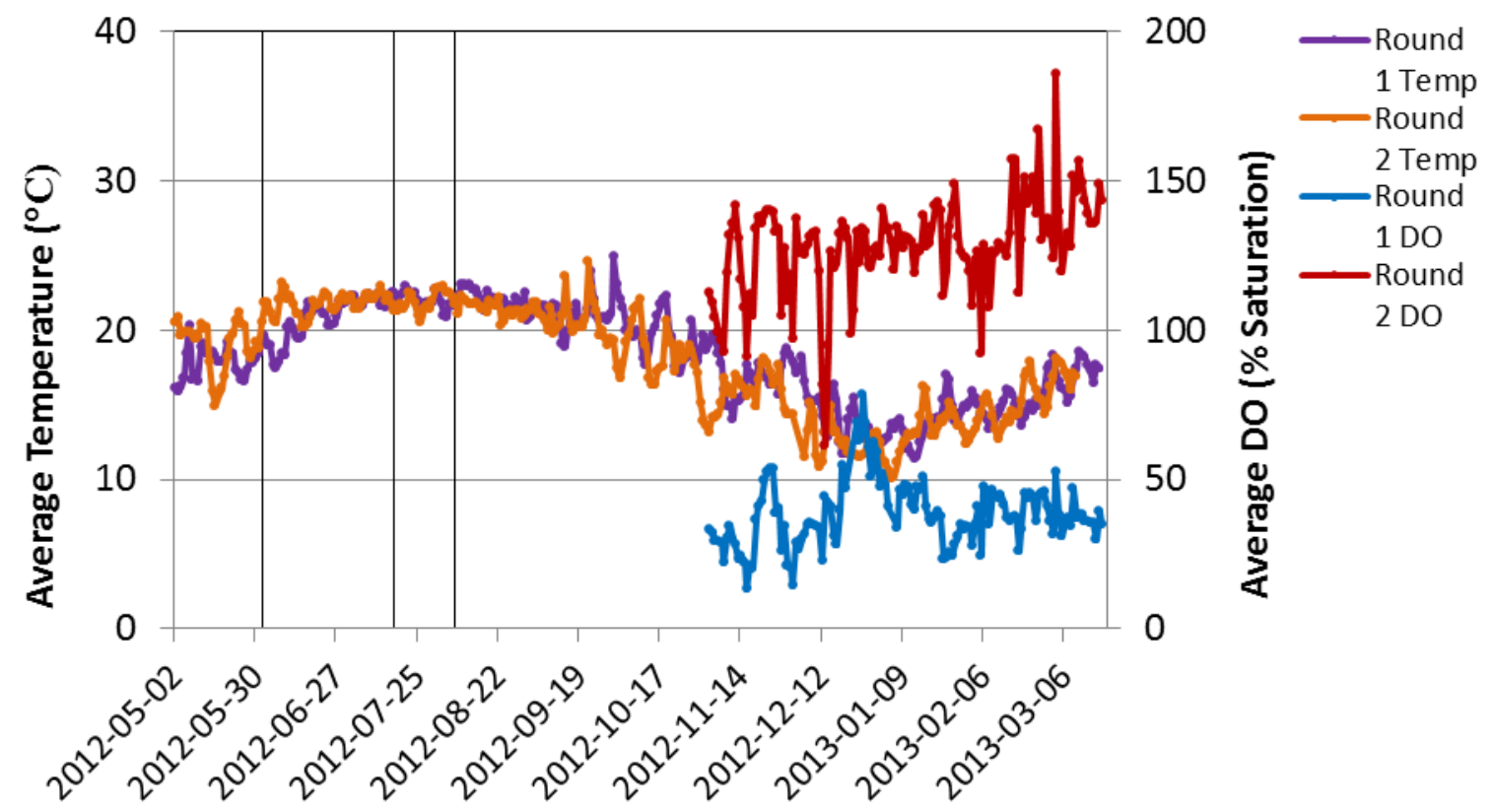

Figure 4.16. Average temperature and DO (\% saturation) of ponds in series. The vertical lines in the plot area, from left to right, represent the beginning of Experiment II, beginning of grazer $\mathrm{CO}_{2}$ addition study in Pond 1 and ending date of said study.

Before Round 1 pond effluent was fed to Round 2, average $\mathrm{pH}$ levels were similar in both sets, falling within the range of 9-10. As illustrated in Figure 4.17, $\mathrm{pH}$ regulated $\mathrm{CO}_{2}$ addition in Round 2 ponds resulted in an average $\mathrm{pH}$ between 8 and 8.5 for most of the experimental period, aside from mechanical failure which interrupted carbon addition and allowed $\mathrm{pH}$ to rise naturally. These spikes in average $\mathrm{pH}$ throughout the year briefly decreased ammonia removal efficiencies in Ponds 1, 2 and 3. 


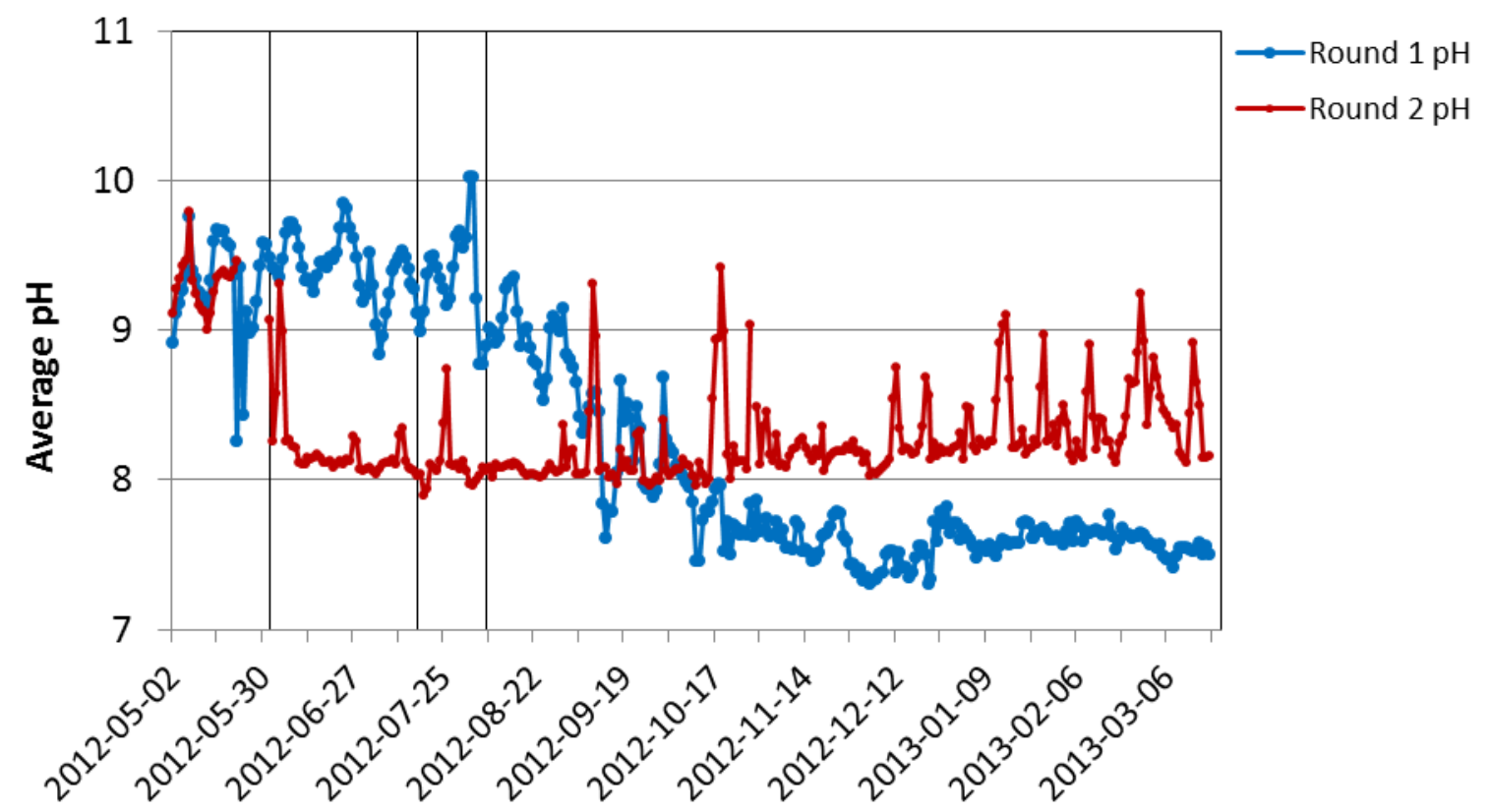

Figure 4.17. Average $\mathrm{pH}$ of Round 1 and Round $2 \mathrm{pH}$ during operation of ponds in series. The decrease in Round $2 \mathrm{pH}$ following the first vertical line resulted from $\mathrm{pH}$ regulated $\mathrm{CO} 2$ addition between the range of 8.5 to 8.6. Spike observed in data series between second and third vertical line is a result of a grazer $\mathrm{CO}_{2}$ experiment in which daytime Pond $1 \mathrm{pH}$ was allowed to rise, naturally, without $\mathrm{pH}$ regulation.

\subsubsection{Nitrogen Removal}

During summer months, operation of ponds in series improved average TAN removal efficiency from $90 \%$ in the Round 1 set to $99 \%$ in the Round 2 set (Table 4.7).

Maximum summer TAN concentrations in Round 2 reached a maximum of $3.4 \mathrm{mg} / \mathrm{L}-\mathrm{N}$ in Pond 1 during interruption of $\mathrm{CO}_{2}$ addition. Beta's summer TAN concentration peaked at $18 \mathrm{mg} / \mathrm{L}-\mathrm{N}$ in Pond 5 on October 31, 2012 when influent TAN concentration reached 46mg/L-N. Noticeable spikes above 10mg/L-N in Round 2 TAN concentration correspond to high influent TAN concentrations and low pond temperatures in February, 2013 (Figure 4.18). Standard deviation for average TAN removal efficiencies of Round 1 ponds increased to $16 \%$ in winter as a result of variance between $42 \%$ and $99 \%$ TAN removal between Ponds 4, 5 and 6. TAN removal was significantly reduced in the Round 
1 ponds during winter, averaging $76 \%$ removal efficiency. However, Round 2 was capable of treating Round 1 pond effluent to levels as low as $0.02 \mathrm{mg} / \mathrm{L}-\mathrm{N}$ with an average 98\% TAN removal efficiency. Nitrification and assimilation of ammonia were the primary mechanisms for ammonia removal, as volatilization of ammonia in Round 2 ponds was unlikely due to the regulation of $\mathrm{pH}$ levels from $\mathrm{CO}_{2}$ supplementation. Average nitrogen content of algal cells in Round 2 ponds during Experiment II was 9.9\% with a standard deviation of 1.8\%. As with 2-day and 3-day HRT ponds discussed in the previous section, there was negligible difference in nitrogen content between summer and winter months.

Table 4.7. TAN removal and pond effluent concentrations of ponds in series compared to Influent TAN characteristics.

\begin{tabular}{cccccc}
\hline \multicolumn{2}{c}{ Influent } & \multicolumn{2}{c}{ Round 2 } & \multicolumn{2}{c}{ Round 1 } \\
\hline Summer & Winter & Summer & Winter & Summer & Winter \\
\hline 49 & 40 & 3.4 & 6.7 & 18 & 27 \\
20 & 17 & 0.01 & 0.02 & 1.0 & 0.2 \\
36 & 31 & $99 \%$ & $98 \%$ & $90 \%$ & $76 \%$ \\
7.1 & 6.6 & $2.1 \%$ & $4.4 \%$ & $6.6 \%$ & $16 \%$ \\
29 & 16 & 86 & 47 & 87 & 47
\end{tabular}




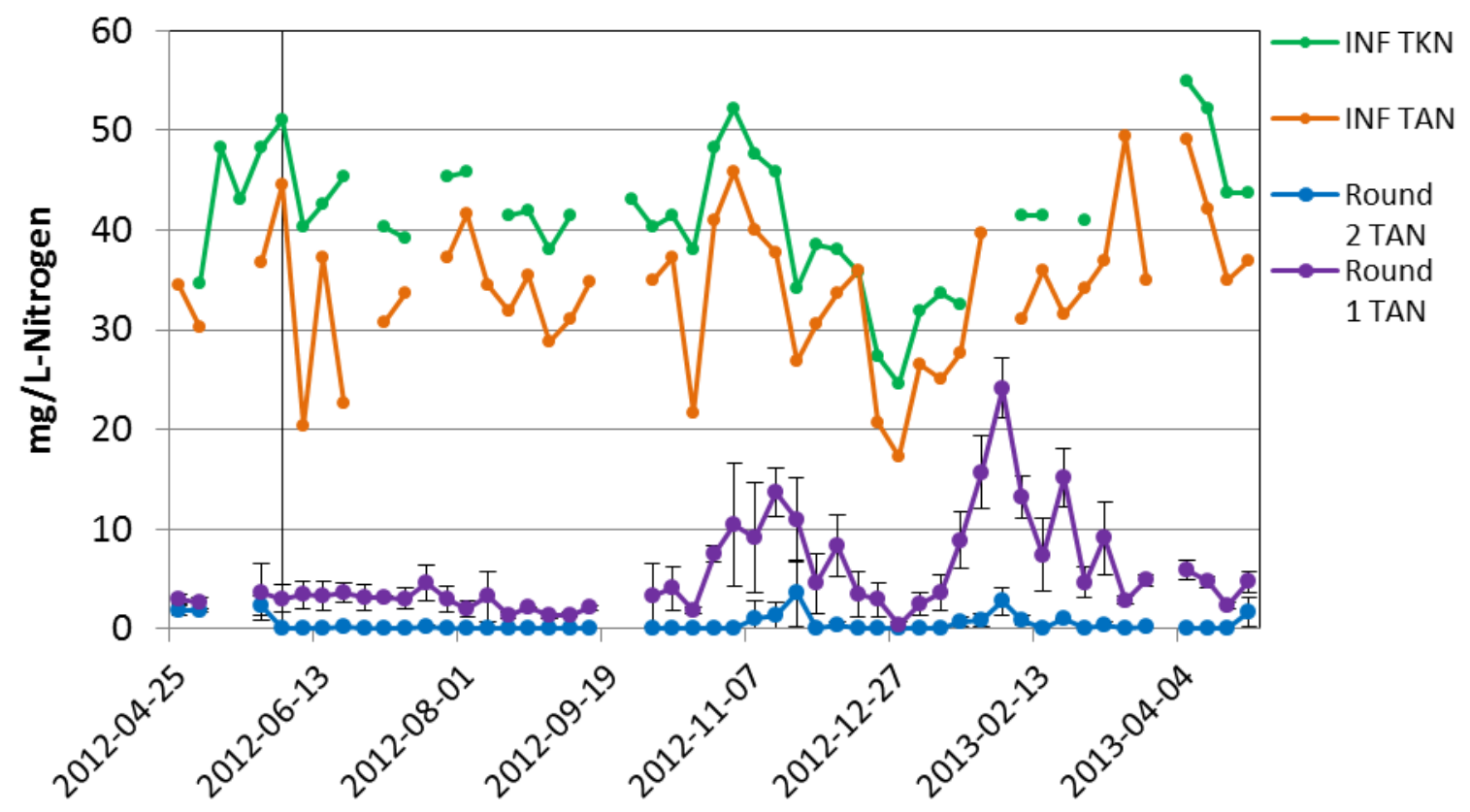

Figure 4.18. Round 1 and Round 2 TAN time series. Gaps in data were not interpolated due to frequency and length of interval between accurate data points. Noticeable TAN increases of Round 1 data series resulted from decreased pond temperatures and biomass productivity during winter.

Composite sampling of P2 eff and P5 eff allowed for total nitrogen analysis between nitrogen constituents of the Influent and effluent from Pond 2 after sedimentation mechanisms were employed through operation of tube settlers (Figure 4.19). Data acquired for Figure consisted of 20 data points for each sample, spanning from August 22, 2012 to April 18, 2013. Average TN concentration was reduced from $42.9 \mathrm{mg} / \mathrm{L}-\mathrm{N}$ in the Influent, to $29.6 \mathrm{mg} / \mathrm{L}-\mathrm{N}$ in P5 eff and $18.6 \mathrm{mg} / \mathrm{L}-\mathrm{N}$ in P2 eff. In the case of further microfiltration or improved tube settler settling efficiencies, complete organic nitrogen removal from Pond 2 would have resulted in an average TN concentration of $12 \mathrm{mg} / \mathrm{L}-\mathrm{N}$. Occasionally, differences in TAN concentrations between Pond 2 eff, Pond 5 eff and their respective ponds, implied occurrence of mineralization within the settling chamber, but produced no significance in regards to treatment efficiencies. Assimilation of nitrate is unlikely if ammonia is present at sufficient concentrations for algal biomass growth. 
To achieve TN levels of $10 \mathrm{mg} / \mathrm{L}-\mathrm{N}$, required by most tertiary treatment standards, nitrate reduction by means of denitrification would have to occur in order to meet said limit.

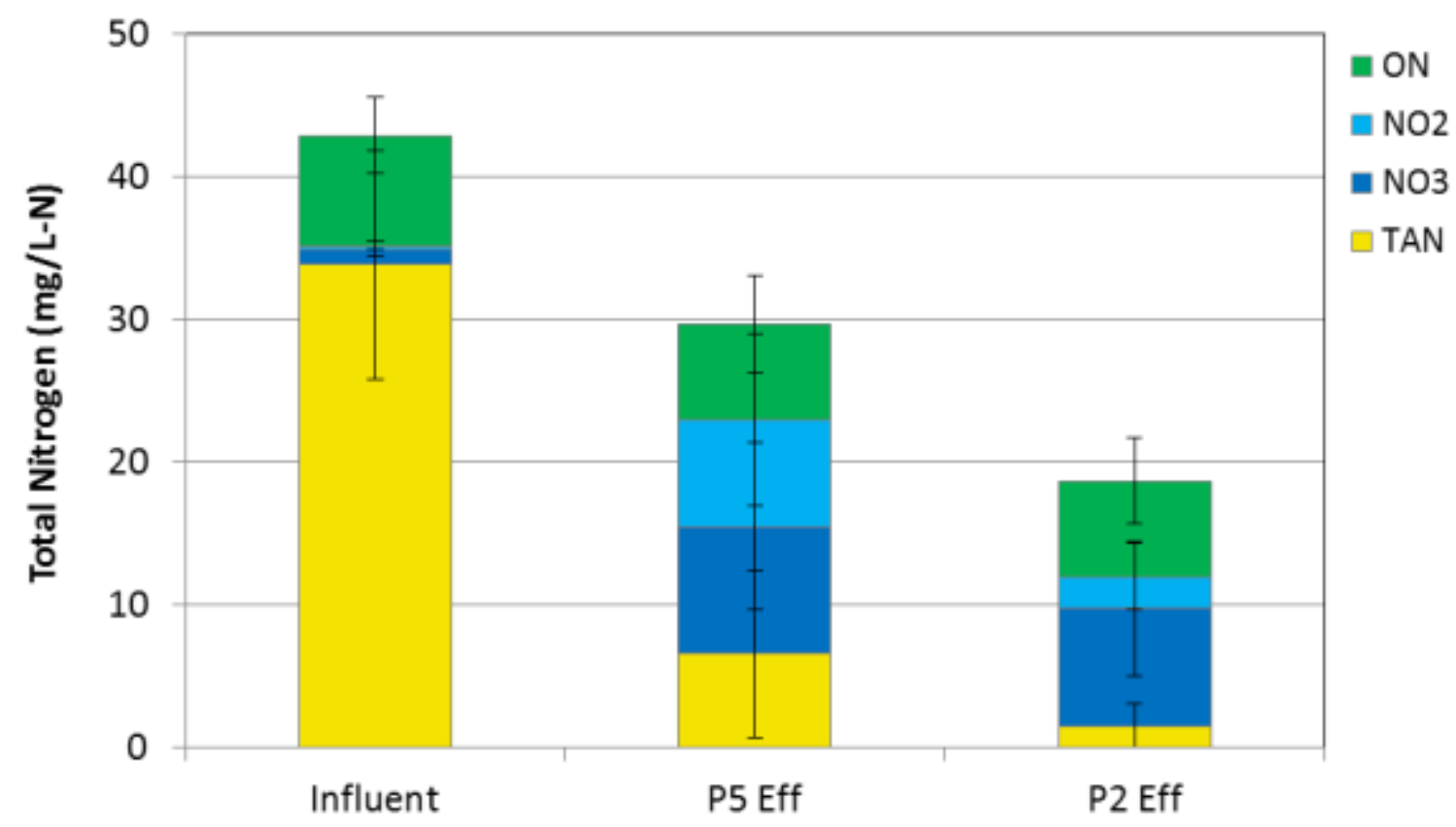

Figure 4.19. Total nitrogen balance between Influent, Round 1 effluent and Round 2 effluent. Data attained from 20 weeks of data analysis spanning from August 22, 2012 to April 18, 2013.

Average nitrate concentrations in Round 1 and Round 2 effluent remained similar throughout experimentation (Figure 4.20 \& Figure 4.21). With photosynthetic oxygenation during the day and $\mathrm{pH}$ levels below 10.5, ammonia in Round 1 ponds was likely oxidized to nitrate during complete nitrification. Noticeable difference in oxidized nitrogen content between sets took place during late summer and late winter in Round 1 when nitrite concentration considerably increased in Round 1 ponds to maximum levels of $17 \mathrm{mg} / \mathrm{L}-\mathrm{N}$. Average nitrite concentration in Round 2 remained below $5 \mathrm{mg} / \mathrm{L}-\mathrm{N}$ for the period of experimentation, suggesting minimal amounts of incomplete nitrification or denitrification. Nitrate removal by means of assimilation was improbable unless 
ammonia concentrations were low, in part because algal cells prefer nitrogen assimilation in the form of ammonia over nitrate (Mayo \& Mutamba, 2005).

Nitrate reduction was expected to increase as photosynthetic oxygenation decreased at night and DO reached levels appropriate for denitrification. Levels of $0 \%$ saturation were recorded in Round 1 ponds during both summer and winter seasons, whereas minimum DO in the Round 2 set remained above $20 \%$ saturation throughout the course of Experiment II. In Round 2 ponds, nitrate reduction may have been impeded by limited carbon availability at night and high nighttime DO saturation, deterring chances of denitrification. Continuous feed of influent into ponds provided adequate oxygen demand for nitrate reduction in Round 1, but carbon degradation could have been limited if facultative bacteria was not present in the ponds. Additional possibilities for nitrite increase in Round 1 ponds may be attributed to composite sampling influence as described in Section. Furthermore, organisms lacking specific reductase enzymes may also contribute to nitrite accumulation by way of incomplete denitrification. 


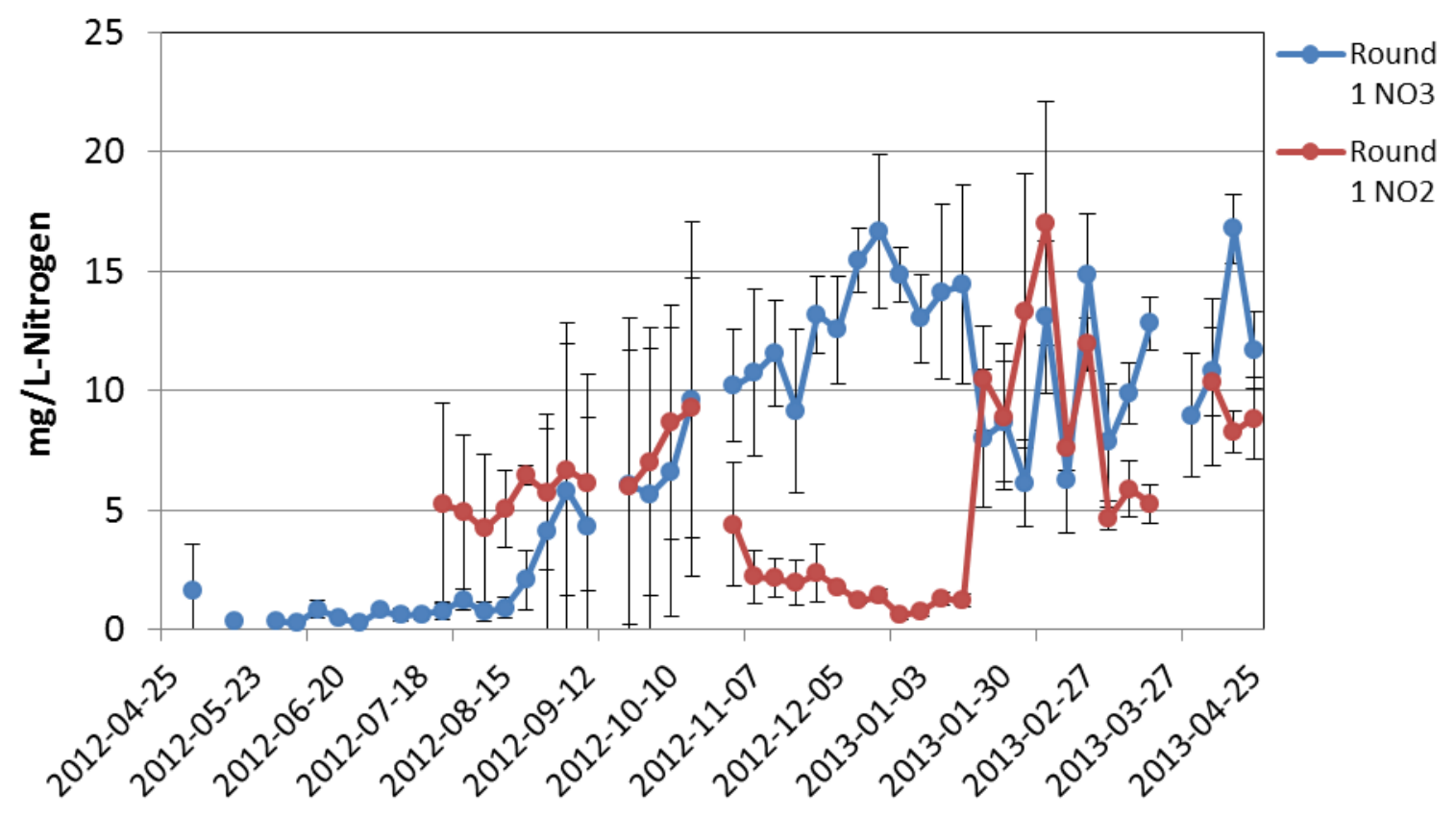

Figure 4.20. Round 1 oxidized nitrogen time series. Gaps in data series are result of inaccurate values attained during weekly analysis. Nitrite accumulation occurred frequently in Round 1 ponds, whereas such increases were not witnessed in Round 2 ponds.

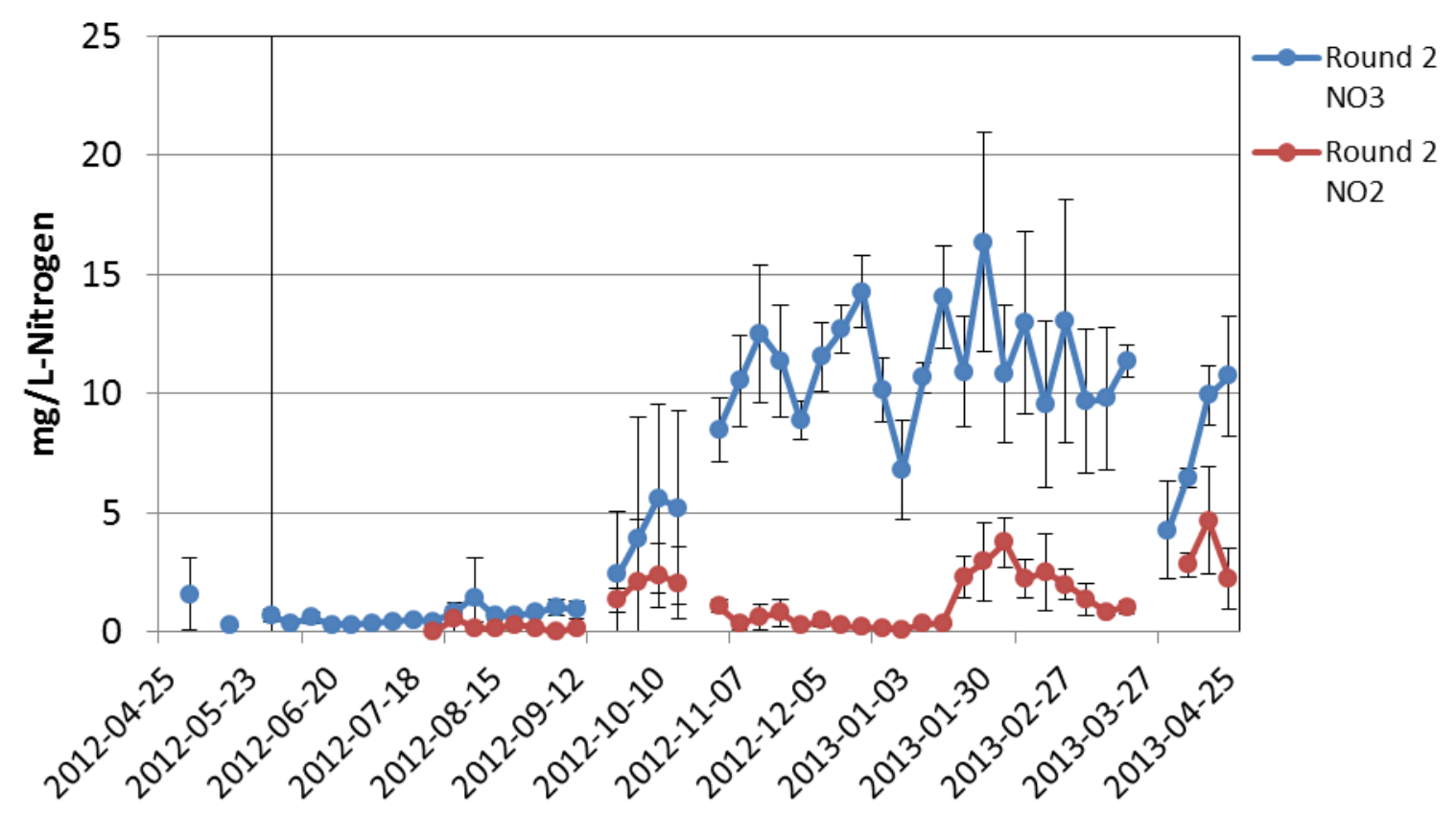

Figure 4.21. Round 2 oxidized nitrogen time series. Gaps in data series are result of inaccurate values attained during weekly analysis. Average nitrite concentrations in Round 2 ponds remained below $5 \mathrm{mg} / \mathrm{L}-\mathrm{N}$ through both seasons. 


\subsubsection{Phosphorus Removal}

DRP concentrations ranged from 2-4mg/L-P in the Influent (Table 4.8), allowing for adequate uptake of $1 \%$ phosphorus content in ponds with $200-400 \mathrm{mg} / \mathrm{L}$ of algal biomass. TP concentration in influent wastewater was measured to be between $3.9 \mathrm{mg} / \mathrm{L}-\mathrm{P}$ and 6.4mg/L-P during four dates of analysis between August 8, 2012 and February 6, 2013

(Figure 4.22). While measured concentrations of 3.9-6.4mg/L-P is typical of domestic wastewater phosphorus content, TP loading rates corresponding to said concentrations would likely prohibit phosphorus luxury uptake (Powell et al, 2009). Average phosphorus content in Round 2 ponds, calculated using composite TP and VSS data from August and December sample dates, was $1.2 \% \pm 0.25 \%$, with no significant change in content between August and December (Table 4.8).

DRP concentration in Round 2 ponds frequently reached non-detectable (N/D) limits in summer, commonly attributed to increased biomass productivity and subsequent improved nutrient uptake. Average summer and winter DRP levels in the Round 2 set were well below $2 \mathrm{mg} / \mathrm{L}-\mathrm{P}$ at $1.2 \mathrm{mg} / \mathrm{L}-\mathrm{P}$ and $1.3 \mathrm{mg} / \mathrm{L}-\mathrm{P}$, respectively. Although phosphorus removal in winter and summer are comparable, high influent DRP levels in early November 2012 and late February 2013 led to increased DRP concentrations in Round 1 and 2 (Figure 4.22). Microbial uptake of phosphorus is the common method of phosphorus removal in HRAPs, but is limited by the amount of phosphorus needed by algal cells to survive, as witnessed by winter time DRP spikes in pond effluent. In both sets, low $\mathrm{pH}$ levels coupled with low concentrations of divalent cations prevents significant phosphorus removal due to autoflocculation. 
Table 4.8. Phosphorus removal comparison of ponds in series.

\begin{tabular}{ccccccc}
\cline { 2 - 7 } & \multicolumn{2}{c}{ Influent } & \multicolumn{2}{c}{ Round 2 } & \multicolumn{2}{c}{ Round 1 } \\
\cline { 2 - 7 } & Summer & Winter & Summer & Winter & Summer & Winter \\
\cline { 2 - 7 } Max DRP (mg/L-P) & 4.0 & 4.2 & 2.8 & 2.1 & 3.2 & 3.0 \\
Min DRP (mg/L-P) & 3.0 & 2.0 & N/D & 0.3 & 0.6 & 1.3 \\
Average DRP (mg/L-P) & 3.5 & 3.0 & 1.2 & 1.3 & 2.2 & 2.1 \\
Standard Deviation & 0.32 & 0.57 & 0.81 & 0.44 & 0.67 & 0.45 \\
\# of samples & 17 & 16 & 53 & 51 & 54 & 50
\end{tabular}

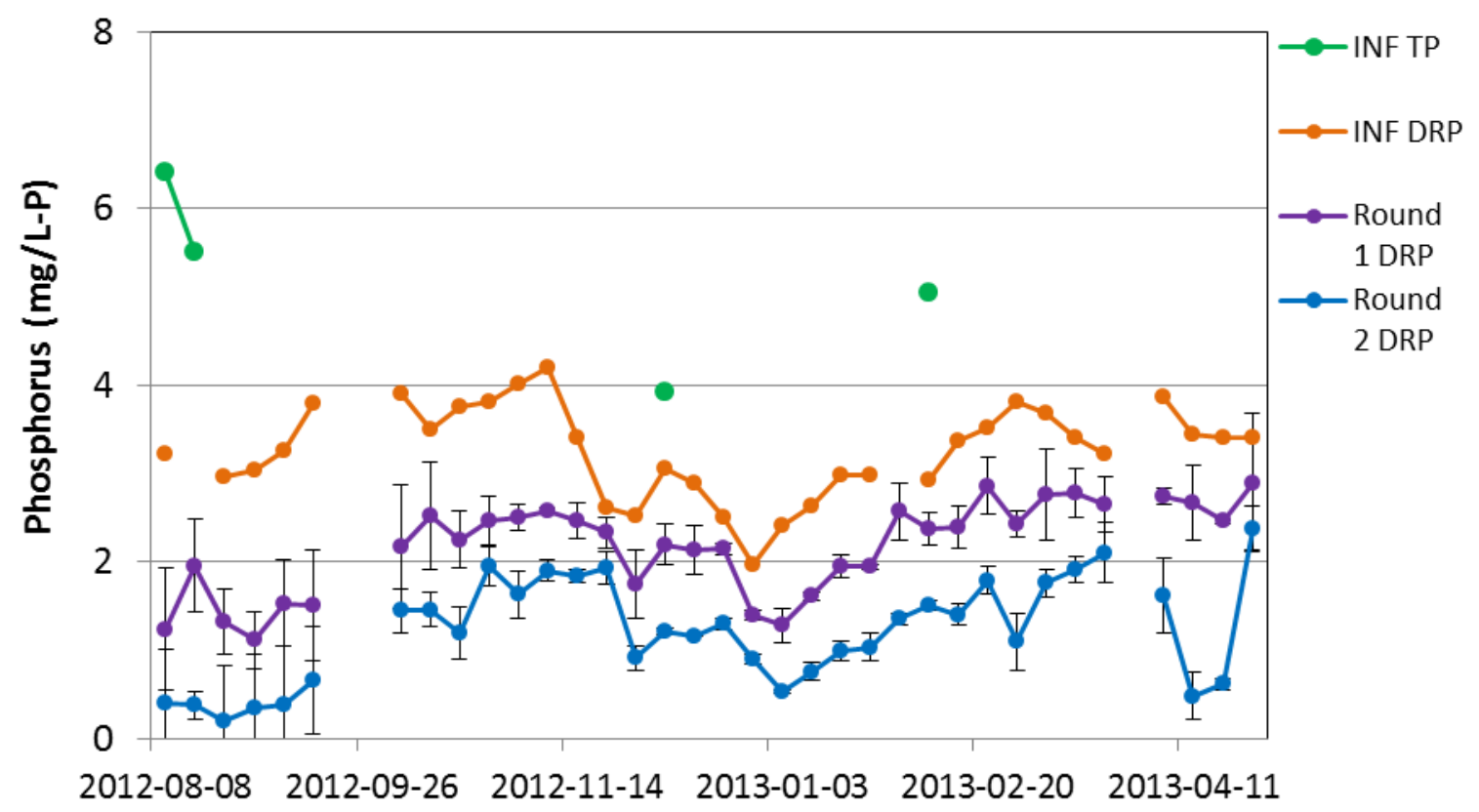

Figure 4.22. Phosphorus concentration time series between influent and ponds in series. Neither Round 1 or Round 2 ponds achieved target concentration of $0.1 \mathrm{mg} / \mathrm{L}-\mathrm{P}$.

Pond 2 eff and Pond 5 eff samples from TP analysis on December 5, 2012 and February 6, 2013 were used to assess achievable treatment levels when utilizing tube settlers for sedimentation. With ponds operated in series, Round 2 TP removal efficiency increased 
by $30-42 \%$ over Round 1 (Figure $4.23 \&$ Figure 4.24). If microfiltration was implemented and particulate phosphorus was completely removed, efficiencies would increase to $72 \%$ and $68 \%$, correspondingly. The removal of DRP during operation of ponds running in series is attributed to phosphorus uptake by the growth of bacteria and microalgae. Particulate phosphorus removal between Influent, P5 eff and P2 eff resulted from degradation of particulate phosphorus compounds or sedimentation of biomass in the tube settlers.

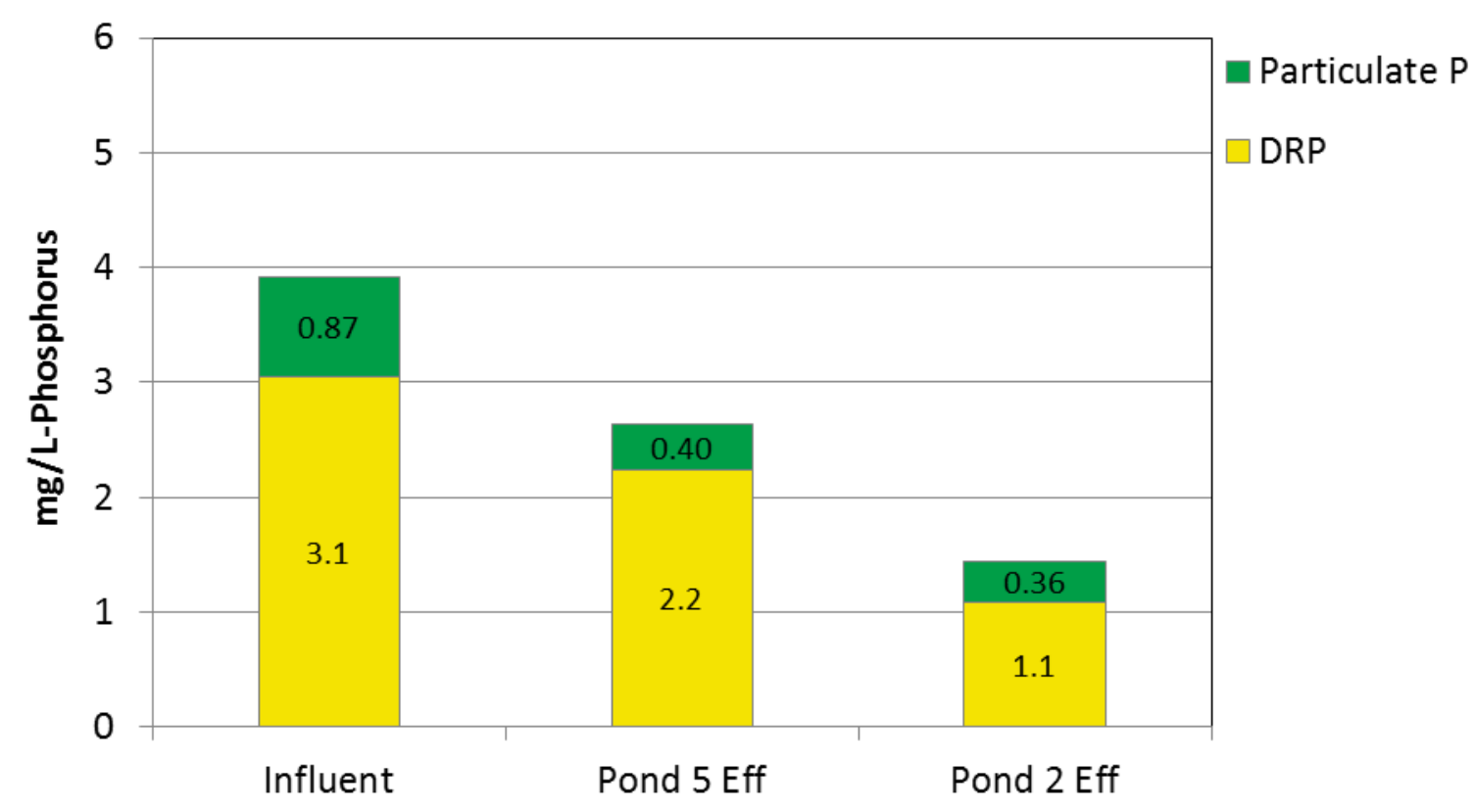

Figure 4.23. Mid-winter total phosphorus balance of tube settler effluent from ponds operating in series. "Pond 5 Eff" represents treatment characteristics of a Round 1 pond and "Pond 2 Eff" represents that of a Round 2 pond. Data set shown was attained from total phosphorus analysis of December 5, 2012 pond samples. Particulate $\mathrm{P}$ was calculated from the difference in TP and DRP. 


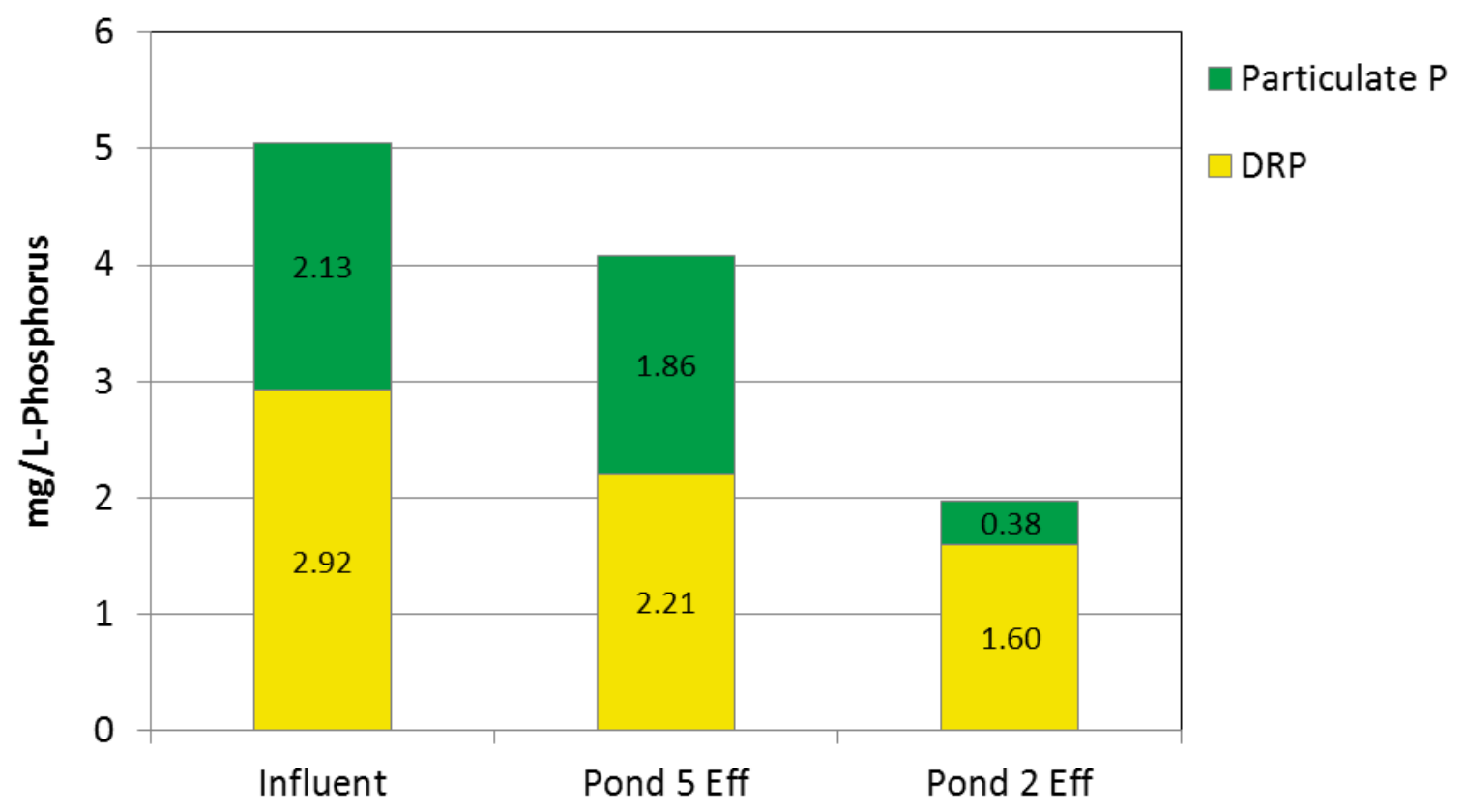

Figure 4.24. Late winter total phosphorus balance of ponds operating in series. "Pond 5 Eff" represents treatment characteristics of a Round 1 pond and "Pond 2 Eff" represents that of a Round 2 pond. Data set shown was attained from total phosphorus analysis of February 6, 2013 pond samples. Particulate P was calculated from the difference in TP and DRP. Compared to December 5 sample date, less DRP was removed from influent TP during colder temperatures in February, 2013.

\subsubsection{BOD Removal}

Round 1 ponds achieved BOD removal efficiencies of $95 \% \pm 2.3 \%$ in both summer and winter (Table 4.9). With an additional four days of treatment in Round 2 ponds, summer and winter BOD removal increased to $97 \%$ in Round 2 ponds. Average Influent BBOD $_{5}$ during summer and winter was measured to be $136 \mathrm{mg} / \mathrm{L} \pm 25 \mathrm{mg} / \mathrm{L}$ and $103 \mathrm{mg} / \mathrm{L} \pm$ 20mg/L, respectively. Round 1 and Round 2 average $\mathrm{scBOD}_{5}$ values remained below $10 \mathrm{mg} / \mathrm{L}$ for the duration of the experiment(Figure 4.25), aside from a spike in $\mathrm{scBOD}_{5}$ in Round 1 ponds on October 17, 2012 (Figure 4.26). This brief decrease in BOD removal efficiency may have resulted from cold air temperatures on October 12 and 13, 2012, during which maximum pond temperatures were limited to $19^{\circ} \mathrm{C}$ in both sets. For 
purposes of secondary treatment, operating ponds in series is unnecessary to attain the standard $40 \mathrm{mg} / \mathrm{L} \mathrm{BOD}_{5}$ discharge limit. In respects to aforementioned tertiary treatment of nitrogen, sufficient oxygen demand must be present to accommodate denitrification mechanisms, therefore biomass recycling or increased BOD addition may be essential to complete nitrate reduction. It is noted that said removal efficiencies are accurate only when considering systems that employ effective sedimentation techniques to separate particulate BOD from soluble BOD.

Table 4.9. BOD removal efficiencies and concentrations of ponds operating in series. Average values were attained from the data series spanning from July 11, 2012 to April 25, 2013.

\begin{tabular}{rcccccc}
\cline { 2 - 6 } & \multicolumn{2}{c}{ Influent } & \multicolumn{2}{c}{ Round 2 } & \multicolumn{2}{c}{ Round 1 } \\
\cline { 2 - 7 } & Summer & Winter & Summer & Winter & Summer & Winter \\
\cline { 2 - 7 } Max TBOD/scBOD $(\mathrm{mg} / \mathrm{L})$ & 177 & 141 & 13 & 10 & 13 & 12 \\
Min TBOD/scBOD $(\mathrm{mg} / \mathrm{L})$ & 82 & 67 & 0.4 & 1.2 & 2.3 & 2.4 \\
Avg TBOD $(\mathrm{mg} / \mathrm{L}) /$ & 136 & 103 & $97 \%$ & $97 \%$ & $95 \%$ & $95 \%$ \\
Avg BOD Removal & & & & & & \\
Standard Deviation & 25 & 20 & $2.2 \%$ & $2.3 \%$ & $2.3 \%$ & $2.3 \%$ \\
\# of samples & 18 & 11 & 41 & 30 & 37 & 32
\end{tabular}




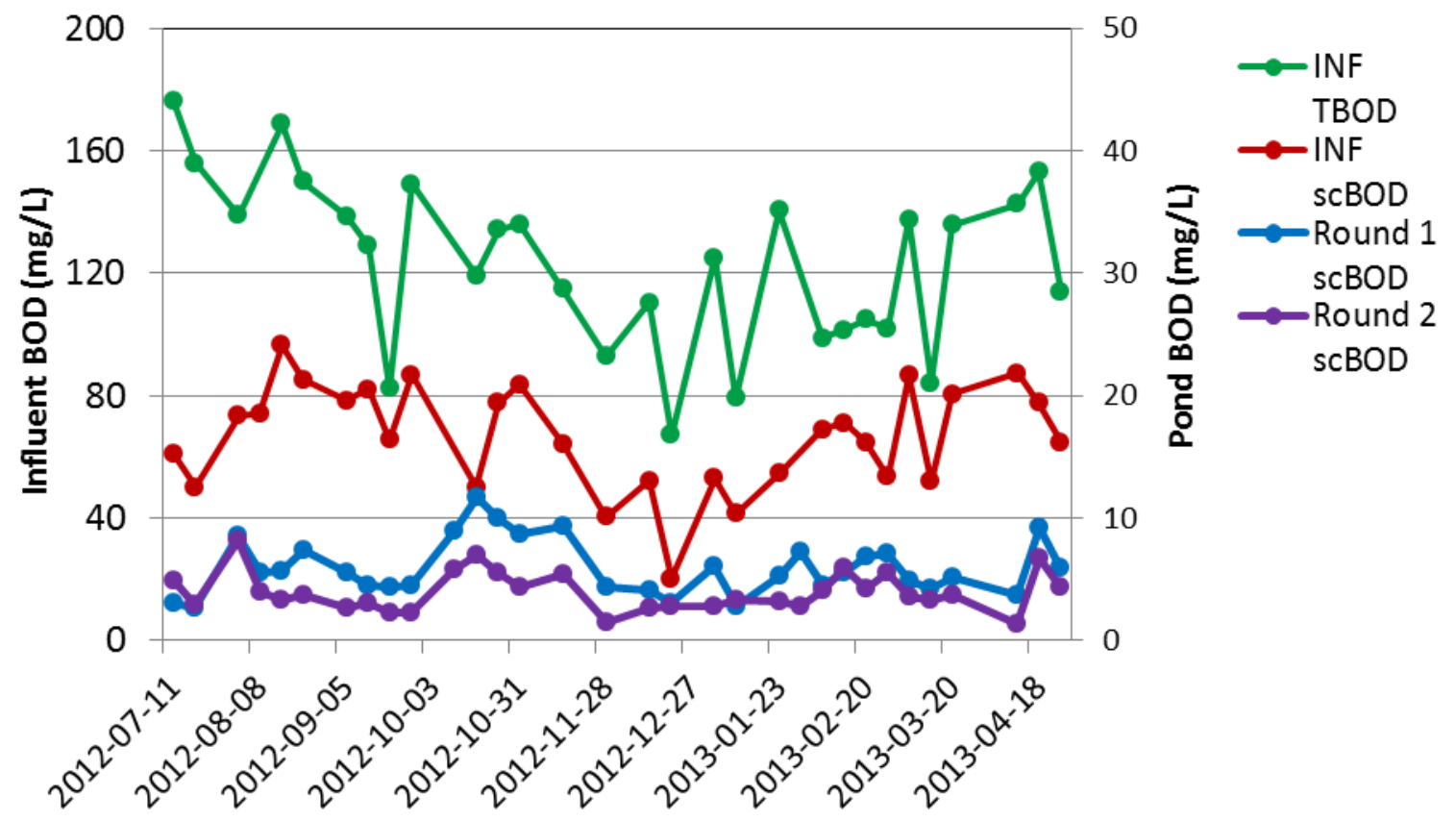

Figure 4.25. Experiment II BOD time series comparing Influent BOD characteristics to pond effluent scBOD. Influent BOD values correspond to primary y-axis on left and pond scBOD corresponds to secondary $y$-axis on the right. Gaps in data series, resulting from blank values in data set source, were connected under the condition that interpolation was representative of actual values.

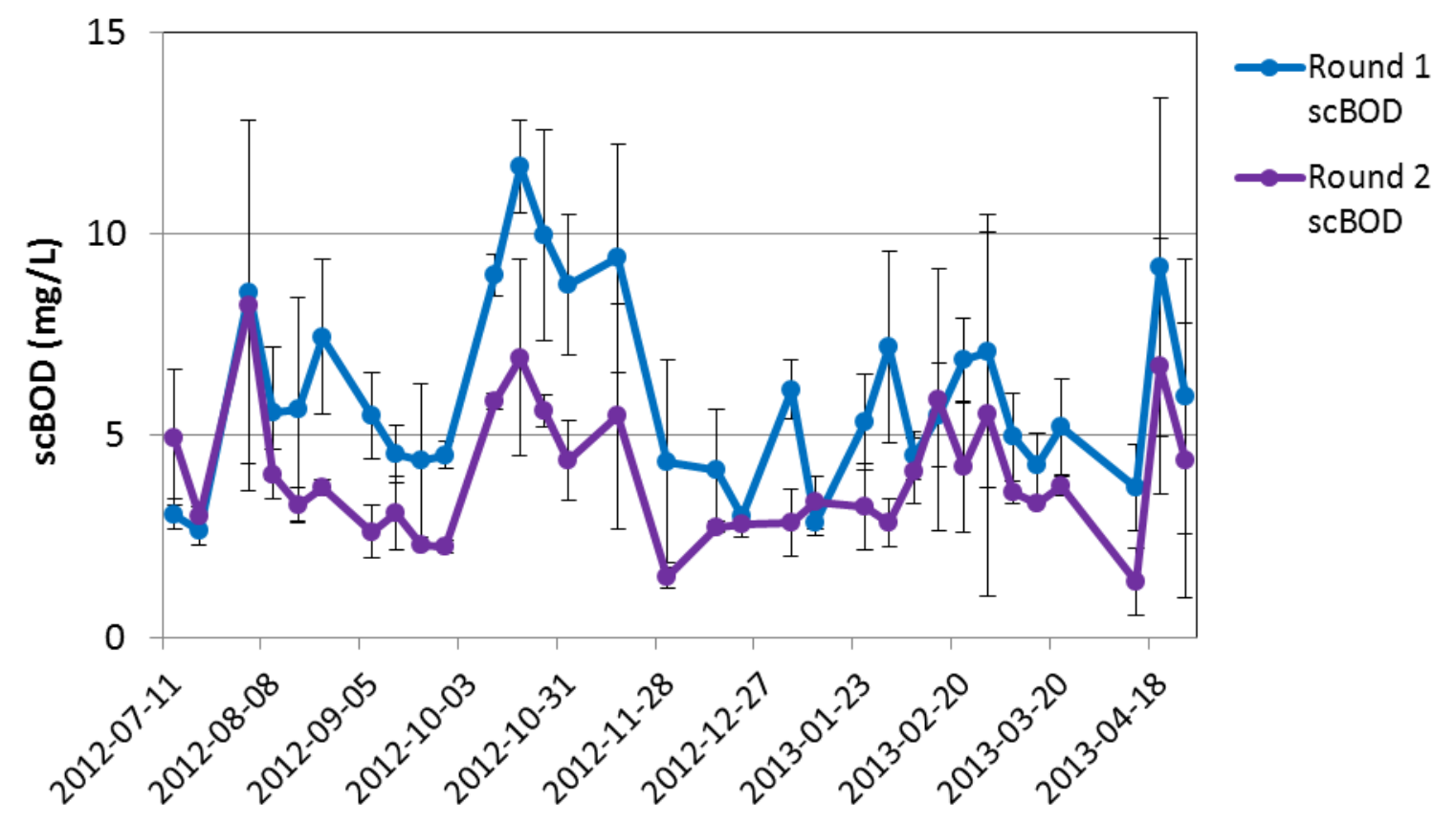

Figure 4.26. Time series comparison of $\mathrm{scBOD}_{5}$ concentrations between Round 1 and Round 2 . Gaps in data series were interpolated only in the instances which time series changes would not be misrepresented. 


\subsection{Experiment III: Aeration of 2-day HRT Ponds}

Experiment III began after environmental conditions during winter months reduced nitrogen removal resulting from colder pond temperatures and less active biological nitrification. Blowers supplied Pond 7 and 9 with oxygen during the night when natural oxygenation was low. To increase the low nighttime DO levels produced from a single blower, a second blower was added to each pond on December 10, 2010. Henceforth, data series may be presented as the "Control Pond" for Pond 8 and as the "Experimental Ponds" for Pond 7 and 9. Analysis for the experiment is divided into three periods: (1) “Before aeration" from October 17, 2012 to November 28, 2012, (2) "During aeration" from December 5, 2012 to February 13, 2013 and (3) “After aeration” from February 20, 2013 to March 6, 2013.

\subsubsection{DO Variation Throughout Pond}

DO levels throughout the ponds were assumed to be accurately represented by measurements attained from DO probes installed near probe stands. To confirm this assumption, the YSI Pro 20 handheld DO probe was used to measure the DO (\% saturation) in Pond 1 at ten different locations throughout the pond channel (Figure 4.27). Measurements were taken immediately before sunup in a span of ten minutes to assure variability was minimized from rapid DO increase resulting from photosynthetic oxygenation. At the time initial reading was taken, the Neptune System used to collect daily field data displayed a DO of $77 \%$ saturation in Pond 1. Measurements throughout the pond varied less than $5 \%$, thereby confirming the initial assumption. 


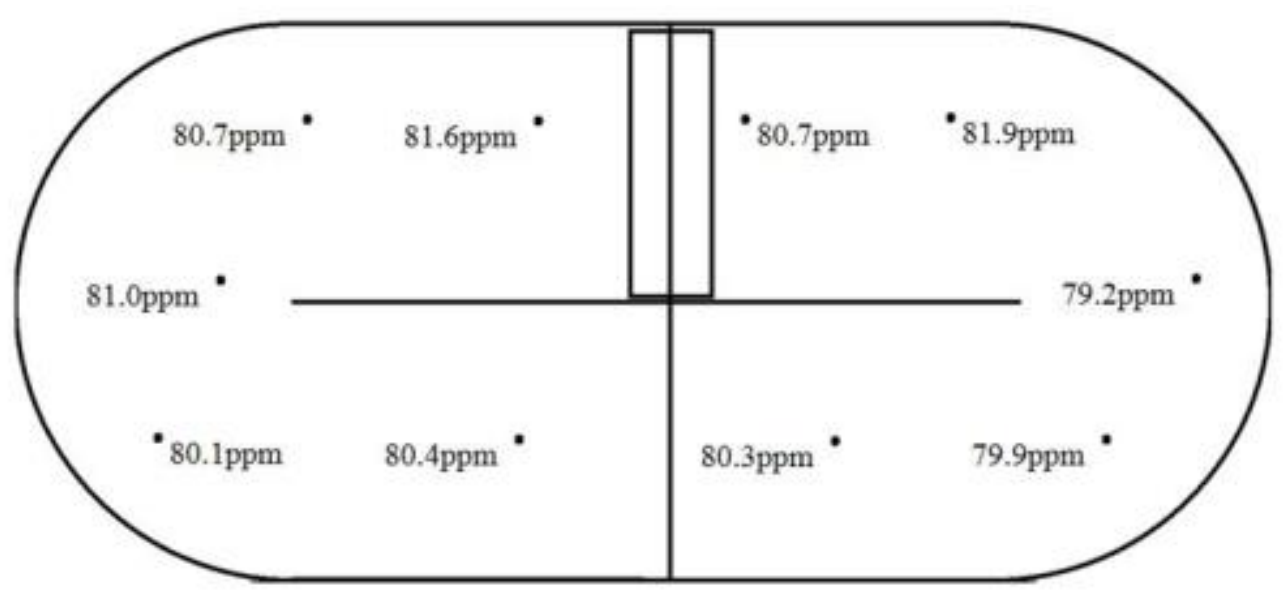

Figure 4.27. Diagram of DO concentration variance throughout Pond 1. Values were attained from portable DO meter immediately before sunup. Maximum difference in values is $3 \%$, thus confirming assumption of homogenous DO concentrations throughout pond channels and turnarounds.

\subsection{2 $\mathrm{pH}$, Temperature and $\mathrm{DO}$}

Aeration during the sundown hours kept Pond 7 and Pond 9 DO levels above 0\% saturation for a majority of the aeration period. Pond 8 , although without aeration, remained above 0\% saturation for a majority of December 2012 and January 2013 (Figure 4.28). Low Influent ammonia levels during December 2012, coupled with decreased algal productivity during winter months, reduced the amount of oxygen consumption required for ammonia oxidation and algal respiration. Additionally, a rainstorm in late December accompanied by daytime air temperature highs around $10^{\circ} \mathrm{C}$, led to minimum pond temperatures of less than $11^{\circ} \mathrm{C}$, resulting in elevated nighttime DO concentration. Throughout experimentation, the difference in minimum DO saturation between the experimental ponds may be attributed to the increased VSS concentration in Pond 9, resulting in more oxygen demand for algal respiration. Maximum DO saturation between control and experimental ponds remained similar during aeration periods with a brief spike in Pond 7 maximum DO as a result of aforementioned rainstorm and cold temperatures in December (Figure 4.29). 


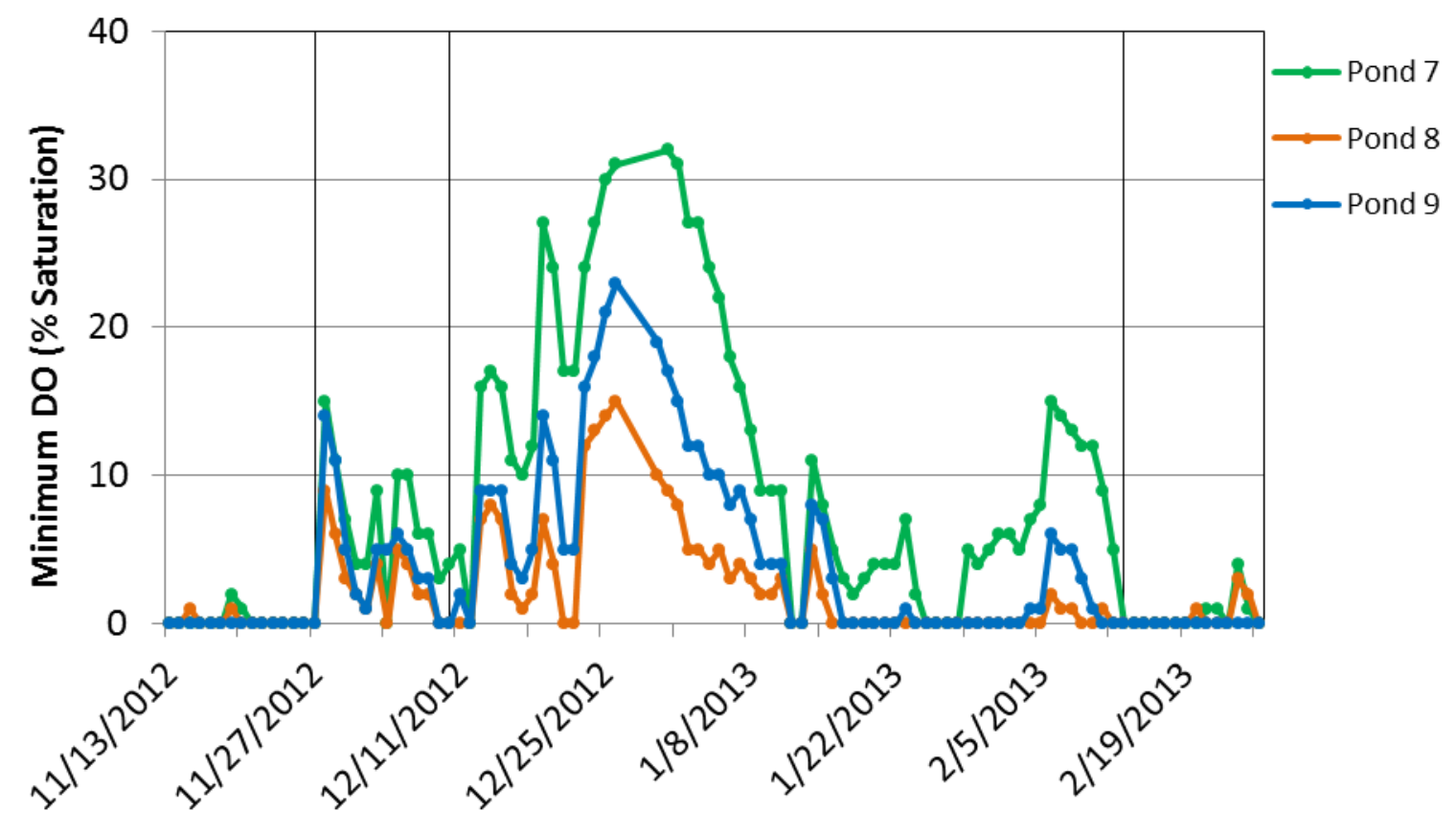

Figure 4.28. Minimum DO (\% saturation) in Gamma ponds during aeration experiment. Use of one blower in experimental ponds occurred between time series denoted by first and second vertical lines. Use of two blowers for aeration is denoted by second and third vertical line. Pond 8 remained without aeration during period of experimentation. Aeration was turned off upon conclusion of experiment on February 13, 2013, as denoted by third vertical line.

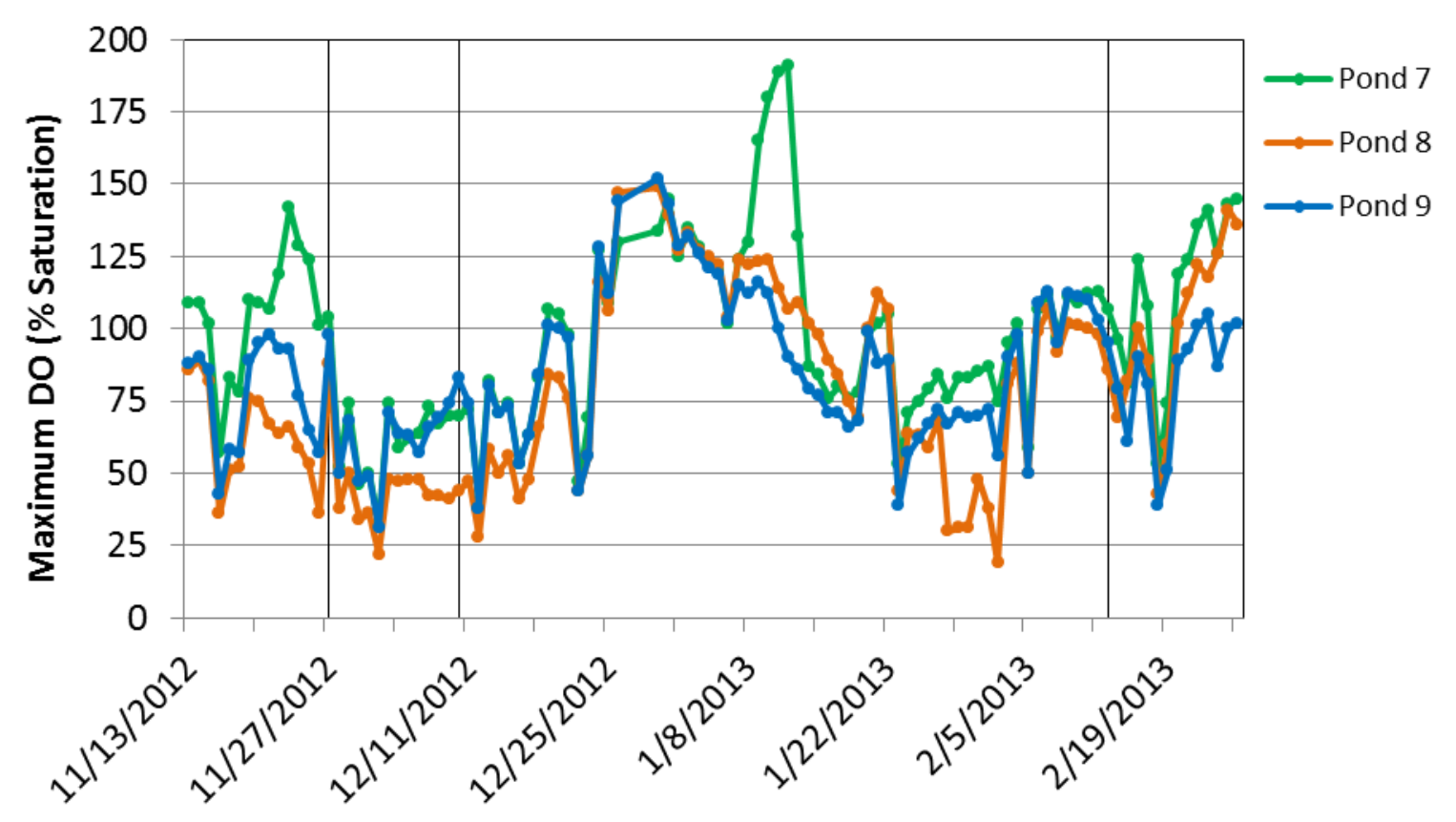

Figure 4.29. Maximum DO (\% saturation) in Gamma ponds during aeration experiment. The vertical lines represent, from left to right, the installation of one blower, implementation of a second blower and the conclusion of Experiment III. 
Daily temperatures between ponds within the same triplicate contained trivial variability, therefore maximums and minimums within a set are used instead of maximums and minimums for individual ponds. Before addition of the second aerator in the experimental ponds, average pond temperatures in the Gamma set remained consistently above $15^{\circ} \mathrm{C}$, but dropped below $15^{\circ} \mathrm{C}$ after December 12, 2012 until January 22, 2013 (Figure 4.30). DO concentrations heightened in winter when low pond temperatures were measured, as expected with increased oxygen solubility in colder temperature water bodies. Temperature and $\mathrm{pH}$ were well below levels that would allow ammonia volatilization, thus establishing assimilation and nitrification as primary mechanisms of ammonia removal.

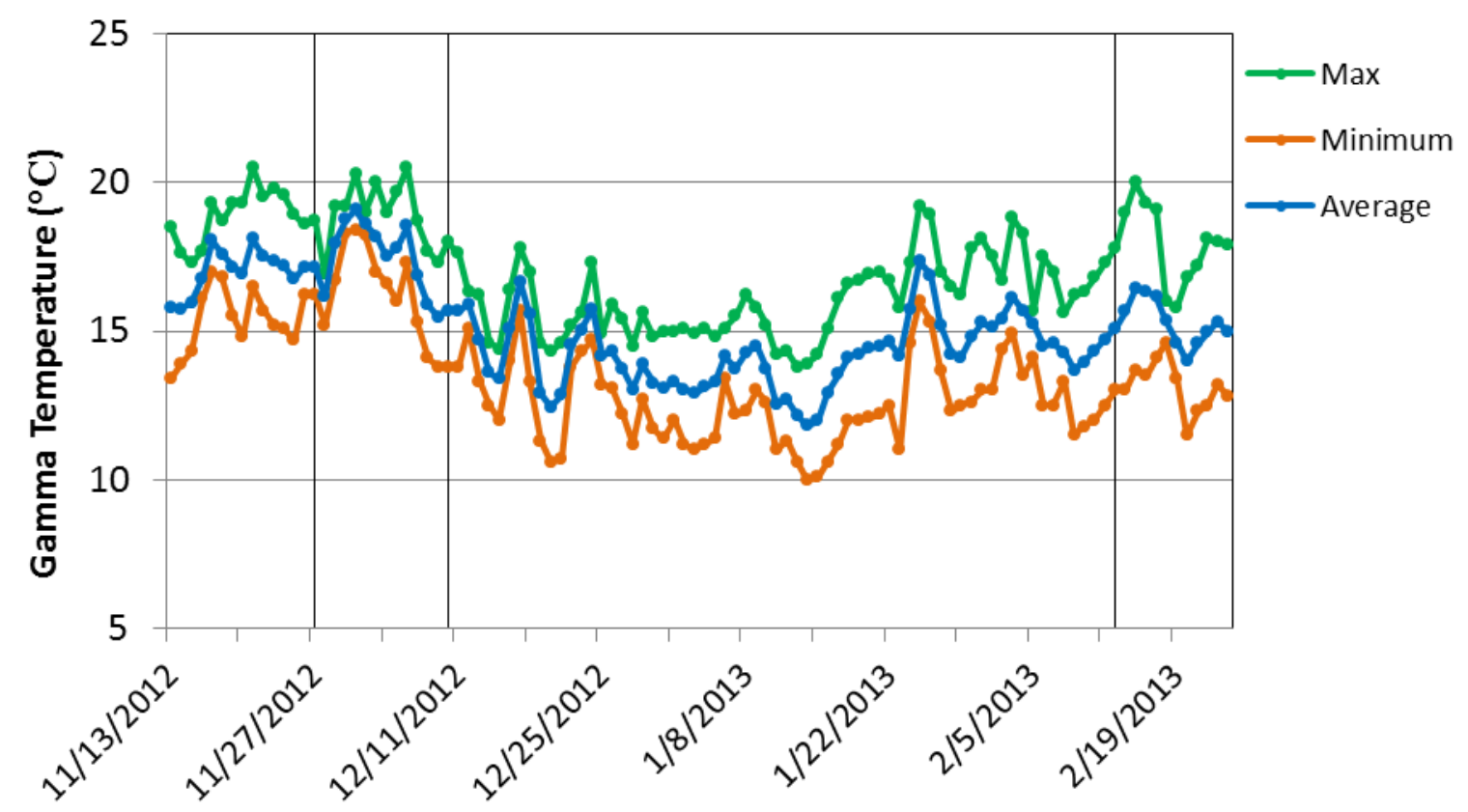

Figure 4.30. Temperature in Gamma ponds during Experiment III. Average values between ponds operating at similar HRTs is negligible, therefore no standard deviation was applied to the data series. 


\subsubsection{Nitrogen Removal}

Before aeration began, TAN removal efficiency ranged from 38\%-91\% in the experimental ponds and 47\%-78\% in the control pond. During aeration, TAN removal efficiency ranged from $42 \%-98 \%$ in the experimental ponds and $24 \%-95 \%$ in the pond without aeration (Table 4.10). Influent ammonia concentrations of $40 \mathrm{mg} / \mathrm{L}-\mathrm{N}$ or above were measured before and during aeration, as a result, TAN removal efficiencies were significantly reduced. Influent TAN significantly decreased after the December 12, 2012 sample date as winter break began for local colleges, which reduces San Luis Obispo's population by roughly $30 \%$. This reduction is typically observed by SLOWRF operators and an increase normally occurs after the first day of the calendar year, as seen in Figure 4.31. More importantly, 5.7" of precipitation in the month of December, 2012 diluted influent wastewater, thereby contributing to reduced measured TAN concentrations. Low pond effluent TAN concentrations were measured in December 2012 during periods of low Influent ammonia loading and dilution from rain events, in which all three ponds operating at 2-day HRTs achieved 95\% removal or greater (Figure 4.31). Although TAN concentrations between aerated and non-aerated ponds appear to follow similar time series patterns, TAN removal was greater in the experimental ponds by $15 \%$ during aeration.

Following aeration, maximum DO fell below 50\% saturation, causing a significant decrease in TAN removal efficiency in all three ponds (Figure 4.32). The DO concentration reduction after aeration corresponded to average Gamma pond temperatures above $14^{\circ} \mathrm{C}$ after cold air temperatures were prevalent in the beginning of February. Despite the temperature increase, which is expected to increase microbial 
metabolism and subsequent ammonia oxidation, less DO was available for the oxidation reaction, prohibiting sufficient TAN removal. Additionally, aerobic organisms in the experimental ponds, which may have become more predominant than facultative microbes during aeration, would have become inefficient in ammonia oxidation at night once aeration was stopped.

Table 4.10. Aeration effects on TAN removal efficiency and concentrations between experimental and control ponds. Data attributed to the "Before Aeration" column began on October 7, 2012 and included data points on November 28, 2012. "After Aeration" includes all data between the dates of February 20, 2013 and March 6, 2013.

\begin{tabular}{cccccc}
\hline \multicolumn{3}{c}{ Control Pond } & \multicolumn{3}{c}{ Experimental Ponds } \\
\hline $\begin{array}{c}\text { Before } \\
\text { Aeration }\end{array}$ & $\begin{array}{c}\text { During } \\
\text { Aeration }\end{array}$ & $\begin{array}{c}\text { After } \\
\text { Aeration }\end{array}$ & $\begin{array}{c}\text { Before } \\
\text { Aeration }\end{array}$ & $\begin{array}{c}\text { During } \\
\text { Aeration }\end{array}$ & $\begin{array}{c}\text { After } \\
\text { Aeration }\end{array}$ \\
\hline \hline 24 & 32 & 28 & 29 & 26 & 23 \\
6.6 & 0.9 & 21 & 2.8 & 0.4 & 14 \\
$57 \%$ & $56 \%$ & $26 \%$ & $59 \%$ & $71 \%$ & $46 \%$ \\
$12 \%$ & $22 \%$ & $12 \%$ & $15 \%$ & $17 \%$ & $14 \%$ \\
7 & 9 & 3 & 14 & 20 & 6
\end{tabular}




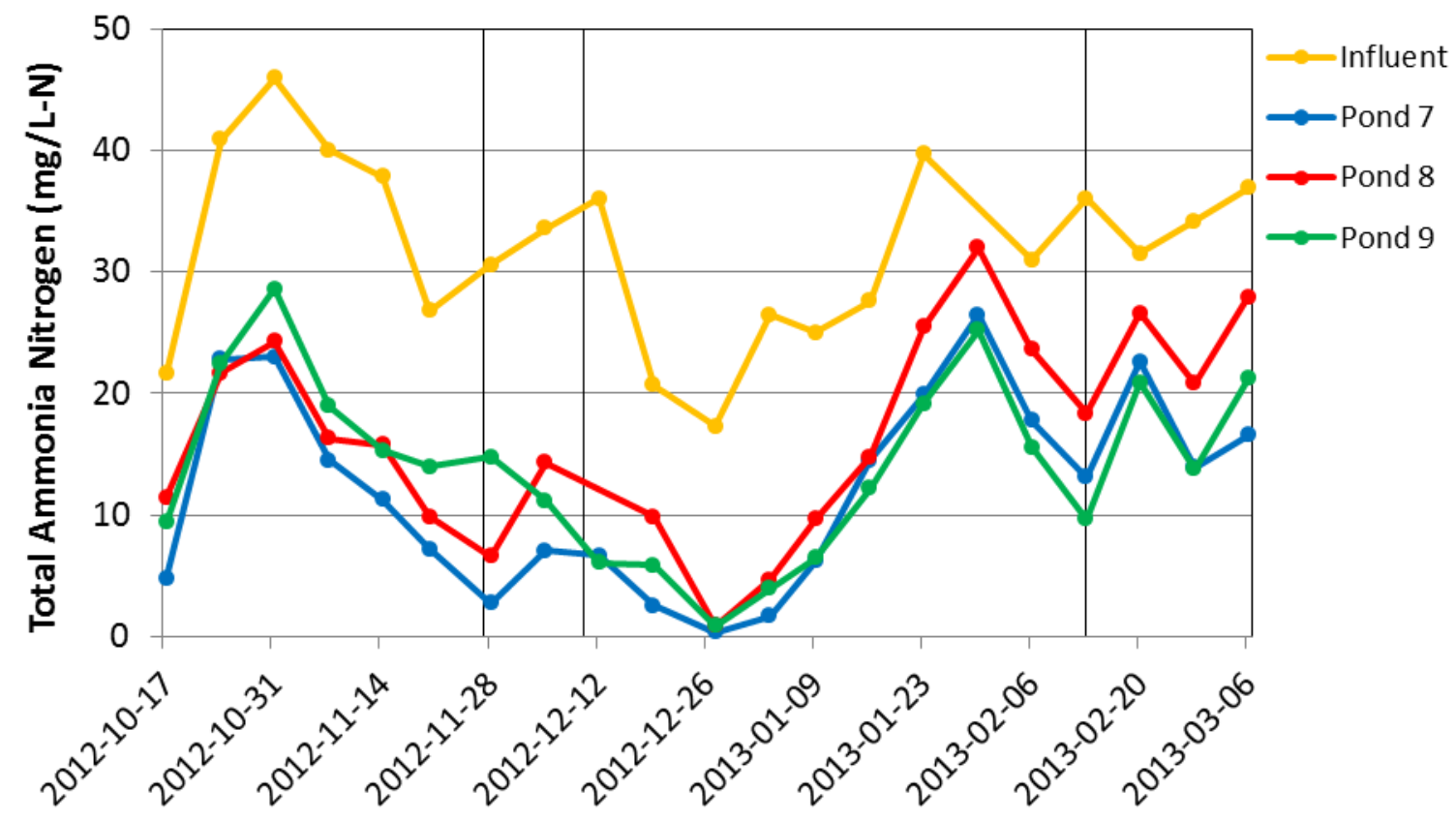

Figure 4.31. TAN concentrations in the Influent and Gamma ponds presented as time series. Aeration periods using one and two blowers is denote by the two $\mathrm{x}$-axis ranges represented by areas between vertical lines.

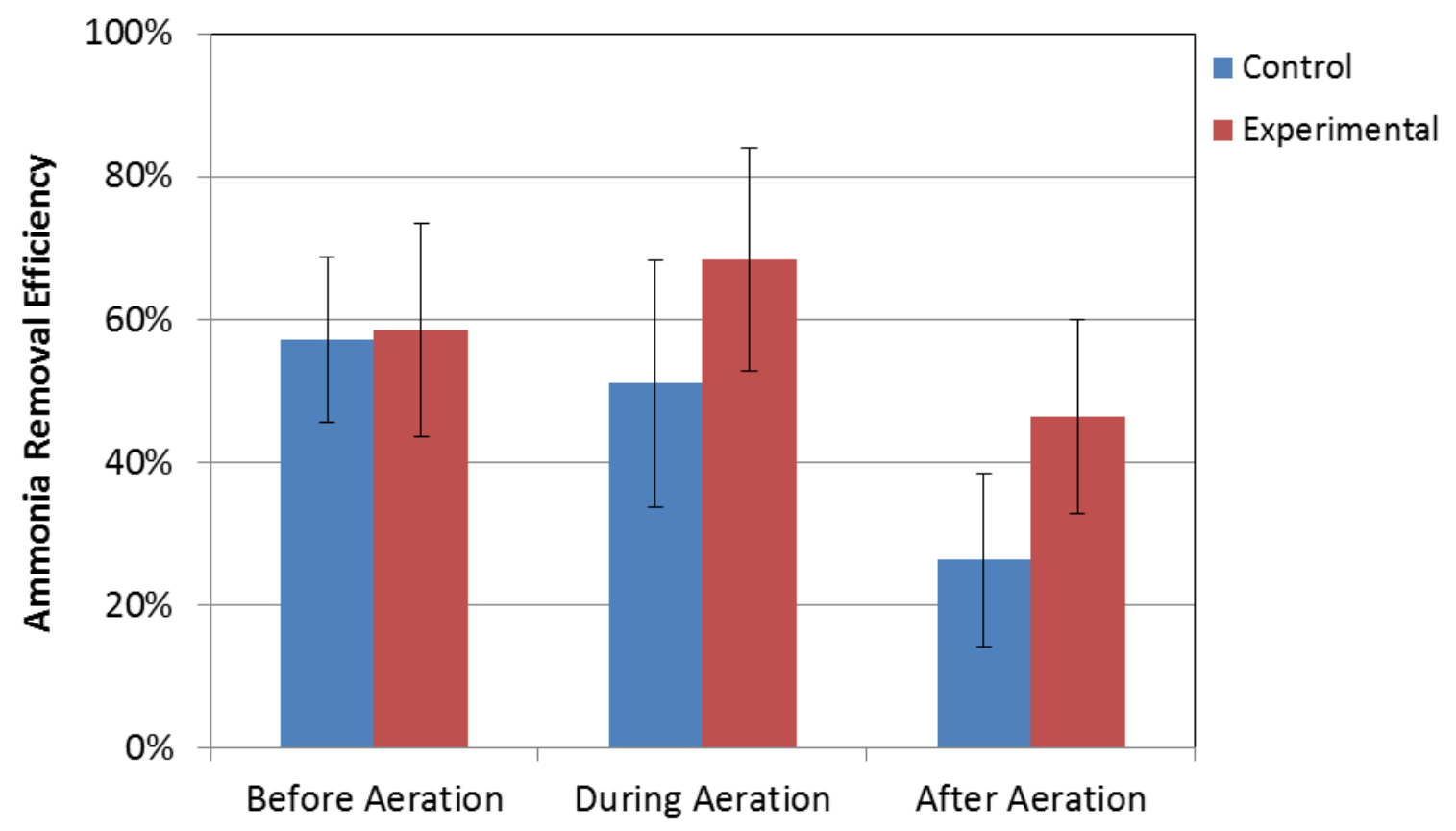

Figure 4.32. Graphical representation of TAN removal efficiencies during Experiment III. Data used for generation of bar graph was taken from the data outlined in Table 4.10.

As recently stated, the changes in TAN concentration were similar between Ponds 7, 8 and 9, with slightly less TAN during and after aeration in the experimental ponds. When 
aerated, nitrate concentrations in Ponds 7 and 9 peaked at $18.4 \mathrm{mg} / \mathrm{L}-\mathrm{N}$ and $15.3 \mathrm{mg} / \mathrm{L}-\mathrm{N}$, respectively (Figure $4.33 \&$ Figure 4.35 ). In the control pond, the maximum nitrate concentration measured was 13.4mg/L-N on December 27, 2012 (Figure 4.34). After the beginning of the 2013 calendar year, increased Influent ammonia concentration and low DO concentrations resulted in elevated TAN concentrations among all 2-day ponds, comparable to TAN levels before aeration began. In the remainder of the aeration period, nitrite increased to levels above $12 \mathrm{mg} / \mathrm{L}-\mathrm{N}$ in Ponds 7 and 9, but consistently remained below 5mg/L-N in Pond 8. A significant decrease in DO was observed in mid-February 2013, corresponding to nitrite and nitrate concentrations less than 5mg/L-N in Ponds 7, 8 and 9 .

Aeration improved nitrification into nitrate species, but was ineffective in nitrogen conversion through cold weather and high influent TAN concentrations during February 2013. Low DO concentrations within experimental ponds led to high nitrite concentration, as a result of incomplete nitrification. Uncontrollable variables, toxicants and inconsistencies of Influent wastewater constituents not measured in the present study, may also contribute to nitrite accumulation. In the control pond, denitrification did not occur at night when low DO concentrations were measured. Furthermore, limited BOD loading at night, characteristic of diel variations for domestic wastewater flows, may have prevented reduction of nitrate. During winter, 2-day HRT ponds were unable to achieve soluble nitrogen species concentrations of $10 \mathrm{mg} / \mathrm{L}-\mathrm{N}$. In conclusion, tertiary treatment using an HRAP at a 2-day HRT is impractical, even in cases for which ponds receive supplemental oxygen during hours of low DO concentrations. Further investigation of aforementioned composite sampling, and its effects on nitrogen conversion once samples 
are drawn, would be beneficial in evaluating aeration effects on nitrogen removal mechanisms in low-HRT ponds.

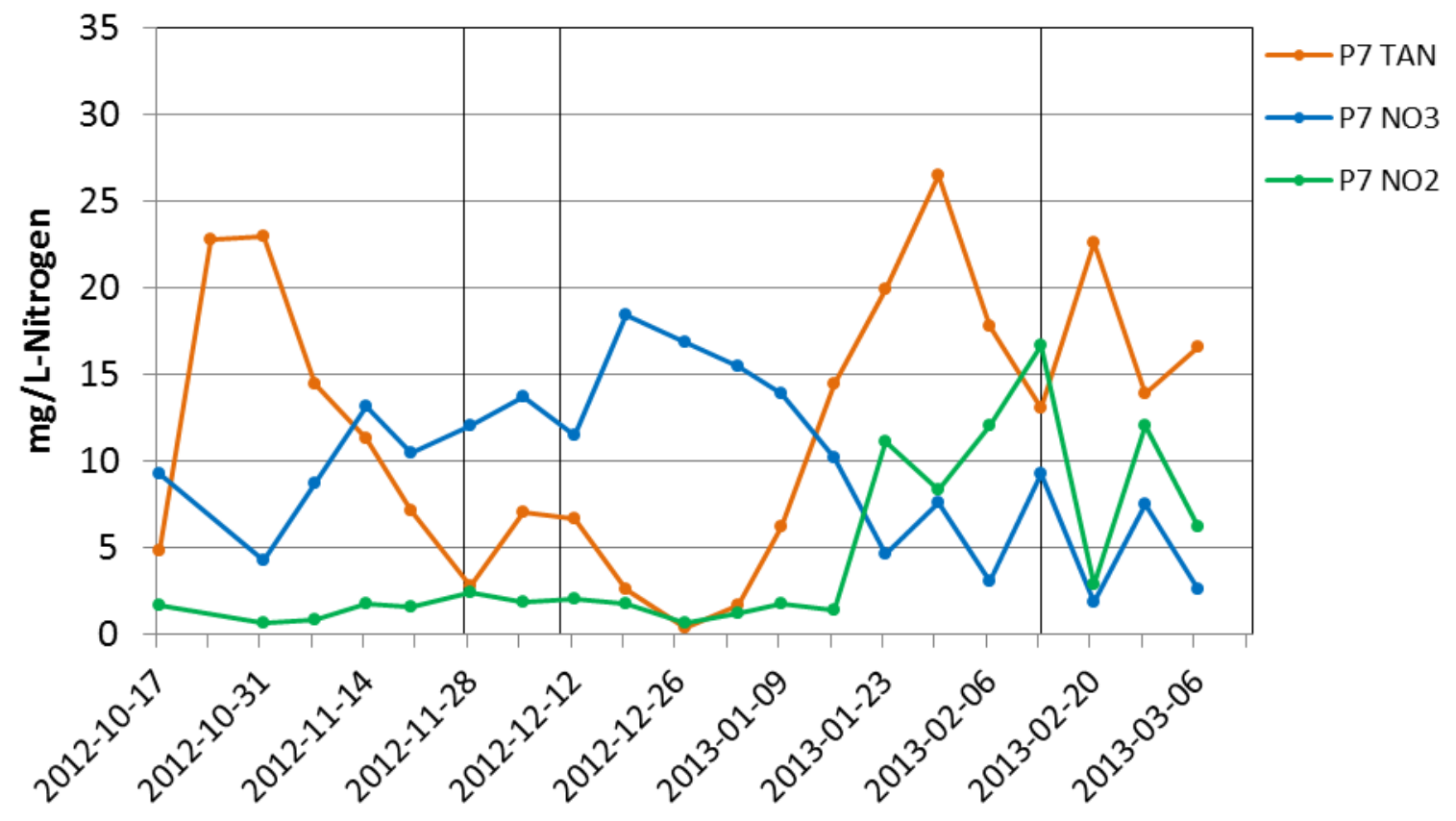

Figure 4.33. Pond 7 soluble nitrogen concentrations during Experiment III.

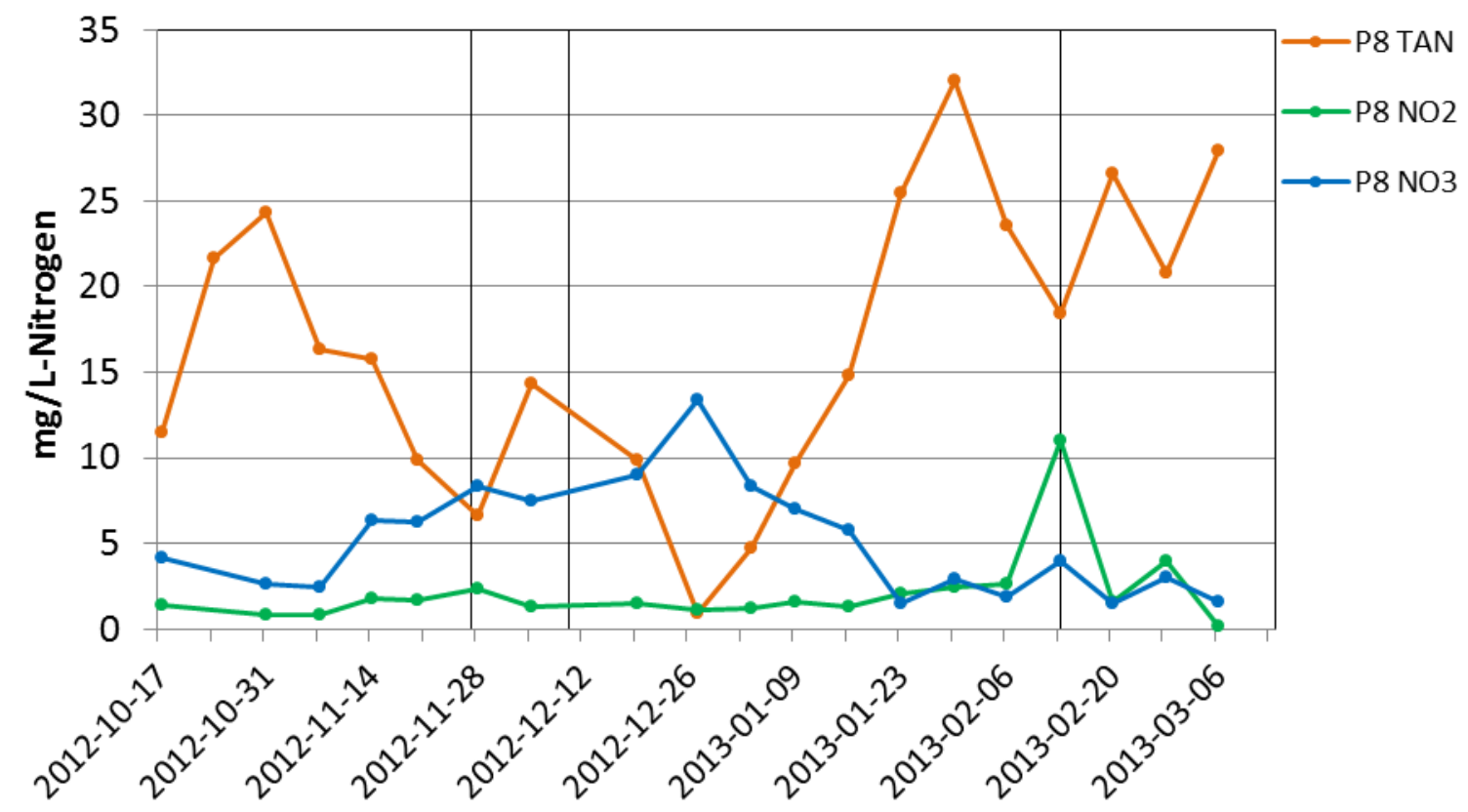

Figure 4.34. Control pond soluble nitrogen concentrations during Experiment III. 


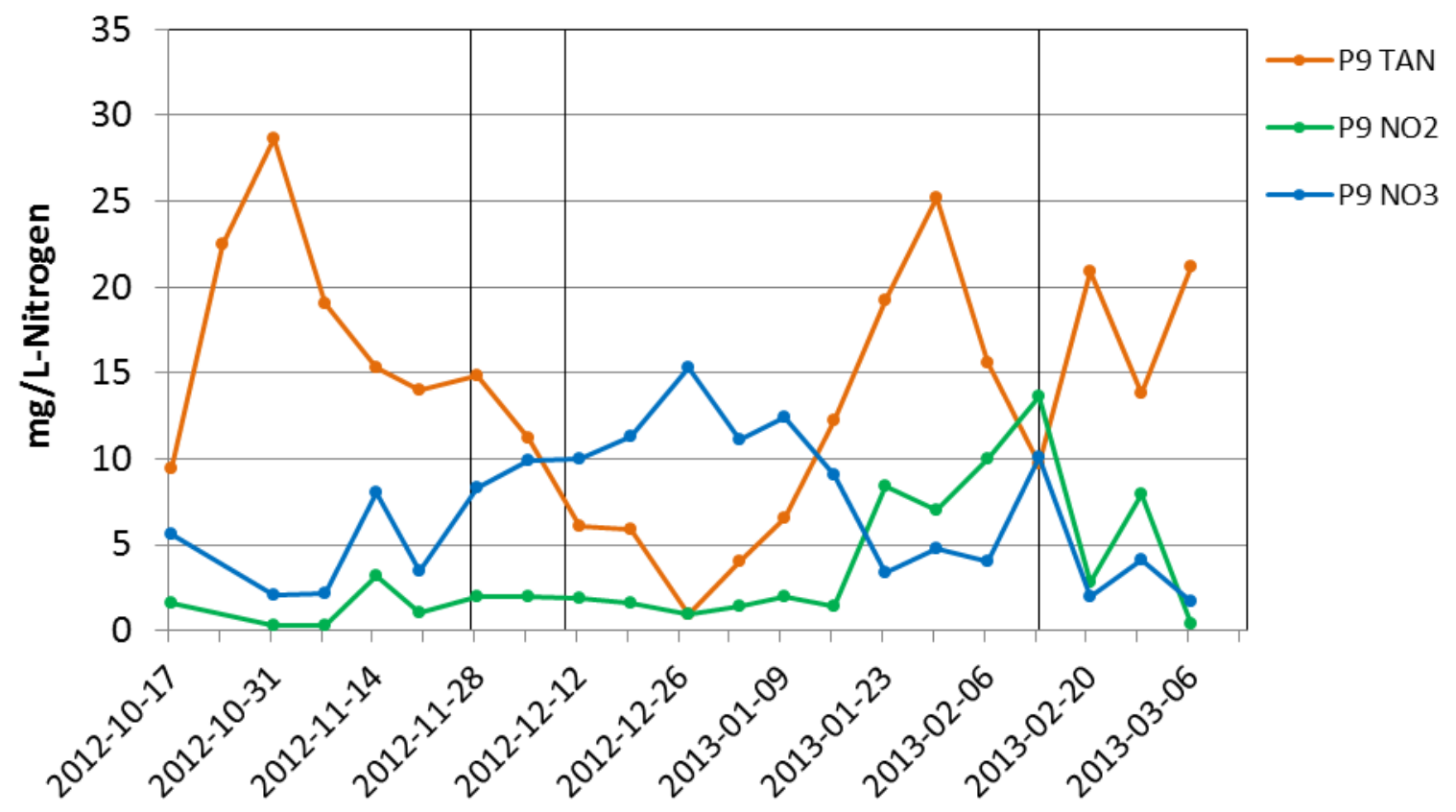

Figure 4.35. Pond 9 soluble nitrogen concentrations during Experiment III. 


\subsubsection{BOD Removal}

BOD removal slightly improved in both the control pond and experimental ponds after aeration began. Pond 8's BOD removal efficiency increased from $92 \%$ to $96 \%$ while BOD removal in the experimental ponds increased from 93\% to 95\% (Table 4.11). Minimum scBOD concentrations fell below $3 \mathrm{mg} / \mathrm{L}$ in non-aerated and aerated ponds on December 19, 2012 at the onset of aforementioned rainstorm. In regards to typical wastewater treatment discharge standards, removal of BOD was adequate in all three 2day HRT ponds. With an average winter Influent $\mathrm{TBOD}_{5}$ concentration of $104 \mathrm{mg} / \mathrm{L} \pm$ $20 \mathrm{mg} / \mathrm{L}$, all ponds maintained $\mathrm{scBOD}_{5}$ concentrations less than $40 \mathrm{mg} / \mathrm{L}$ throughout winter (Figure 4.36). With no correlation between aeration and BOD removal in winter, it is concluded that secondary treatment of domestic wastewater may be completed in 2day HRT ponds without aeration.

Table 4.11. Secondary treatment results of aeration experiment. Maximum and minimum influent $\mathrm{TBOD}_{5}$ concentrations during study were $140 \mathrm{mg} / \mathrm{L}$ and $67 \mathrm{mg} / \mathrm{L}$, respectively.

\begin{tabular}{ccccccc}
\cline { 2 - 6 } & \multicolumn{3}{c}{ Control Pond } & \multicolumn{3}{c}{ Experimental Ponds } \\
\cline { 2 - 7 } & $\begin{array}{c}\text { Before } \\
\text { Aeration }\end{array}$ & $\begin{array}{c}\text { During } \\
\text { Aeration }\end{array}$ & $\begin{array}{c}\text { After } \\
\text { Aeration }\end{array}$ & $\begin{array}{c}\text { Before } \\
\text { Aeration }\end{array}$ & $\begin{array}{c}\text { During } \\
\text { Aeration }\end{array}$ & $\begin{array}{c}\text { After } \\
\text { Aeration }\end{array}$ \\
\cline { 2 - 7 } Max scBOD (mg/L) & 16 & 6 & 7.3 & 12 & 10 & 12 \\
Min scBOD (mg/L) & 2.4 & 2.7 & 4.8 & 2.4 & 2.9 & 4.0 \\
Avg \%BOD Removal & $92 \%$ & $96 \%$ & $95 \%$ & $93 \%$ & $95 \%$ & $93 \%$ \\
Standard Deviation & $3.6 \%$ & $0.5 \%$ & $0.7 \%$ & $2.8 \%$ & $1.3 \%$ & $3.8 \%$ \\
\# of samples & 5 & 6 & 3 & 9 & 14 & 6
\end{tabular}




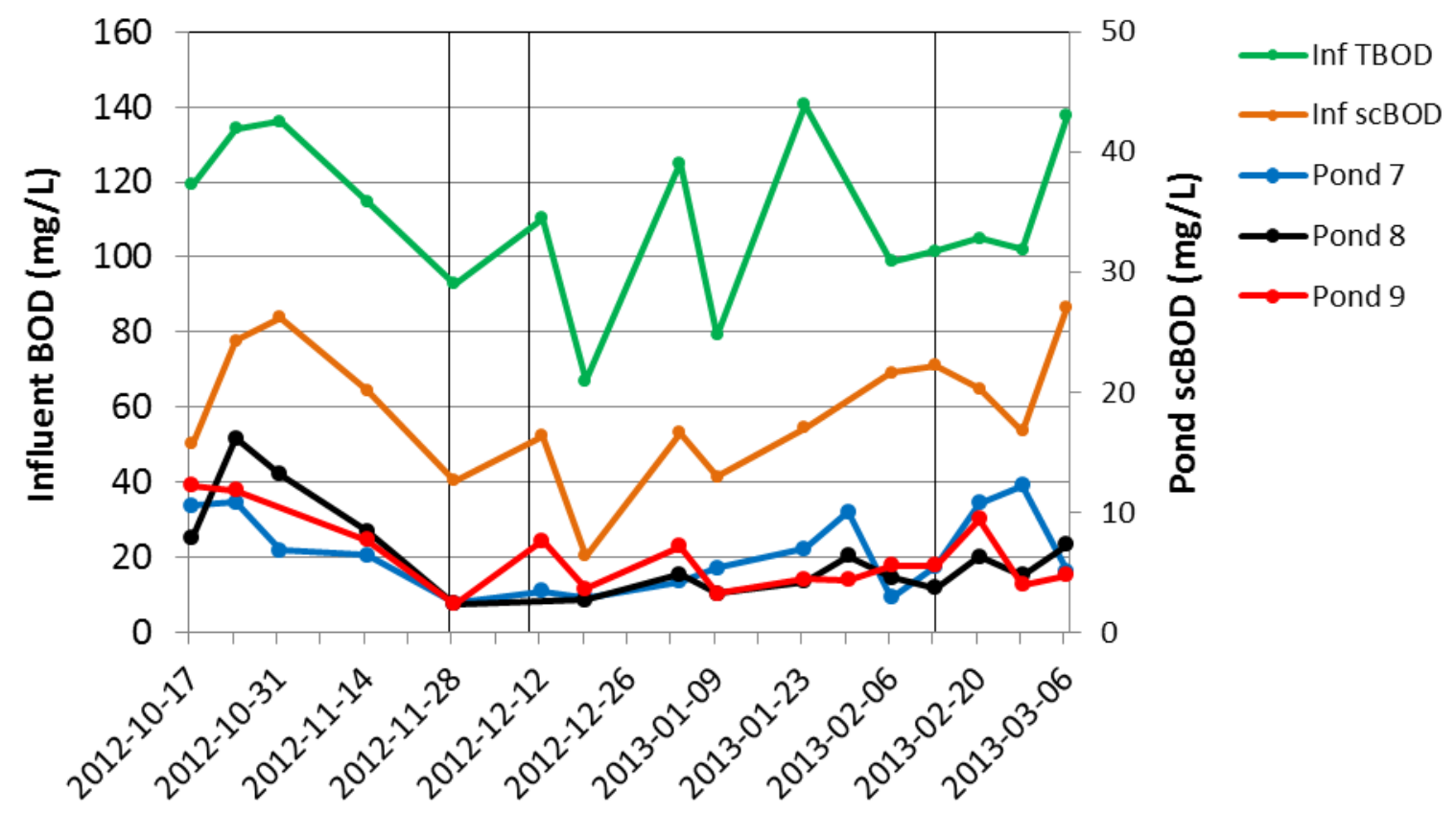

Figure 4.36. Gamma scBOD $\mathrm{B}_{5}$ time series during aeration experiment. Influent BOD concentrations correspond to primary y-axis on the left. Pond BOD values correspond to the secondary $y$-axis on the right. During date range displayed on $\mathrm{x}$-axis, BOD was not measured on five of the sample dates. Resulting gaps in time series were interpolated. 


\section{Conclusions}

The final chapter of this thesis summarizes significant findings and limitations of the research. The main objective of this study was to evaluate nutrient removal in wastewater-fed HRAPs as a potential energy efficient alternative to conventional secondary and tertiary treatment systems. Experiments performed during the period of study and their respective goals are as follows:

1. Experiment I documented seasonal treatment performance by HRAPs operated at two different HRTs and loading rates. Two sets of triplicates HRAPs operated at HRTs of 3days (Beta set) and 2-days (Gamma set), throughout a 12-month period from April 25, 2012 to April 25, 2013. BOD, nitrogen, and phosphorus transformations and removals were monitored. Ponds operating at 3-d HRT were expected to achieve greater nutrient removal than ponds operating at 2-d HRTs, while both sets were anticipated to sustain $\mathrm{scBOD}_{5}$ concentrations of $<40 \mathrm{mg} / \mathrm{L}$, which is a common total $\mathrm{BOD}_{5}$ discharge standard in California. During winter, lower assimilation of nitrogen and phosphorus was anticipated as a result of low algal productivity. Lastly, pond characteristics such as $\mathrm{pH}$, DO, and temperature were recorded to aid in analysis of nutrient removal mechanisms.

2. Experiment II tested the ability of ponds-in-series to achieve low total nitrogen levels. Ponds were operated in series from June 1, 2012 to April 25, 2013 with triplicate 3-day HRT ponds (Round 1) followed by triplicate 4-day HRT ponds (Round 2) supplemented with $\mathrm{CO}_{2}$. The focus of the experiment was to attain total soluble nitrogen concentrations of $10 \mathrm{mg} / \mathrm{L}-\mathrm{N}$ throughout winter. With a total HRT of 7 days, TAN removal efficiencies of $95 \%$ or greater were expected in Alpha pond effluent during both winter and summer. 
3. Experiment III was conducted to determine effects of nighttime aeration on nitrogen and BOD removal in 2-day HRT ponds. The key hypothesis was that aeration at night would counter microbial respiration keeping DO concentration high enough to sustain nitrification and improve TAN removal efficiencies. The control pond, without aeration, was expected to remove any nitrate via denitrification due to low DO concentrations at night. Assuming complete removal of particulate $\mathrm{BOD}$, attainment of $\mathrm{scBOD}_{5}$ concentrations below $40 \mathrm{mg} / \mathrm{L}$ would confirm secondary treatment capability, while a total soluble nitrogen concentration of less than $10 \mathrm{mg} / \mathrm{L}-\mathrm{N}$ would show tertiary treatment.

\subsection{Experimental Conclusions}

The conclusions drawn from the above experiments and a summary of results are provided in the following sections.

\subsubsection{Experiment I: Varying HRT}

During summer, HRAPs operating at 3-day and 2- day HRTs removed an average of 90\% and 78\% of Influent TAN, respectively, with corresponding standard deviations of 7\% and $17 \%$. In winter, TAN removal efficiency in the 3-day HRT ponds declined to $76 \%$ with a standard deviation of $16 \%$, and 2-day HRT removal efficiency declined to $62 \%$, with a standard deviation of $20 \%$. TAN removal efficiency was most affected by fluctuations in pond temperatures and Influent TAN concentrations, as supported by lessened treatment performance in winter and increased reaction rates during periods of low ammonia loading. Both 3-day and 2-day pond effluent maintained average DRP concentrations between 2-3mg/L-P. Average BOD removal during both seasons was $95 \%$ or better with standard deviations of less than $2.4 \%$ in all cases. 


\subsubsection{Experiment II: Ponds in Series}

Ponds operating at 4-day HRTs (Round 2), fed by treated effluent of 3-day HRT ponds (Round 1), resulted in average TAN concentrations as low as $0.02 \mathrm{mg} / \mathrm{L}-\mathrm{N}$ in both summer and winter, corresponding to removal efficiencies of $99 \%$ and $98 \%$.

Unintentional interruptions in $\mathrm{CO} 2$ supplementation in the Round 2 ponds resulted in brief periods of less TAN removal. Elevated oxidized nitrogen concentrations were measured during winter, increasing total soluble nitrogen concentrations above the 10 $\mathrm{mg} / \mathrm{L}$ total $\mathrm{N}$ target. Average Round $2 \mathrm{DRP}$ concentrations were $1.2 \mathrm{mg} / \mathrm{L}-\mathrm{P}$ in summer and $1.3 \mathrm{mg} / \mathrm{L}-\mathrm{P}$ in winter, with respective standard deviations of $0.81 \mathrm{mg} / \mathrm{L}-\mathrm{P}$ and 0.44 $\mathrm{mg} / \mathrm{L}-\mathrm{P}$. Tertiary treatment of domestic wastewater using HRAPs in series may be completed if system is operating under environmental conditions characteristic of spring and summer weather patterns. Average BOD removal remained above 97\%, proving reliable secondary treatment capability of HRAPs operating in series, provided suspended solids are removed. 


\subsubsection{Experiment III: Aeration of 2-day HRT Ponds}

HRAP influent $\mathrm{TBOD}_{5}$ ranged from $67-141 \mathrm{mg} / \mathrm{L}$ during the winter months of November 2012 to February 2013. HRAPs operating at 2-day HRTs throughout winter months maintained $\mathrm{scBOD}_{5}$ concentrations of less than $20 \mathrm{mg} / \mathrm{L}$. Aeration of 2-day HRT ponds during sundown hours in winter increased TAN removal efficiency by $15 \%$ compared to the control pond. Removal of TAN by nitrification did not result in subsequent denitrification; consequently, the 2-day ponds did not achieve total soluble nitrogen concentrations of $10 \mathrm{mg} / \mathrm{L}-\mathrm{N}$ regardless of Influent TAN concentration. Provided effective suspended solids removal techniques are used to remove particulate BOD from pond effluent, the HRAPs operating at a 2-day HRT met typical secondary treatment goals during winter.

\subsection{Limitations of Study}

Accurate TN and TP data were unattainable as a result of sampling error that occurred over the course of experimentation. Observed TSS concentrations in composite samples were considerably greater than actual TSS in the ponds. Misrepresentative samples containing high amounts of biomass led to inaccurate results of particulate phosphorus and organic nitrogen concentrations, most notably in 3-day and 2-day HRT ponds. Nutrient imbalances imparted by the presence of water fowl and sampling issues disallowed production of sufficient total nitrogen and total phosphorus data. Statistical analysis including t-tests and ANOVA tests would be required to assess variability between replicates and further evaluate treatment performance. 


\subsection{Future Research}

Further observations of treatment performance and refinement of experimental conditions are required to confirm and elaborate on the conclusions of this study.

To further evaluate treatment capabilities of HRAPs, data acquisition and analysis must be improved in several cases: (1) continuous measurement of soluble nitrogen species, (2) instantaneous measurement of oxidation-reduction potential, (3) observation of temperature effects on nitrogen removal mechanisms, (4) study of aeration frequency and duration necessary for enhanced nitrification and (5) effects on treatment performance in low-HRT ponds resulting from variable organic loading rates.

Nitrogen removal mechanisms in low-HRT ponds may be better understood upon insight of: (1) nitrifying and denitrifying bacteria present during experimentation, (2) effects of extreme $\mathrm{DO}$ and $\mathrm{pH}$ diel variation on nitrifying organisms and (3) understanding of removal mechanisms and biochemical activity impeded during storage of composite samples throughout sample collection period. Controlled variables such as sludge recycling, pond depth and channel velocity should be employed as experimental conditions to further assess treatment performance. Lastly, luxury uptake of phosphorus may be more accurately quantified by measurement of different phosphorus constituents present during diel variation. 


\section{References}

Benemann, John R. "Bio-fixation of CO2 and Greenhouse Gas Abatement with Microalgae-Technology Roadmap." Final report to the US Department of Energy, National Energy Technology Laboratory (2003): 55.

California Energy Commission. "California's Water - Energy Relationship." Final Staff Report: CEC-700-2005-011-SF. November 2005.

Craggs, R. J., Lundquist, T., \& Benemann, J. (2012). Wastewater Treatment Pond Algal Production for Biofuel. In R. Gordon \& J. Seckbach (Eds.), The Science of Algal Fuels, 25: pp. $425-445$

de la Noüe, J., Laliberté, G., \& Proulx, D. (1992). Algae and waste water. Journal of Applied Phycology, 4 (3): pp. 247-254.

Garcia, J., Mujeriego, R., \& Hernandez-Marine, M. (2000). High rate algal pond operating strategies for urban wastewater nitrogen removal. Journal of Applied Phycology, 12 (3-5), pp. 331-339.

Kenny, J.F., Barber, N.L., Hutson, S.S., Linsey, K.S., Lovelace, J.K., and Maupin, M.A., 2009, Estimated use of water in the United States in 2005: U.S. Geological Survey Circular 1344, $52 \mathrm{p}$.

Mayo, A. W., \& Mutamba, J. (2004). Effect of HRT on nitrogen removal in a coupled HRP and unplanted subsurface flow gravel bed constructed wetland. Physics and Chemistry of the Earth, Parts A/B/C, 29 (15-18), 1253-1257.

Mayo, A. W., \& Mutamba, J. (2005). Modelling nitrogen removal in a coupled HRP and unplanted horizontal flow subsurface gravel bed constructed wetland. Physics and Chemistry of the Earth, Parts A/B/C, 30 (11-16), pp. 673-679.

Metcalf \& Eddy. (2003). Wastewater engineering: treatment and resuse ( $4^{\text {th }}$ ed.). Boston: McGraw-Hill.

Nurdogan, Y. (1988). Microalgal separation from high rate ponds. (Doctoral dissertation). Retrieved from ProQuest Dissertations and Theses. (Accession Order No. AAT 8902223)

Oswald, W. J., Gotaas, H. B., Golueke, C. G., Kellen, W. R., Gloyna, E. F., \& Hermann, E. R. (1957). Algae in Waste Treatment [with Discussion]. Sewage and Industrial Wastes, 29 (4), pp. 437-457.

Oswald, W.J., (1995) "Ponds in the twenty-first century" Journal of Water Science Technology 31 (12): pp. 1-8.

Oswald, W.J., (2003) "My sixty years in applied algology" Journal of Applied Phycology 15: pp. 99-106. 
Park, J. B. K., Craggs, R. J., \& Shilton, A. N. (2011). Wastewater treatment high rate algal ponds for biofuel production. Bioresource Technology, 102 (1), pp. 35-42.

Perez-Garcia, O., Escalante, F. M. E., de-Bashan, L. E., \& Bashan, Y. (2011). Heterotrophic cultures of microalgae: Metabolism and potential products. Water Research, 45 (1), pp. 11-36.

Powell, N., Shilton, A., Chisti, Y., \& Pratt, S. (2009). Towards a luxury uptake process via microalgae - Defining the polyphosphate dynamics. Water Research, 43 (17), pp. 4207-4213.

Powell, N., Shilton, A. N., Pratt, S., \& Chisti, Y. (2008). Factors Influencing Luxury Uptake of Phosphorus by Microalgae in Waste Stabilization Ponds. Environmental Science \& Technology, 42 (16), pp. 5958-5962.

Ripley, E.B. (2013). Settling performance in high rate algae ponds, M.S. thesis, Department of Civil and Environmental Engineering, California Polytechnic State University, San Luis Obispo.

Shin, H.K., Polprasert, C., 1988. Ammonia nitrogen removal in attached growth ponds. J. Environ. Eng., ASCE 114 (4), pp. 847-863.

SWRCB (2010). Monitoring Strategies for Chemicals of Emerging Concern (CECs) in Recycled Water. State Water Resources Control Board CEC Panel.

USEPA (2012a, May 21). Basic Information about Nitrate in Drinking Water. Retrieved from http://water.epa.gov/drink/contaminants/basicinformation/nitrate.cfm

USEPA (2012b). Clean Watersheds Needs Survey 2008 Report to Congress, U.S. Environmental Protection Agency. 


\section{Appendices}

APPENDIX A: Sample Schedule

APPENDIX B: Experimental and Operational Events

APPENDIX C: Startup TAN Concentration in Alpha Ponds

APPENDIX D: Morning and Evening TAN Concentrations

APPENDIX E: San Luis Obispo Weather 


\section{Appendix A Sample Schedule}

The constituents listed in Chapter 3, excluding TP, were measured in all nine ponds and the Influent on a weekly basis. scBOD $_{5}$ and Influent BOD $_{5}$ tests began on July 11, 2012. DRP data acquisition started on August 8, 2012 and TP data was collected a total of four times between the months of August 2012 and February 2013. Measurement of nitrite did not begin until July 25, 2012. The remaining constituents were measured from the beginning of Experiment I until conclusion of study. Failed QA/QC, improper procedures or limited lab analysts may have contributed to inability to use or acquire data sets for a given constituent. Table A.1 provides a reference as to which constituents were measured during each week of analysis. In the event that missing data points produced gaps within a time series graph, a data series was connected if the interpolated result was representative of the expected change in the pond constituent. 
Table A.1. Sampling schedule for listed constituents during operation of pilot plant. March 28, 2013 marks the only date that no measurements were made on any of the noted constituents.

\begin{tabular}{|c|c|c|c|c|c|c|c|c|c|}
\hline \multirow{2}{*}{ Date } & \multicolumn{9}{|c|}{ Constituent } \\
\hline & $\mathrm{scBOD}_{5}$ & TSS/VSS & Akalinity & $\mathrm{DRP}$ & $\mathrm{TP}$ & Nitrate & Nitrite & TAN & TKN \\
\hline $2012-04-25$ & & - & - & & & & & $\cdot$ & \\
\hline $2012-05-02$ & & - & - & & & - & & - & - \\
\hline $2012-05-09$ & & - & - & & & & & & - \\
\hline $2012-05-16$ & & - & - & & & • & & & - \\
\hline $2012-05-23$ & & - & - & & & & & - & - \\
\hline $2012-05-30$ & & - & - & & & - & & - & - \\
\hline $2012-06-06$ & & • & • & & & • & & • & $\cdot$ \\
\hline $2012-06-13$ & & . & - & & & . & & . & - \\
\hline $2012-06-20$ & & $\cdot$ & • & & & • & & • & $\cdot$ \\
\hline $2012-06-27$ & & - & - & & & - & & - & - \\
\hline $2012-07-05$ & & • & • & & & • & & • & $\cdot$ \\
\hline $2012-07-11$ & $\cdot$ & • & • & & & • & & • & $\cdot$ \\
\hline $2012-07-18$ & - & • & - & & & - & & - & - \\
\hline $2012-07-25$ & & $\cdot$ & $\cdot$ & & & $\cdot$ & • & $\cdot$ & $\cdot$ \\
\hline $2012-08-01$ & - & - & - & & & - & - & - & - \\
\hline $2012-08-08$ & - & - & - & - & • & - & - & - & \\
\hline $2012-08-15$ & • & • & • & $\cdot$ & $\cdot$ & • & $\cdot$ & • & $\cdot$ \\
\hline $2012-08-22$ & • & - & • & - & & • & • & • & $\cdot$ \\
\hline $2012-08-29$ & & $\cdot$ & $\cdot$ & $\cdot$ & & $\cdot$ & $\cdot$ & $\cdot$ & $\cdot$ \\
\hline $2012-09-05$ & - & - & - & - & & - & - & - & - \\
\hline $2012-09-12$ & - & - & - & - & & - & - & - & - \\
\hline 2012-09-19 & - & - & & & & & & & \\
\hline $2012-09-26$ & - & - & • & & & - & - & 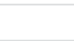 & $\cdot$ \\
\hline $2012-10-03$ & & • & • & • & & • & • & $\cdot$ & $\cdot$ \\
\hline $2012-10-10$ & • & • & - & - & & • & • & • & • \\
\hline $2012-10-17$ & $\cdot$ & $\cdot$ & • & $\cdot$ & & • & $\cdot$ & - & $\cdot$ \\
\hline $2012-10-24$ & - & • & - & • & & & & • & - \\
\hline $2012-10-31$ & - & - & - & - & & - & - & - & - \\
\hline $2012-11-07$ & & • & • & - & & • & • & • & - \\
\hline $2012-11-14$ & • & - & • & - & & • & • & • & - \\
\hline $2012-11-21$ & & - & • & - & & • & • & - & • \\
\hline $2012-11-28$ & • & - & - & - & & - & - & - & - \\
\hline $2012-12-05$ & & • & • & • & • & • & • & • & • \\
\hline $2012-12-12$ & • & • & & • & & • & • & • & • \\
\hline $2012-12-19$ & - & - & - & - & & - & • & - & - \\
\hline $2012-12-27$ & & - & & - & & • & • & • & - \\
\hline $2013-01-02$ & - & - & - & - & & - & - & - & - \\
\hline 2013-01-09 & • & $\cdot$ & & $\cdot$ & & • & • & • & $\cdot$ \\
\hline $2013-01-16$ & & - & - & - & & - & - & - & - \\
\hline $2013-01-23$ & - & - & - & - & & - & - & - & \\
\hline $2013-01-30$ & • & - & • & • & & • & • & - & • \\
\hline $2013-02-06$ & - & • & - & - & - & - & - & - & - \\
\hline $2013-02-13$ & - & • & - & - & & - & - & - & - \\
\hline $2013-02-20$ & - & - & - & - & & - & - & - & \\
\hline $2013-02-27$ & • & • & • & • & & • & • & • & - \\
\hline 2013-03-06 & • & - & • & - & & • & • & - & \\
\hline $2013-03-13$ & • & • & • & - & & • & • & • & \\
\hline $2013-03-21$ & $\cdot$ & $\cdot$ & $\cdot$ & $\cdot$ & & $\cdot$ & • & $\cdot$ & \\
\hline $2013-03-28$ & & & & & & & & & \\
\hline 2013-04-04 & & • & - & • & & - & & - & - \\
\hline 2013-04-11 & • & - & - & - & & - & • & - & - \\
\hline 2013-04-18 & - & - & - & - & & - & - & - & $\cdot$ \\
\hline $2013-04-25$ & • & • & • & $\cdot$ & & • & • & - & $\cdot$ \\
\hline
\end{tabular}




\section{Appendix B Experimental and Operational Events}

Samples were collected weekly throughout the all experimental periods. In some cases, composite sampling failure, additional experimental conditions or pond maintenance may led to collection of grab samples. TABLE summarizes the dates for which respective grab samples were used for analysis instead of composite samples. After sustained solids sampling issues into the 2013 calendar year, water quality analysis was performed exclusively on grab samples from March 6, 2013 to April 11, 2013. Additional information such as periods of $\mathrm{CO} 2$ addition in the Alpha set and aeration in the Gamma set, is also noted in Table B.1. Inoculation dates for Pond 5 and 6 are recorded, although data evaluated in this study was unaffected by inoculation experiments. 


\section{Appendix C Start-Up TAN Concentration in Alpha Ponds}

Alpha ponds were independently operating at an HRT of 4-days for the entire period of pilot plant operation. Primary effluent seed and influent was effective in creating a eutrophic environment to stimulate microalgal growth. Ammonia removal in Ponds 1 and 3 significantly improved from 54\% and 22\% on February 29, 2012 to 95\% and 74\% on March 7, 2012, respectively (Figure C.1). From April 11, 2012 until $\mathrm{CO}_{2}$ addition to Alpha began for Experiment II, ammonia removal efficiencies for all three 4-day ponds reached $86 \%$. Several dates of weekly analysis for sample ammonia concentrations were not reported due to failed $\mathrm{QA} / \mathrm{QC}$ tests and equipment malfunction.

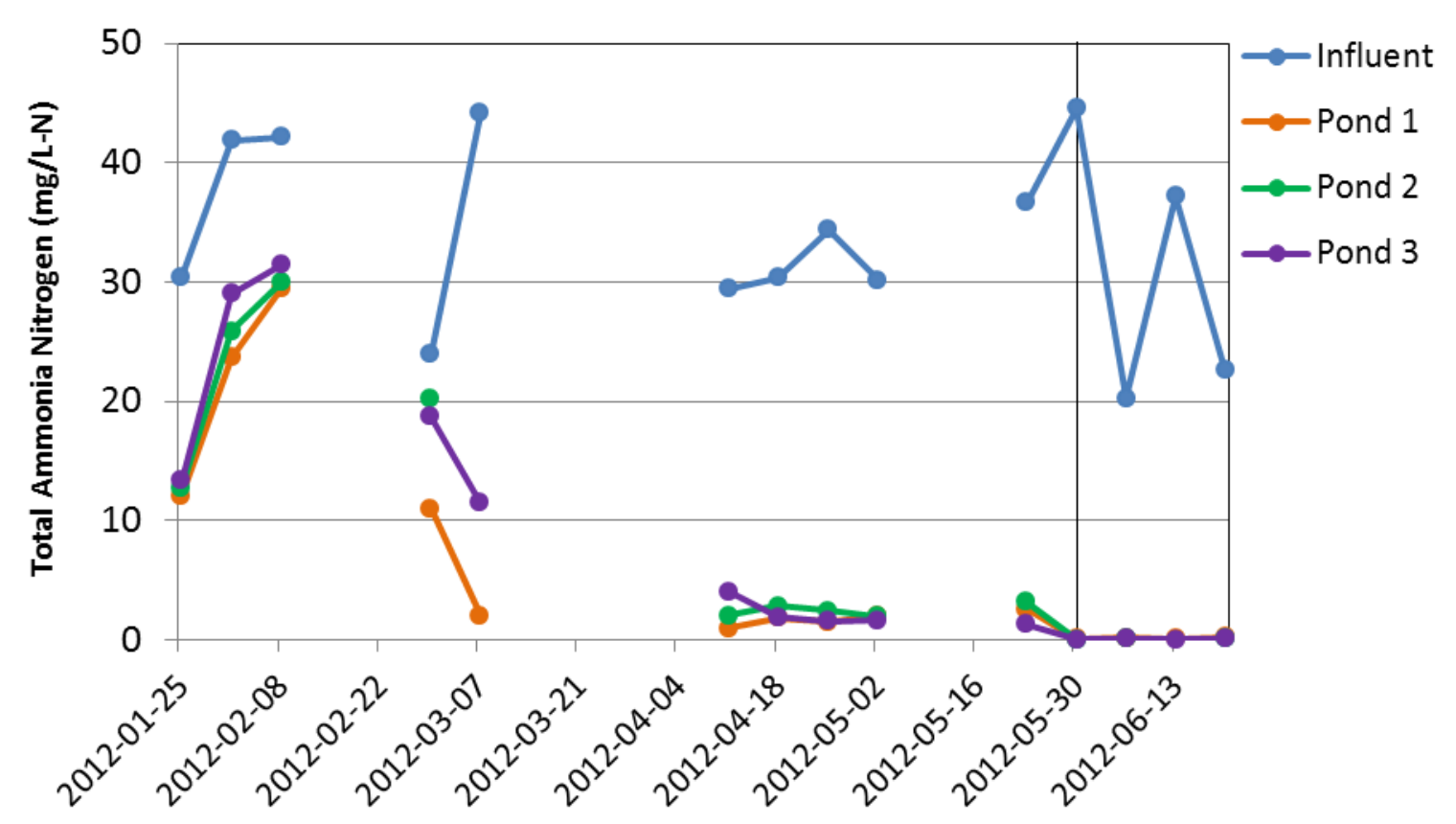

Figure C.1. Time series representation of TAN concentrations in 4-day HRT ponds at startup. Gaps in data series represent weeks in which inaccurate or imprecise values were measured as a result of failed QA/QC or methodical errors. 


\section{Appendix D Morning and Evening TAN Concentrations}

Diel studies of measured constituents were not completed during experimentation. Morning and evening comparisons to composite samples were completed for TAN concentrations to confirm the daily fluctuation typical of domestic wastewater flows (Figure D.1). Data interpretation is limited by the low number of samples drawn, however, Figure D.1 indicates TAN loading in the morning hours around 8:00AM. In a 3-day and 4-day ponds, 8:00am TAN concentrations were greater than evening concentrations by $3.7 \mathrm{mg} / \mathrm{L}-\mathrm{N}$ and $4.8 \mathrm{mg} / \mathrm{L}-\mathrm{N}$, respectively.

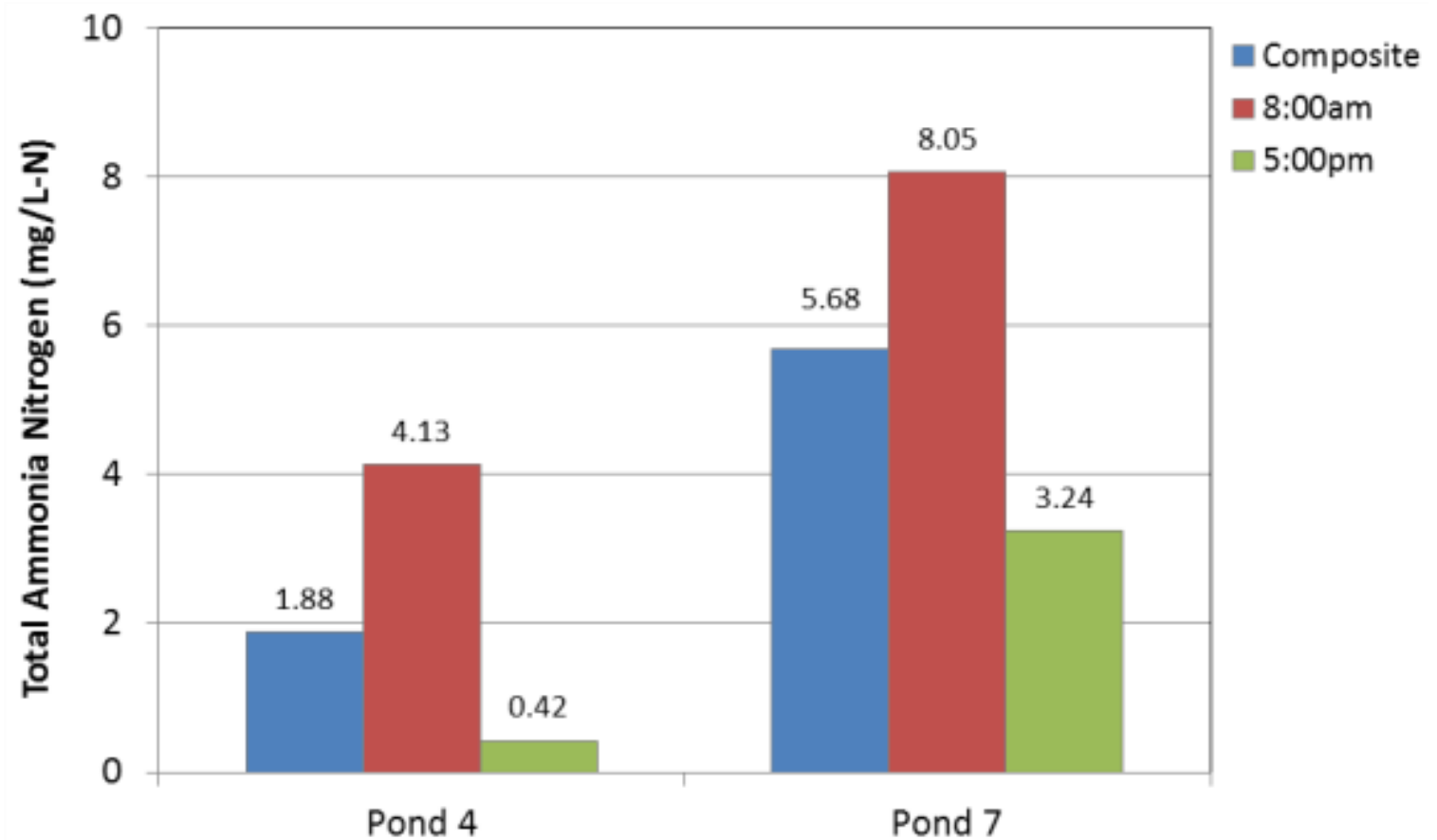

Figure D.1. Morning and evening TAN concentrations for Ponds 4 and 7, in comparison to composite samples. Significant difference between morning and evening TAN concentrations confirmed anticipated diurnal variation of domestic wastewater flow 


\section{Appendix E San Luis Obispo Weather}

Weather data was located at the CIMIS weather station (52) located at the Cal Poly campus. Pond temperatures are greatly influenced by the environmental conditions in which they operate; therefore average air temperature typically results in lower pond temperatures. In turn, days of low average air temperature would be expected to hinder nutrient removal mechanisms. Solar radiation affects algal productivity and may result in inhibition of photosynthesis under extreme conditions. Temperature and solar radiation follow nearly identical seasonality patterns. Precipitation may also cause dilutions of influent wastewater which may lead to periods of low nutrient or organic constituent measurements. Treatment observed under high rainfall conditions may be misleading in respects to nutrient removal efficiencies. Said environmental conditions were monitored from startup until conclusion of study.

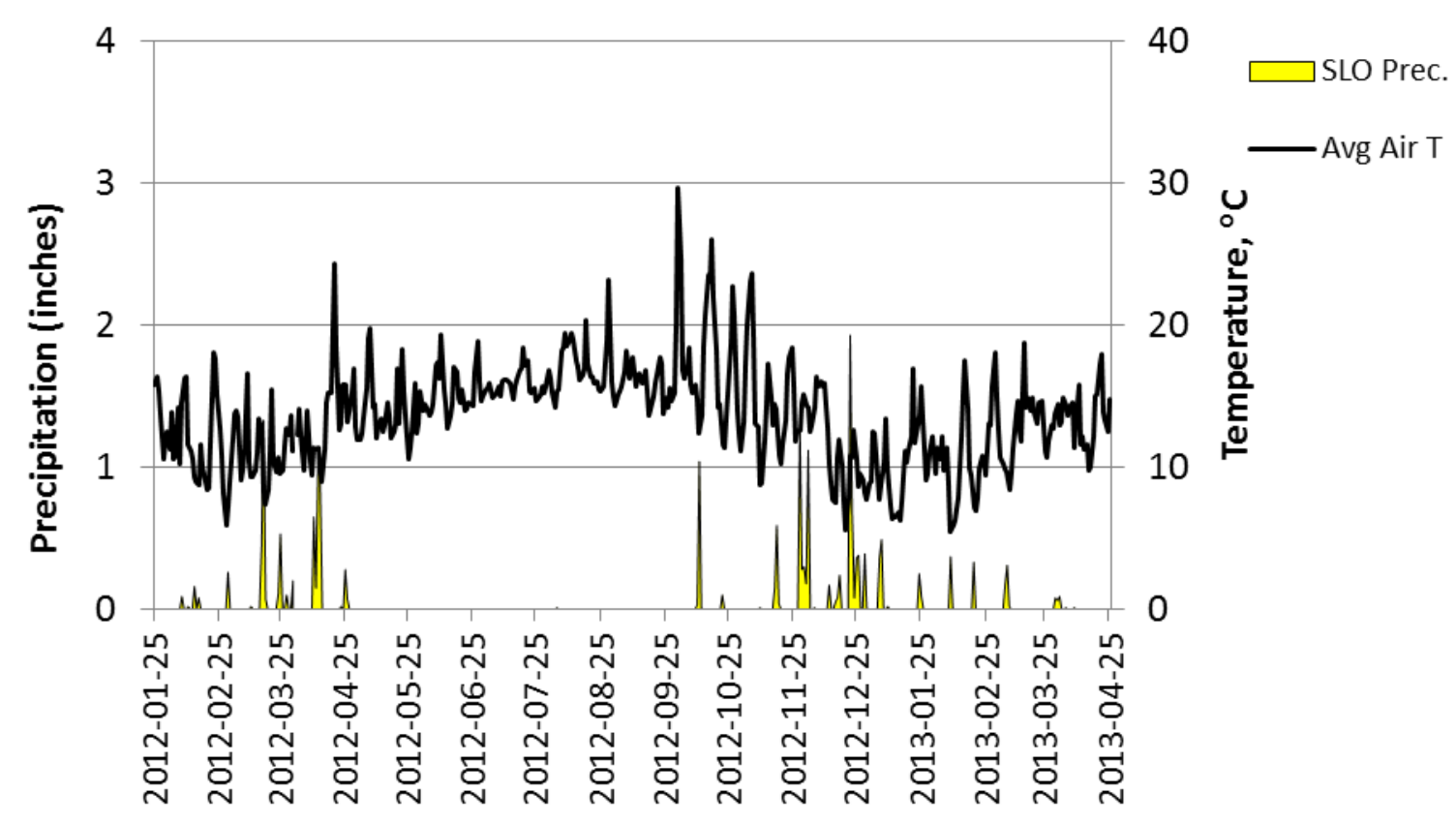

Figure E.1. Daily average air temperature and precipitation in San Luis Obispo, California. Data was obtained from CIMIS Weather Station No. 52 located 5 miles away from AFS. 


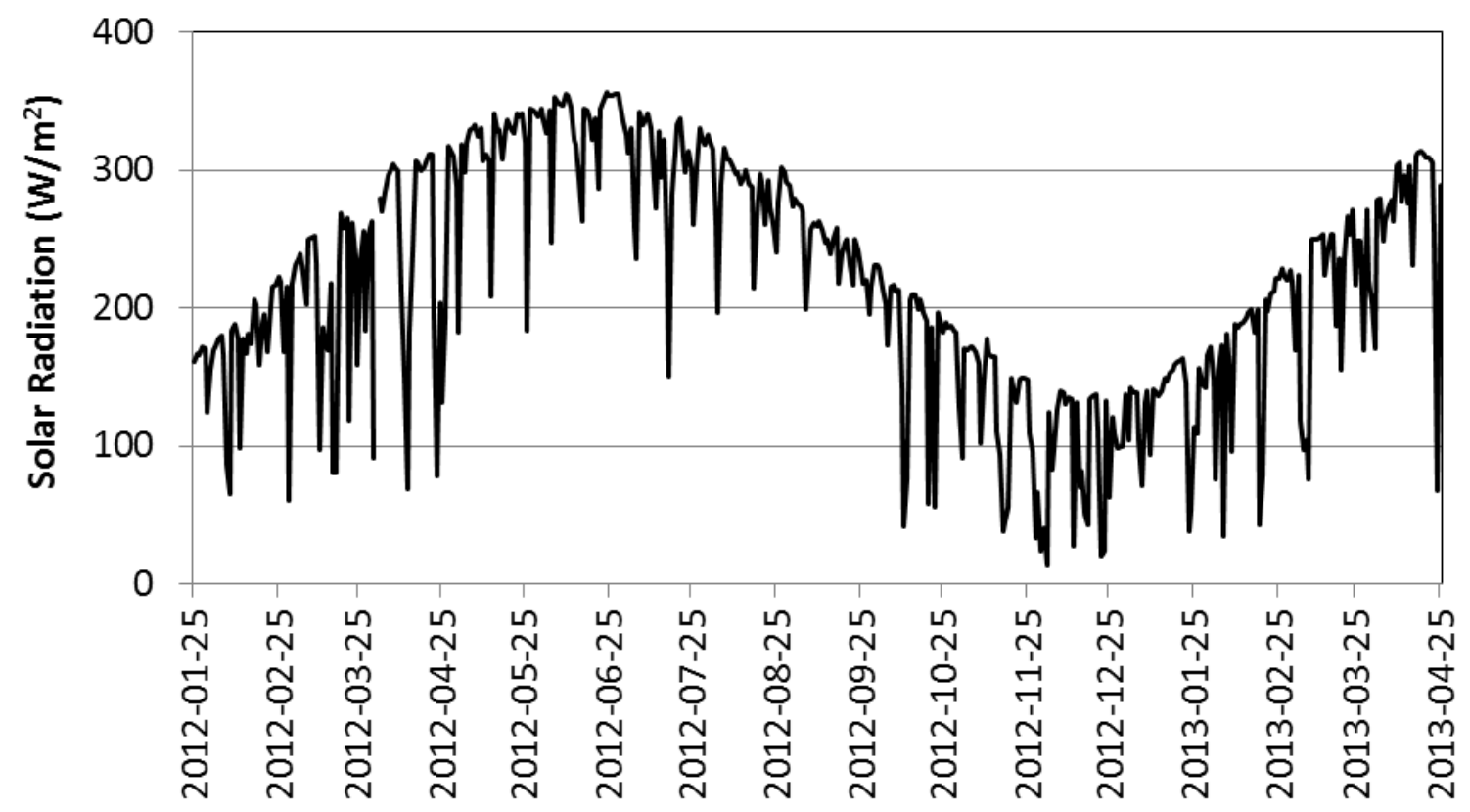

Figure E.2. Time series of daily solar radiation HRAPs were exposed to in San Luis Obispo, California. Data was obtained from CIMIS Weather Station No. 52 located 5 miles away from AFS. 